SAND- $-90-0528$

DE91 000476

SAND90-0528

Unlimited Release

\title{
Far-Field Dispersal Modeling for Fuel-Air-Explosive Devices
}

\author{
Micheal W. Glass \\ Fluid Mechanics and Heat Transfer Division 1512 \\ Sandia National Laboratories \\ Albuquerque, NM 87185 \\ Prepared for the \\ Office of Munitions \\ Office of the Undersecretary of Defense (RE/TWP) \\ Washington, D.C. 20301 \\ under the \\ Joint DOD/DOE Munitions Technology Development Program
}

\begin{abstract}
A computer model for simulating the explosive dispersal of a fuel agent in the far-field regime is described and is applied to a wide variety of initial conditions to judge their effect upon the resulting fuel/air cloud. This work was directed towards modeling the dispersal process associated with Fuel-Air-Explosive devices. The far-field dispersal regime is taken to be that time after the initial burster charge detonation in which the shock forces no longer dominate the flow field and initial canister and fuel mass breakup has occurred.

The model was applied to a low vapor pressure fuel, a high vapor pressure fuel and a solid fuel. A strong dependence of the final cloud characteristics upon the initial droplet size distribution was demonstrated. The predicted fuel-air clouds were highly non-uniform in concentration.




\section{Table of Contents}

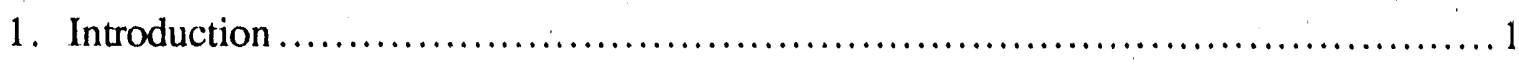

1.1 The Dispersal Process..................................................... 2

1.2 Background on FAE Dispersal Modeling ............................................ 3

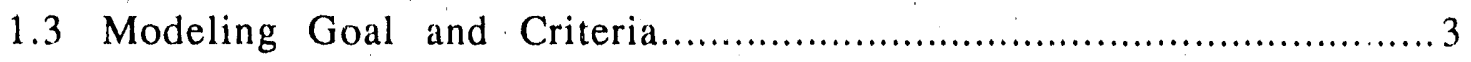

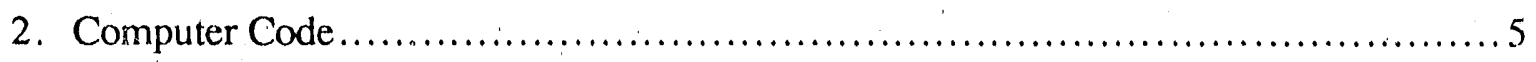

3. Modifications to the Computer Code.......................................................... 9

3.1 Pre- and Post-Processing Utilities........................................9

3.2 Solid Particle Heat Transfer ................................................. 10

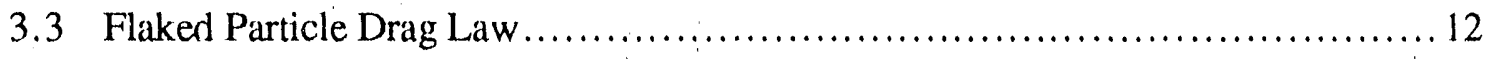

4. Results........................................................................... 14

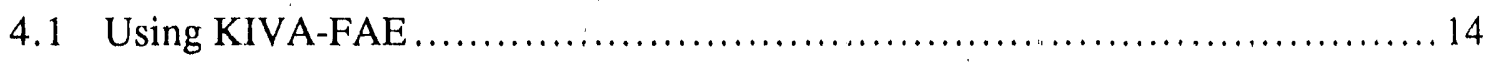

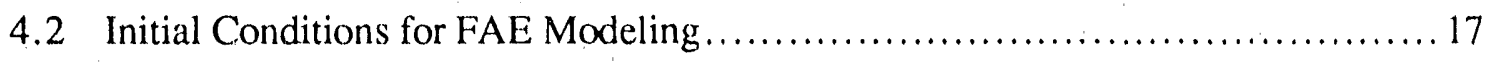

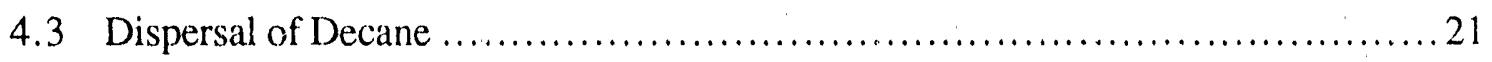

4.3.1 Effect of Initial Droplet Size and Distribution ........................ 22

4.3.2 Effect of Initial Height-of-Burst ................................. 23

4.3.3 Effect of Device Delivery Velocity..........................................24

4.4 Dispersal of Propylene Oxide ................................................ 24

4.5 Dispersal of Flaked Aluminum Powder............................................25

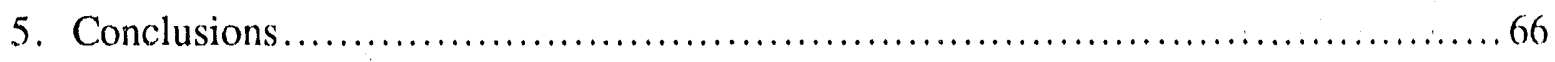

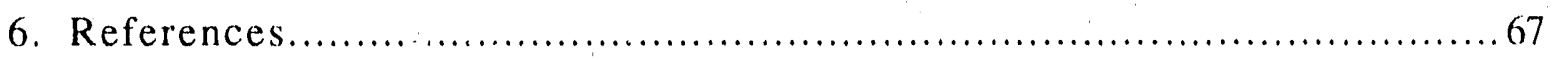




\section{List of Figures}

Figure 1: Typical FAE Device Schematic ........................................

Figure 2: FAE far-field dispersal model flowchart......................................11

Figure 3: Typical computational mesh used in two-dimensional

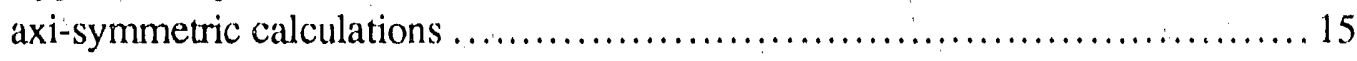

Figure 4: Schematic of initial conditions for dispersal model testing $\ldots \ldots \ldots \ldots \ldots \ldots \ldots$

Figure 5: Initial configuration for FAE model ................................... 18

Figure 6: Initial velocity, temperature, and density profiles ....................... 19

Figure 7: Velocity profile and fuel parcel positions at $t=0 \mathrm{~ms}$, Case $1 \ldots \ldots \ldots \ldots \ldots \ldots 26$

Figure 8: Velocity profile and fuel parcel positions at $t=15 \mathrm{~ms}$, Case $1 \ldots \ldots \ldots \ldots \ldots . \ldots 26$

Figure 9: Velocity profile and fuel parcel positions at $t=30 \mathrm{~ms}$, Case $1 \ldots \ldots \ldots \ldots . . .27$

Figure 10: Velocity profile and fuel parcel positions at $t=45 \mathrm{~ms}$, Case $1 \ldots \ldots \ldots \ldots \ldots 27$

Figure 11: Velocity profile and fuel parcel positions at $t=60 \mathrm{~ms}$, Case $1 \ldots \ldots \ldots \ldots \ldots . \ldots 28$

Figure 12: Velocity profile and fuel parcel positions at $t=75 \mathrm{~ms}$, Case $1 \ldots \ldots \ldots \ldots \ldots 28$

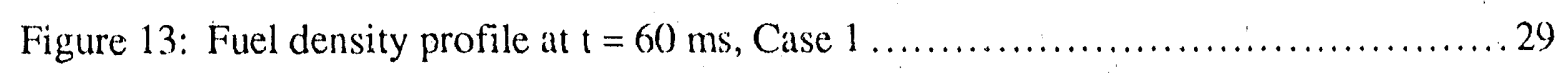

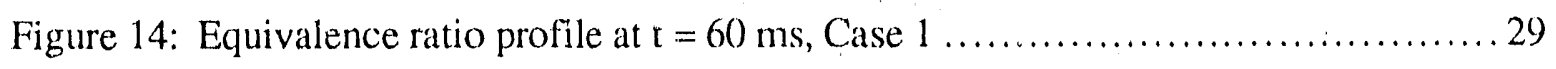

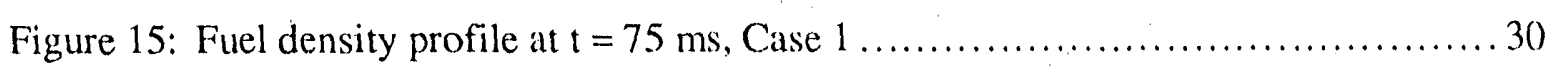

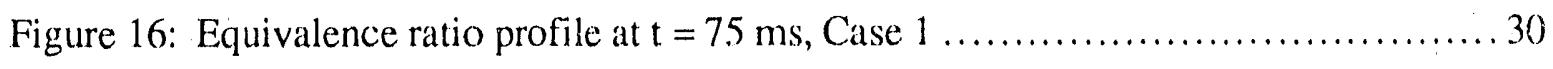

Figure 17: Velocity profile and fuel parcel positions at $t=60 \mathrm{~ms}$, Case $2 \ldots \ldots \ldots \ldots \ldots . \ldots . \ldots$.

Figure 18: Velocity profile and fuel parcel positions at $t=75 \mathrm{~ms}$, Case $2 \ldots \ldots \ldots \ldots \ldots . \ldots 31$

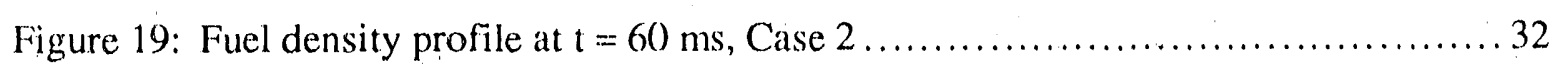

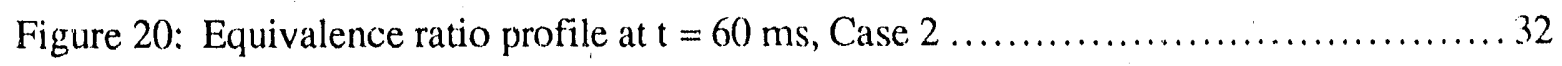

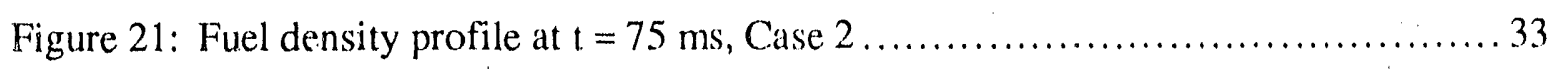

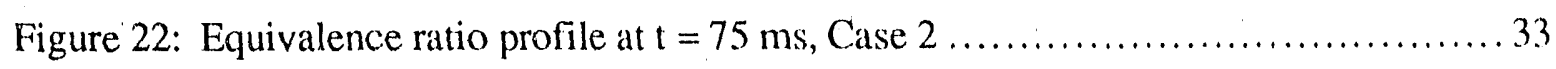


Figure 23: Velocity profile and fuel parcel positions at $\mathrm{t}=60 \mathrm{~ms}$, Case $3 \ldots \ldots \ldots \ldots \ldots . \ldots 34$

Figure 24: Velocity profile and fuel parcel positions at $\mathrm{t}=75 \mathrm{~ms}$, Case $3 \ldots \ldots \ldots \ldots \ldots 34$

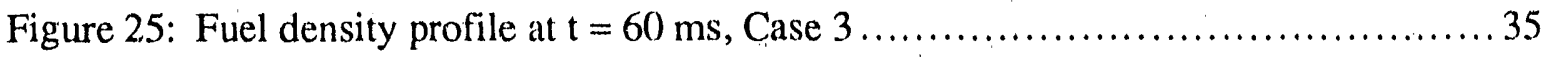

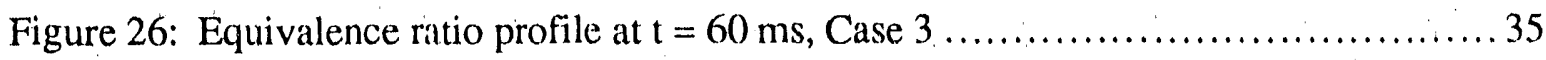

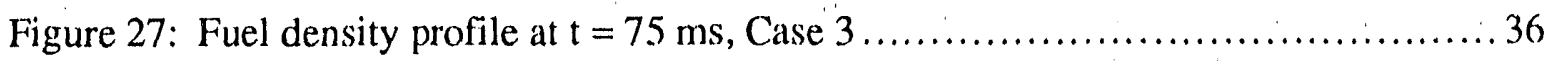

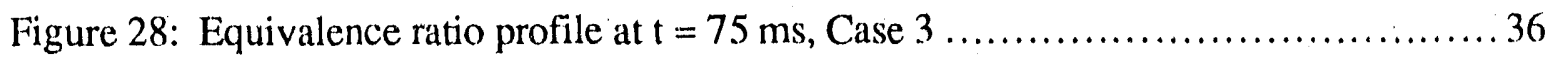

Figure 29: Velocity profile and fuel parcel positions at $t=60 \mathrm{~ms}$, Case $4 \ldots \ldots \ldots \ldots \ldots . \ldots 37$

Figure 30: Velocity profile and fuel parcel positions at $\mathrm{t}=75 \mathrm{~ms}$, Case $4 \ldots \ldots \ldots \ldots \ldots . \ldots . \ldots . \ldots$

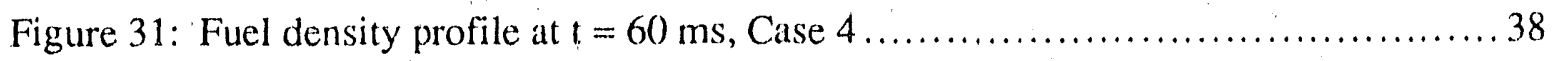

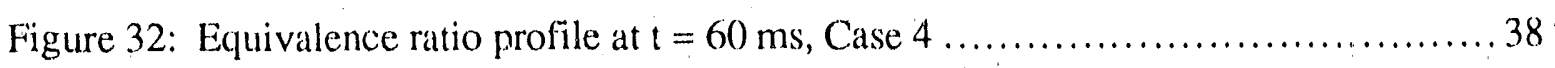

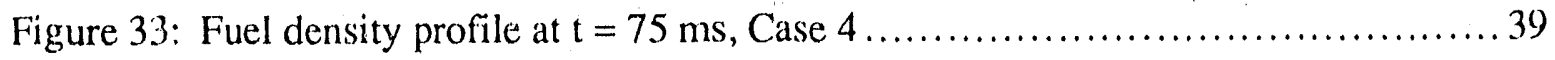

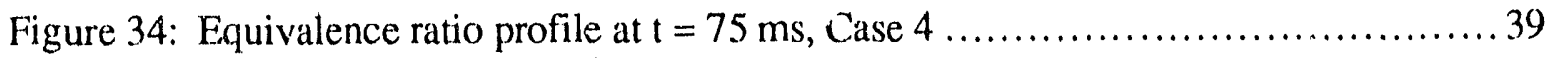

Figure 35: Velocity profile and fuel parcel positions at $t=60 \mathrm{~ms}$, Case $5 \ldots \ldots \ldots \ldots \ldots .40$

Figure 36: Velocity profile and fuel parcel positions at $t=75 \mathrm{~ms}$, Case $5 \ldots \ldots \ldots \ldots \ldots \ldots 40$

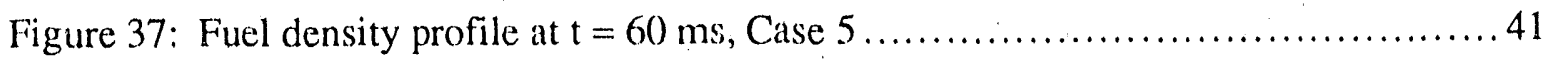

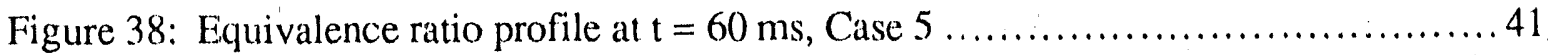

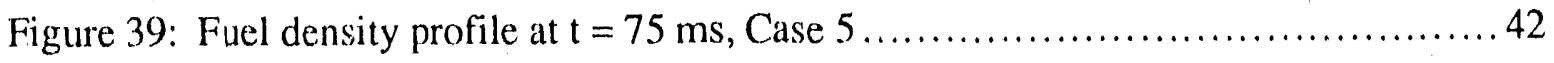

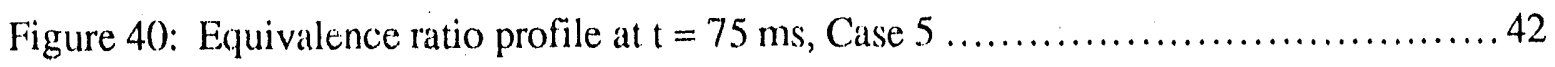

Figure 41: Velocity profile and fuel parcel positions at $t=60 \mathrm{~ms}$, Case $6 \ldots \ldots \ldots \ldots \ldots . \ldots 3$

Figure 42: Velocity profile and fuel parcel positions at $t=75 \mathrm{~ms}$, Case $6 \ldots \ldots \ldots \ldots \ldots .43$

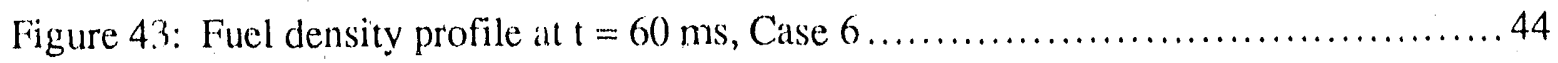

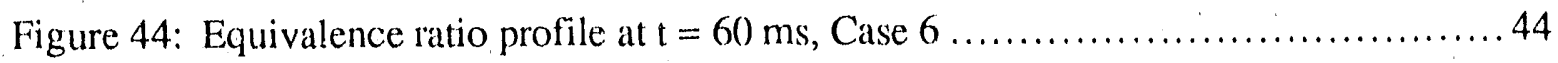

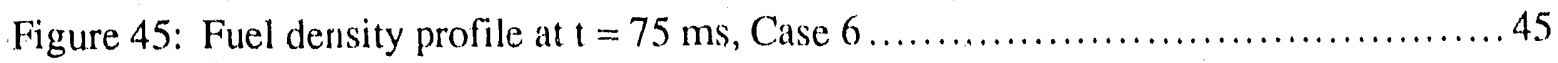

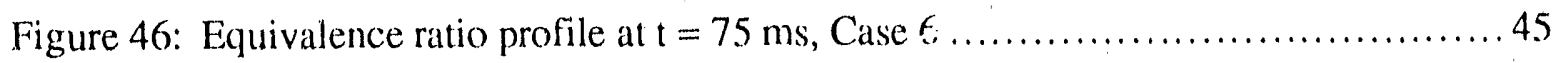


Figure 47: Velocity profile and fuel parcel positions at $t=60 \mathrm{~ms}$, Case $7 \ldots \ldots \ldots \ldots \ldots \ldots 46$

Figure 48: Velocity profile and fuel parcel positions at $t=75 \mathrm{~ms}$, Case $7 \ldots \ldots \ldots \ldots \ldots \ldots 46$

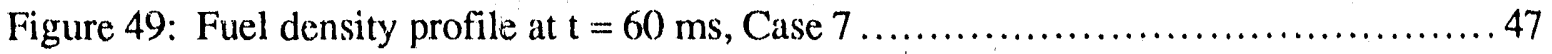

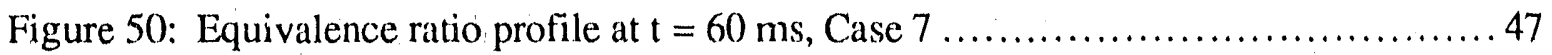

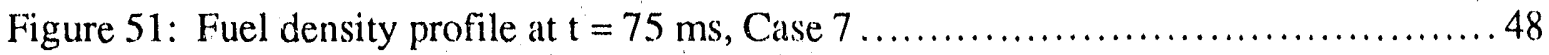

Figure 52: Equivalence ratio profile at $\mathrm{t}=75 \mathrm{~ms}$, Case $7 \ldots \ldots \ldots \ldots \ldots \ldots \ldots \ldots \ldots \ldots . \ldots \ldots$

Figure 53: Velocity profile and fuel parcel positions at $\mathrm{t}=60 \mathrm{~ms}$, Case $8 \ldots \ldots \ldots \ldots \ldots \ldots 49$

Figure 54: Velocity profile and fuel parcel positions at $t=75 \mathrm{~ms}$, Case $8 \ldots \ldots \ldots \ldots \ldots \ldots 49$

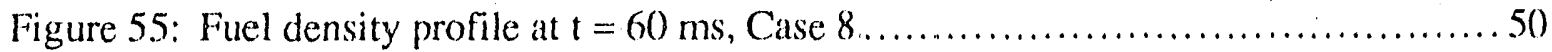

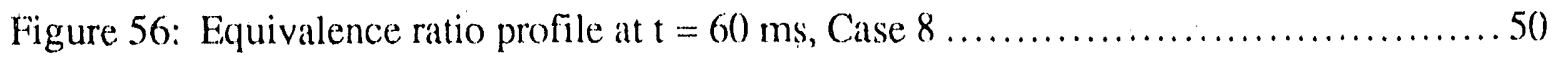

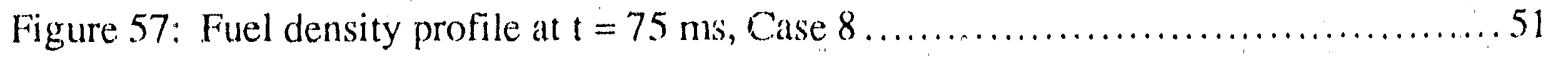

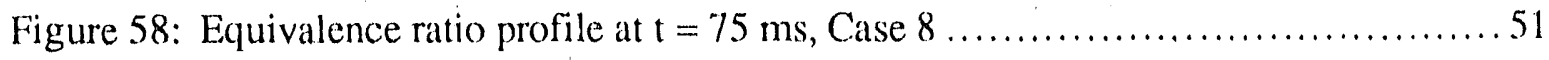

Figure 59: Velocity profile and fuel parcel positions at $\mathrm{t}=60 \mathrm{~ms}$, Case $9 \ldots \ldots \ldots \ldots \ldots \ldots 2$

Figure 60: Velocity profile and fuel parcel positions at $\mathrm{t}=75 \mathrm{~ms}$, Case $9 \ldots \ldots \ldots \ldots \ldots \ldots \ldots 2$

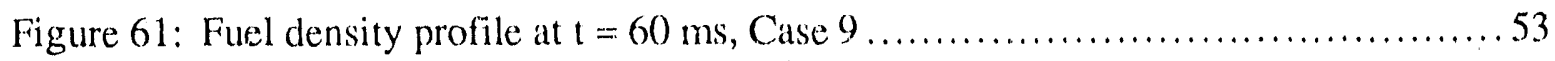

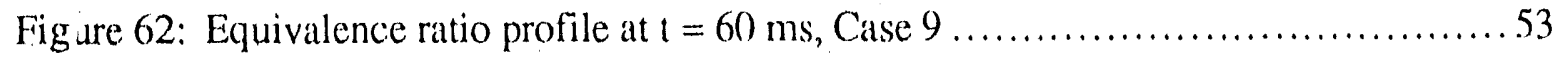

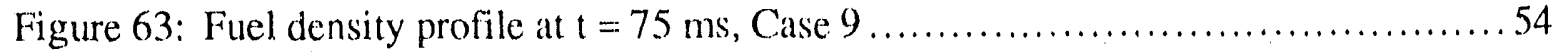

Figure 64: Equivalence ratio profile at $\mathrm{t}=75 \mathrm{~ms}$, Case $9 \ldots \ldots \ldots \ldots \ldots \ldots \ldots \ldots \ldots \ldots \ldots \ldots$

Figure 65: Velocity profile and fuel parcel positions at $\mathrm{t}=60 \mathrm{~ms}$, Case $10 \ldots \ldots \ldots \ldots \ldots \ldots 5$

Figure 66: Velocity profile and fitel parcel positions at $t=75 \mathrm{~ms}$, Case $10 \ldots \ldots \ldots \ldots \ldots \ldots 5 . \ldots 5$

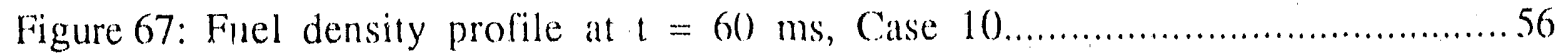

Figure 68: Equivalence ratio profile at $\mathrm{t}=60 \mathrm{~ms}$, Case $10 \ldots \ldots \ldots \ldots \ldots \ldots \ldots \ldots \ldots \ldots \ldots$

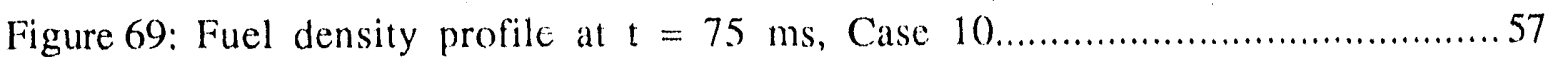

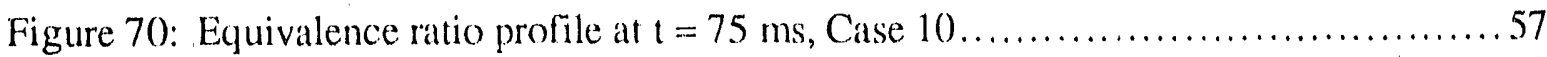


Figure 71: Velocity profile and fuel parcel positions at $\mathrm{t}=60 \mathrm{~ms}$, Case $11 \ldots \ldots \ldots \ldots \ldots . \ldots 58$

Figure 72: Velocity profile and fuel parcel positions at $\mathrm{t}=75 \mathrm{~ms}$, Case $11 \ldots \ldots \ldots \ldots \ldots . \ldots 58$

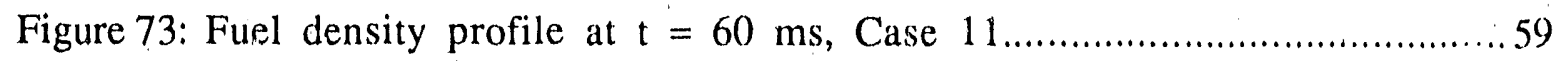

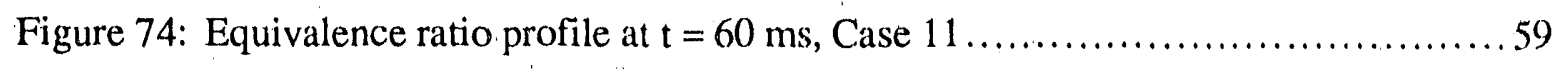

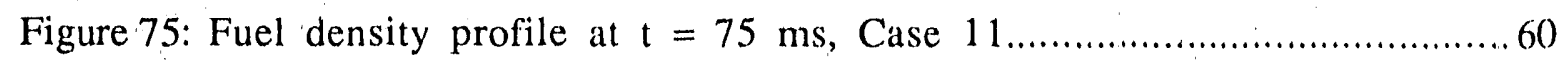

Figure 76: Equivalence ratio profile at $t=75 \mathrm{~ms}$, Case $11 \ldots \ldots \ldots \ldots \ldots \ldots \ldots \ldots \ldots 6$.

Figure 77: Velocity profile and fuel parcel positions at $\mathrm{t}=0 \mathrm{~ms}$, Case $12 \ldots \ldots \ldots \ldots \ldots \ldots 61$

Figure 78: Velocity profile and fuel parcel positions at $\mathrm{t}=15 \mathrm{~ms}$, Case $12 \ldots \ldots \ldots \ldots \ldots .61$

Figure 79: Velocity profile and fuel parcel positions at $\mathrm{t}=30 \mathrm{~ms}$, Case $12 \ldots \ldots \ldots \ldots \ldots 62$

Figure 80: Velocity profile and fuel parcel positions at $\mathrm{t}=45 \mathrm{~ms}$, Case $12 \ldots \ldots \ldots \ldots \ldots 62$

Figure 81: Velocity profile and fuel parcel positions at $\mathrm{t}=60 \mathrm{~ms}$, Case $12 \ldots \ldots \ldots \ldots \ldots \ldots 6 . \ldots \ldots$

Figure 82: Velocity profile and fuel parcel positions at $t=75 \mathrm{~ms}$, Case $12 \ldots \ldots \ldots \ldots \ldots 63$

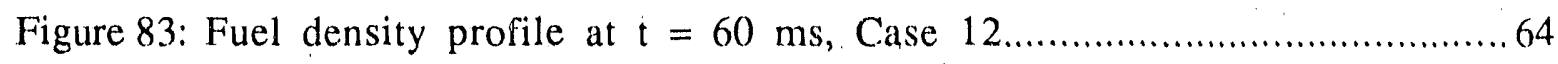

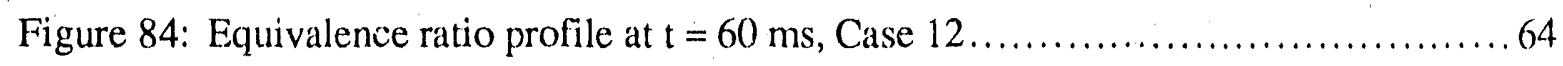

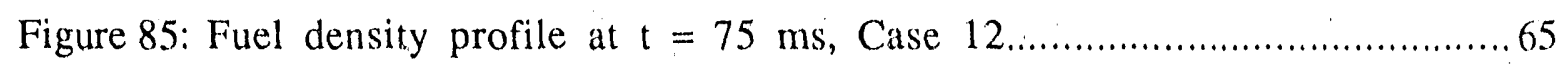

Figure 86: Equivalence ratio profile at $t=75 \mathrm{~ms}$, Case $12 \ldots \ldots \ldots \ldots \ldots \ldots \ldots \ldots \ldots \ldots \ldots$ 


\section{List of Tables}

Table 1: Reynold's-averaged equations used by KIVA-FAE $\ldots \ldots \ldots \ldots \ldots \ldots \ldots \ldots \ldots . \ldots 7$

Table 2: CPU Timing Results for the Various Fluid-Particle Sub-Models ............... 17

Table 3: Initial Distribution of Energy from the Burster Charge Detonation................ 18

Table 4: Summary of Decane Dispersal Conditions ............................... 22 


\section{List of Symbols}

\section{Roman:}

$\mathrm{C}_{\mathrm{D}}$

$c_{p}$

$\mathrm{c}_{\mathrm{pi}}$

$\left(c_{p}\right)_{i j k}^{n}$

$c_{\varepsilon_{1}}, c_{\varepsilon_{2}}, c_{\varepsilon_{3}}$

$c_{\mu}$

D

$d_{p}$

$f(\mathrm{r})$

$f_{\mathrm{m}}(\mathrm{r})$

F

g

$h_{i}$

I

k

$\mathrm{K}_{\text {gas }}$

LSGS

$\mathrm{M}_{\mathrm{i}}$

$\mathrm{M}_{\text {fucl }}$

$M_{\text {gas }}$

$n_{\mathrm{i}}$

$\mathrm{N}_{\mathrm{p}}$

$\mathrm{Nup}$

p

$\mathrm{Pr}_{\mathrm{T}}$ drag coefficient

specific heat at constant pressure

specific heat at constant pressure of $i^{\text {th }}$ species

specific heat of gas in cell(ijk) during the $n^{\text {th }}$ time cycle

coefficients in $\varepsilon$-equation

coefficients in eddy-viscosity formula

gas diffusion constant

particle diameter

particle size distribution

particle mass distribution

drag force on gas

gravitational acceleration

specific enthalpy of $\mathrm{i}^{\text {th }}$ species

specific internal energy of the gas

turbulent kinetic energy

thermal conductivity of the gas

sub-grid turbulent length scale

mass of $i^{\text {th }}$ species

mass of fuel

mass of burster charge detonation products

number of particles in the

total number of particles $i^{\text {th }}$ group of particles

particle Nusselt number

pressure

turbulent Prandlt number 


\begin{tabular}{|c|c|}
\hline $\operatorname{Pr}_{k}, \operatorname{Pr}_{\varepsilon}$ & coefficients in the $k-\varepsilon$ equations \\
\hline$q$ & aspect ratio of oblate spheroid \\
\hline$\dot{Q}_{\mathrm{p}}$ & particle heat transfer to the gas \\
\hline r & radial coordinate, particle radius \\
\hline$r_{i}$ & particle radius of $i^{\text {th }}$ group of particles \\
\hline$r_{p}$ & particle radius \\
\hline rSauter & Sauter mean radius \\
\hline $\overrightarrow{\mathrm{r}}$ & size mean radius \\
\hline$\overline{\mathrm{r}}_{\text {mass }}$ & mass mean radius \\
\hline $\mathrm{R}$ & gas constant \\
\hline $\mathrm{Re}$ & Reynold's number \\
\hline $\mathrm{s}_{\mathrm{i}}$ & particle surface area of $\mathrm{i}^{\text {th }}$ group of particles \\
\hline$S_{p}$ & total surface area of all particles \\
\hline $\mathrm{Sc}_{\mathrm{T}}$ & turbulent Schmidt number \\
\hline$t$ & time \\
\hline $\mathrm{T}$ & temperature \\
\hline $\mathrm{T}_{\text {gas }}$ & gas temperarure \\
\hline $\mathrm{T}_{\mathrm{p}}$ & particle temperature \\
\hline $\mathbf{u}$ & mean gas velocity \\
\hline $\mathrm{V}$ & volume \\
\hline$V_{i j k}^{n}$ & volume of the cell(ijk) during the $n^{\text {th }}$ time cycle \\
\hline$v$ & velocity \\
\hline $\mathrm{v}_{\mathrm{r}}$ & r-component of velocity \\
\hline$v_{z}$ & z-component of velocity \\
\hline$\dot{\mathrm{W}}$ & source term from droplet interactions \\
\hline $\bar{W}$ & average molecular weight of the gas \\
\hline $\mathrm{z}$ & axial coordinate \\
\hline
\end{tabular}




\section{Greek:}

$\beta_{\|}$

$\beta_{\perp}$.

$\delta$

$\delta \mathrm{t}$

$\Delta \mathrm{H}_{\mathrm{det}}$

$\triangle \mathrm{KE}$

$\Delta \mathrm{IE}$

$\varepsilon$

$\mu$

$\mu_{\text {laminar }}$

$\mu_{\text {turbulent }}$

$\pi$

$\rho$

$\rho_{\mathrm{i}}$

$\dot{\rho}_{i}$

$\rho_{\mathrm{ijk}}^{\mathrm{n}}$

$\sigma$

\section{Subscripts:}

gas

fuel

laminar

turbulent

p

i

$\mathrm{ijk}$ dynamic shape factor for oblate spheroid parallel to the flow dynamic shape factor for oblate spheroid perpendicular to the flow unit tensor

subcycle time step

heat of detonation

change in kinetic energy

change in internal energy

turbulent dissipation rate

gas viscosity

laminar viscosity coefficient

turbulent viscosity coefficient

pi

density

density of $i^{\text {th }}$ species

mass source term for $\mathrm{i}^{\text {th }}$ species

gas density in cell(ijk) during the $n^{\text {th }}$ time cycle

stress tensor

gas

fuel

laminar

turbulent

particle

$\mathrm{i}^{\text {th }}$ species

ijkth cell 
Superscripts:

$\begin{array}{ll}\mathrm{n} & \mathrm{n}^{\text {th }} \text { particle } \\ \mathrm{T} & \text { transpose of tensor }\end{array}$

$\checkmark$ 


\section{Introduction}

Fuel-Air-Explosive (FAE) devices use a small explosive charge to disperse a liquid or solid fuel agent into a relatively extensive cloud. After the cloud has expanded to a suitable fuel/air ratio, the mixture is detonated by secondary detonators. For optimum efficiency, all of the fuel would be consumed in the FAE detonation process. This ideal situation is heavily dependent upon the characteristics of the fuel/air cloud and the process by which the cloud is formed. The current modeling effort is intended to aid in understanding the dispersal process and to identify the relative importance of various design parameters.

Though explosively dispersed weapons have been around since World War I in the form of chemical weapons and more recently in the form of high yield blast weapons, developmental work on FAE devices has been generally limited to experimental programs. As part of the "Enhanced Blast Munitions Technology Base Development Program," dispersal modeling for FAE was identified as an area which required further work for understanding the physics involved with explosively dispersing a fuel [1].

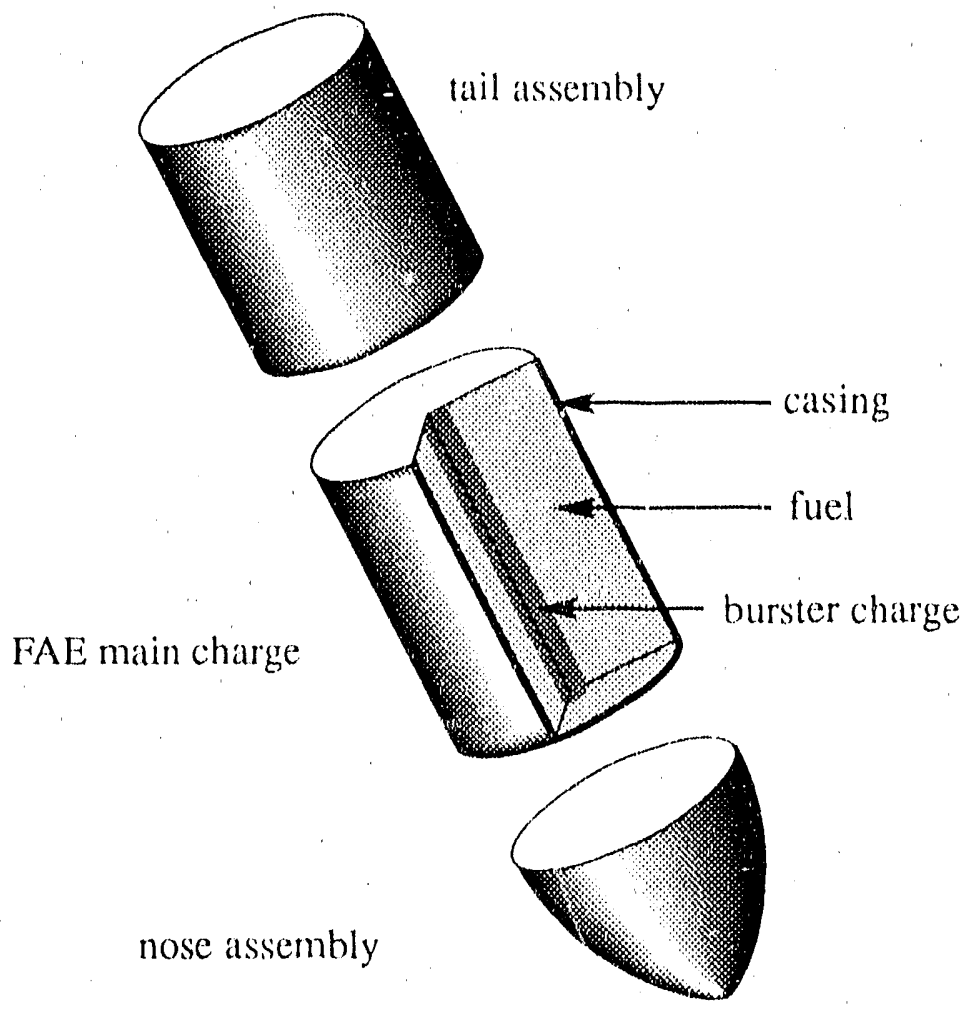

Figure 1: Typical FAE device schematic. 


\subsection{The Dispersal Process}

The explosive dispersal of the fuel agent involves the interaction of many con This can be broken down into several regimes based upon the dominant forces at that particular time [2]. The first of these is the ejection regime where the explosive forces of the burster charge predominate. In this regime the explosive forces are accelerating the fuel mass. The ejection regime is then followed by a transition regime in which the explosive forcus are comparable to the fuel-air interaction forces. Transition finally occurs over to the expansion regime in which the fuelair forces are dominant. In this regime the fuel-air interaction forces tend to decelerate the fuel mass.

The ejection regime covers the time from initial hurster charge detonation to a point in time where the initial mass of fuel has been sufficiently dispersed and shock forces no longer dominate the flow field. Sub-processes which are present during the ejection regime include: (1) the detonation of the burster charge; (2) rupturing of the device's casing; and (3) initial breakup and acceleration of the fuel mass. The ejection regime is characterized by the presence of a strong shock wave with shock and rarefaction waves reverberating through the fuel agent and the explosive gases. The ejection regime typically lasts until the fuel mass has expanded to about 6 times its initial dimensions. If the final cloud size is taken to be approximately 25 times its initial dimensions [2], then the ejection regime covers a very small fraction of the cloud's total volume expansion.

The transition regime is characterized by the shock wave dying out and the aerodynamic fluidparticle forces growing in significance. At this time the fuel agent no longer occupies a significant volume fraction of the two-phase mixture and is recognizable as discrete droplets in a continuous gas phase. The transition regime is typically limited to the first half of the device's expansion or the first $1 / 8$ of the cloud's total volume expansion.

The expansion regime is characterized by the deceleration of the fuel particles due to aerodynamic drag. Since the expansion regime covers the final $7 / 8$ of the cloud's total volume expansion, the final cloud chiari cteristics are predominantly controlled by the processes within this regime.

Because of the wide range of forces and phenomonologies involved with the dispersal process, the current modeling effort is conveniently divided into what are termed the near-field and far-field regimes. These coincide with the ejection and expansion regimes, respectively, with the crossover occurring somewhere within the transition regime. The near-field dispersal model must be able to model the strong shock forces present during the ejection regime, the fragmentation of the device's casing, and the initial breakup of the fuel mass. The far-field dispersal model must be able to model the coupled two-phase flow of finely dispersed fuel particles within the expanding cloud. Fluid-particle interactions such as droplet breakup and evaporation must also be well modeled. 


\subsection{Background on FAE Dispersal Modeling}

Previous modeling efforts have been very limited with most of the studies limited to specific aspects of the problem instead of modeling the entire process [3]. Ivandaev et al. [4] performed a one-dimensional numerical investigation of simple situations involving an expanding cloud of finely dispersed particles under the influence of a blast wave. Several simplifying assumptions were used such as no particle breakup, no fuel evaporation, and all the fuel particles were spherical and monodispersed. Though these simplifications physically limit the analysis results to solid fuel agents, the analysis was conducted using water as the liquid agent being dispersed. The analysis was also limited to the ejection regime of the dispersal process.

Rosenblatt et al. [5] performed a two-dimensional numerical investigation of both the dispersal process and the subsequent detonation of the fuel/air cloud. Their analysis was based upon an adaptation of the DICE code used by the Defense Nuclear Agency to model simulated nuclear blasts [6]. Their model of the dispersal process began after the ejection regime (or in the far-field) and included sub-models for fuel evaporation and aerodynamic breakup of fuel droplets. The primary drawback of the model was that it was very computationally intensive and, hence, expensive to run [6].

\subsection{Modeling Goal and Criteria}

The goal of the FAE fuel dispersal modeling effort is to accurately model the dynamics of the expanding fuel cloud in order to correctly characterize the properties of the final fuel/air cloud. Several parameters of this dynamic process are important in understanding the dispersal and in designing modern FAE devices. Prediction of cloud parameters such as growth rate, shape, fuel droplet size distribution, and uniformity of fuel concentration are necessary.

The temporal evolution of the cloud determines both the cloud growth rate and final cloud shape. Growth rate and shape are important factors for determining the appropriate time to initiate the cloud detonation with secondary detonators. The combination of these two parameters along with the total mass of the fuel determines the bulk density of the cloud and the fuel/air ratio which is critical for proper detonation of the fuel. The cloud shape also affects the blast wave characteristics of the fuel/air detonation. Fuel droplet size is thought to be critical during the cloud detonation process. Cloud uniformity plays a very important role upon the efficiency of the subsequent fuel-air detonation and in the uniformity of the blast wave. If the the cloud is nonuniform in fuel concentration, then any excess fuel in fuel-rich areas will not supply energy to the blast wave and fuel-lean areas can prevent the detonation from propagating through the cloud, thus producing a non-uniform blast wave. 
A criterion imposed upon the modeling effort by the "Enhanced Blast Munitions Technology Base Development Program," was to use existing codes as much as possible. Additionally, we foresaw the need to be able to perform both two- and three-dimensional calculations. Twodimensional calculations can be used to cost-effectively study the basic fuel dispersal process and the influence of a majority of the FAE device design parameters such as fuel agent, aspect ratio, fuel/burster charge mass ratio and height of burst. However, three-dimensional calculations will be necessary to study the effects of the device delivery process if it is anything other than normal to the ground plane. 


\section{Computer Code}

The numerical code selected for the basis of the far-field dispersal modeling effort was KIVA 17-10]. KIVA was developed at Los Alamos National Laboratory (LANL) for modeling incylinder dynamics of advanced internal combustion engines, such as the direct-injection stratifiedcharge (DISC) engine. As such, it has the ability to model the transient three-dimensional dynamics of closely coupled two-phase systems. KIVA uses finite-difference approximations to solve the Reynold's-averaged Navier-Stokes equations on an arbitrary Lagrangian-Eulerian grid. During the preliminary evaluation of the code, several features were especially attractive: (1) ability to perform two- and three-dimensional calculations; (2) cylindrical geometry available even for three-dimensional computations; (3) a fluid turbulence model (both $k-\varepsilon$ and a sub-grid model); and (4) an enhanced spray model for the fuel droplets. As mentioned earlier, the ability to perform both two- and three-dimensional calculations was considered very important. In this way, the effects of new code modifications and a parametric study of many of the input parameters can be assessed on a two-dimensional calculation instead of a computationally intensive and costly threedimensional calculation. But at the same time, three-dimensional calculations will be necessary when the delivery angle of the FAE device is considered to be something other than normal to the ground plane. Though turbulence models are not well-developed for compressible flows in unconfined geometries, the presence of the standard $k-\varepsilon$ model and sub-grid model were deemed sufficient at this time. The enhanced spray model utilizes a stochastic parcel method to model the droplets. In such a technique, each computational parcel represents a number of actual fuel particles with identical properties. Probability distributions often govern the change in properties during the course of a calculation. In such instances, droplet properties are determined using a Monte Carlo formulation of the problem. The stochastic parcel method of representing the fiel particles significantly reduces the computational requirements for modeling the two-phase system. The droplet model also includes: (1) droplet turbulence; (2) droplet evaporation; (3) droplet collisions and coalescence; and (4) an aerodynamic breakup of the droplets.

The current FAE far-field model, KIVA-FAE, is based upon the most recent release of KIVA, KIVA-II. The basic equations that are solved for the fluid phase are list in Table 1.

Built-in to KIVA is the ability to specify an initial distribution for the fuel droplets. The characteristic droplet size measurement parameter supplied as an input to KIVA is the Sauter mean radius, $\mathrm{r}_{\text {Sauter. }}$ This is a surface area mean radius defined as

$$
r_{\text {Sauter }}=\frac{\sum s_{i} r_{i}}{s_{p}}=\frac{\sum n_{i} r_{i}^{3}}{\sum n_{i} r_{i}^{2}} .
$$


The initial distribution applied to the droplets can be either monodisperse or polydisperse with the droplet sizes following a $\chi$-squared distribution as given by Equation 2 .

$$
f(r)=\frac{1}{\ddot{r}} e^{-r / r}
$$

For such a distribution, the number averaged droplet radius, $\overline{\mathrm{r}}$, is related to the Sauter radius by

$$
\overline{\mathrm{r}}=\frac{1}{3} \mathrm{r}_{\text {Sauter }} .
$$

Given the droplet radius distribution described by Equation 2, the droplet mass distribution can be derived by

$$
\begin{gathered}
f_{\mathrm{m}}(r)=\frac{\frac{\mathrm{r}^{3}}{\overrightarrow{\mathrm{r}}} \mathrm{e}^{-\mathrm{r} / \mathrm{r}}}{\int_{0}^{\infty} \frac{\mathrm{r}^{3}}{\overline{\mathrm{r}}} \mathrm{e}^{-\mathrm{r} / \overline{\mathrm{r}}} \mathrm{dr}} \\
f_{\mathrm{m}}(\mathrm{r})=\frac{\mathrm{r}^{3}}{6 \mathrm{r}^{-4}} \mathrm{e}^{-\mathrm{r} / \mathrm{r}} .
\end{gathered}
$$

Hence, the mass mean radius of the distribution given by Equation 5 is

$$
\overline{\mathrm{r}}_{\text {mass }}=4 \overline{\mathrm{r}}=\frac{4}{3} \mathrm{r}_{\text {Sauter }} .
$$




\section{Mass Conservation:}

$$
\begin{gathered}
\frac{\partial \rho_{i}}{\partial t}+\nabla \cdot\left(\rho_{i} \mathbf{u}\right)=\nabla \cdot\left[\rho D \nabla\left(\frac{\rho_{i}}{\rho}\right)\right]+\dot{\rho}_{i} \\
\rho=\sum_{i} \rho_{i} \\
\frac{\partial \rho}{\partial t}+\nabla \cdot(\rho \mathbf{u})=\dot{\rho} .
\end{gathered}
$$

\section{Momentum Conservation:}

$$
\frac{\partial(\rho \mathbf{u})}{\partial \mathrm{t}}+\nabla \cdot(\rho \mathbf{u u})=-\nabla \mathrm{p}-\nabla\left(\frac{2}{3} \rho \mathbf{k}\right)+\nabla \cdot \sigma+\mathbf{F}+\rho \mathbf{g}
$$

\section{Energy Conservation:}

$$
\frac{\partial \rho I}{\partial t}+\nabla \cdot(\rho \mathbf{I} \mathbf{u})=-p \nabla \cdot \mathbf{u}+\nabla \cdot\left[K_{\text {gas }} \nabla T+\rho D \sum_{i} h_{i} \nabla\left(\frac{\rho_{i}}{\rho}\right)\right]+\rho \varepsilon+\dot{Q}_{p}
$$

\section{Turbulent kinetic energy:}

$$
\frac{\partial \rho \mathrm{k}}{\partial \mathrm{t}}+\nabla \cdot(\rho \mathrm{ku})=-\frac{2}{3} \rho \mathrm{k} \nabla \cdot \mathbf{u}+\sigma: \nabla \mathbf{u}+\nabla \cdot\left[\left(\frac{\mu}{\mathrm{Pr}_{\mathrm{k}}}\right) \mathrm{k}_{\mathrm{T}} \nabla \mathrm{k}\right]-\rho \varepsilon+\dot{\mathrm{W}}
$$




\section{Turbulent kinetic energy dissipation rate:}

$$
\frac{\partial \rho \varepsilon}{\partial \mathrm{t}}+\nabla \cdot(\rho \varepsilon u)=-\left(\frac{2}{3} c_{\varepsilon_{1}}-c_{\varepsilon_{3}}\right) \rho \varepsilon \nabla \cdot \mathbf{u}+\nabla \cdot\left[\left(\frac{\mu}{\operatorname{Pr}_{\varepsilon}}\right) \nabla \varepsilon\right]+\frac{\varepsilon}{k}\left[c_{\varepsilon_{1}} \sigma: \nabla \mathbf{u}-c_{\varepsilon_{2}} \rho \varepsilon+c_{s} \dot{W}\right]
$$

Sub-grid scale turbulence model constraint:

$$
\varepsilon \geq\left[\frac{c_{\mu}}{\operatorname{Pr}_{\varepsilon}\left(c_{\varepsilon_{2}}-c_{\varepsilon_{1}}\right)}\right]^{\frac{1}{2}} \frac{k^{3 / 2}}{L_{S G S}}
$$

\section{Miscellaneous Relationships}

$$
\begin{gathered}
\mathrm{p}=\frac{\rho \mathrm{RT}}{\overline{\mathrm{w}}} \\
\sigma=-\frac{2}{3} \rho \mathrm{k} \delta+\mu\left[\nabla \mathbf{u}+\nabla \mathbf{u} \mathrm{T}-\frac{2}{3}(\nabla \cdot \mathbf{u}) \delta\right] \\
\mu=\mu_{\text {laminar }}+\mu_{\text {turbulent }} \quad \text { with } \mu_{\text {turbulent }}=\mathrm{C}_{\mu} \rho \frac{\mathrm{k}^{2}}{\varepsilon} \\
\mathrm{k}_{\mathrm{T}}=\frac{\mathrm{c}_{\mathrm{p}} \mu}{\operatorname{Pr}_{\mathrm{T}}} \\
\mathrm{D}=\frac{\mu}{\rho S \mathrm{c}_{\mathrm{T}}}
\end{gathered}
$$




\section{Modifications to the Computer Code}

Several modifications were made to KIVA before it was used to model the far-field dispersal problem. The first of these was to convert system specific subroutine calls from the LANL, version of CTSS to Sandia National Laboratories' (SNL) version of CTSS. The graphics routines used for post-processing were also converted from a LANL graphics package to SNL's DISSPLA graphics package. While running test problems to become familiar with KIVA, it was realized that the limits on the maximum size of the computational domain could prevent KIVA from modeling large, fully three-dimensional FAE dispersai problems. The primary limitation imposed upon the code was due to Sandia's implementation of the DISSPLA graphics library under CTSS. The current implementation prevents codes which use the graphics library to make use of the CRAY/XMP's extended memory features. To alleviate this restriction, the post-processing features were extracted from the main code to form a separate post-processor. Because KIVA-II was originally developed to model internal combustion engines, it incorporated an extensive amount of code which was very specific towards this task such as the grid generation routines, piston movement, and fuel injectors. This code was removed and replaced with a pre-processor front-end which was specifically coded to handle FAE modeling. KIVA also incorporated its fuel library within the main body of its code. This was eliminated by implementing a separate database for both the fuels and gas species. In this way, additional fuels can be easily added to the library without requiring a complete recompilation of the code. And finally, additions were made to the code to handle solid fuels. These additions included a heat transfer model for solid particles and an appropriate drag law for nonspherical particles.

\subsection{Pre- and Post-Processing Utilities}

It was recognized that a more robust approach would be recuired in order to fully utilize KIVAIl for a wide variety of situations with a minimum of effort. 'To this end, the code was divided into three major segments: (1) the pre-processor; (2) the computational model; and (3) the postprocessor. The pre-processor serves several purposes. First, it incorporates a basic algebraic grid generator. The grid generator provide various primitives for creating lines, arcs, and guadrilaterals with either uniforn, geometric, or hyperbolic tangent grid point spacing along the boundary. Once this is done, both vertical and horizontal linear interpolation between line segments, tensor product interpolation, transfinite interpolation, or hermite cubic interpolation schemes are available to complete the grid. The algebraic grid generator provides a very effective method to quickly formulate a wide variety of computational meshes without a large effort in recoding. The preprocessor also defines most of the variable initializations and initial conditions of the problem such as the velocity and scalar fields. And lastly, the pre-processor will serve as an interface to the nearfield code, converting its output into an appropriate input file for KIVA-FAE. The computational segment of KIVA-II has remained largely unchanged. The post-processor provides graphics output of the results and serves as an interface to any future FAE blast wave code. In actuality, 
two post-processors have been written. The first of thesc utilizes much of the post-processing routines that were available from within KIVA-II with appropriate conversions to use the DISSPLA graphics lihrary. The second post-processor produces nodal results files which are compatible with the $P$ ITRAN post-processing code.

Figure 2 presents the current flowchart for the FAE far-field dispersal model. The flowchart indicates all of the program modules, required input files, and resulting output files.

\subsection{Solid Particle Heat Transfer}

Heat transfer between solid fuel particles and the gas phase is accounted for by the equation:

$$
\sum_{i} M_{i} c_{p i} \frac{d T_{p}}{d t}=Q_{p}
$$

where the co. . 'ective heat transfer $\dot{Q}_{p}$ is given by

$$
\dot{\mathrm{Q}}_{\mathrm{p}}=-\frac{N \mathrm{u}_{\mathrm{p}} \mathrm{K}_{\mathrm{gass}} S_{\mathrm{p}}}{\mathrm{d}_{\mathrm{p}}}\left(\mathrm{T}_{\mathrm{p}}-\mathrm{T}_{\mathrm{gas}}\right)
$$

The actual computations were performed in a manner similar to the particle evaporation submodel already in KIVA. As such, the solid-particle heat iransfer is sub-cycled within the current time step with a sub-cycle time step, $\delta t$, given hy

$$
\delta t \leq \frac{p_{i j k}^{n} V_{i j k}^{n}\left(c_{p}\right)_{i j k}^{n}}{N u_{p} K_{g a s} 4 \pi r_{p} N_{p}}
$$

This criterion implies that the energy transferred within the first subcycle is one-half the total energy available for transfer. 


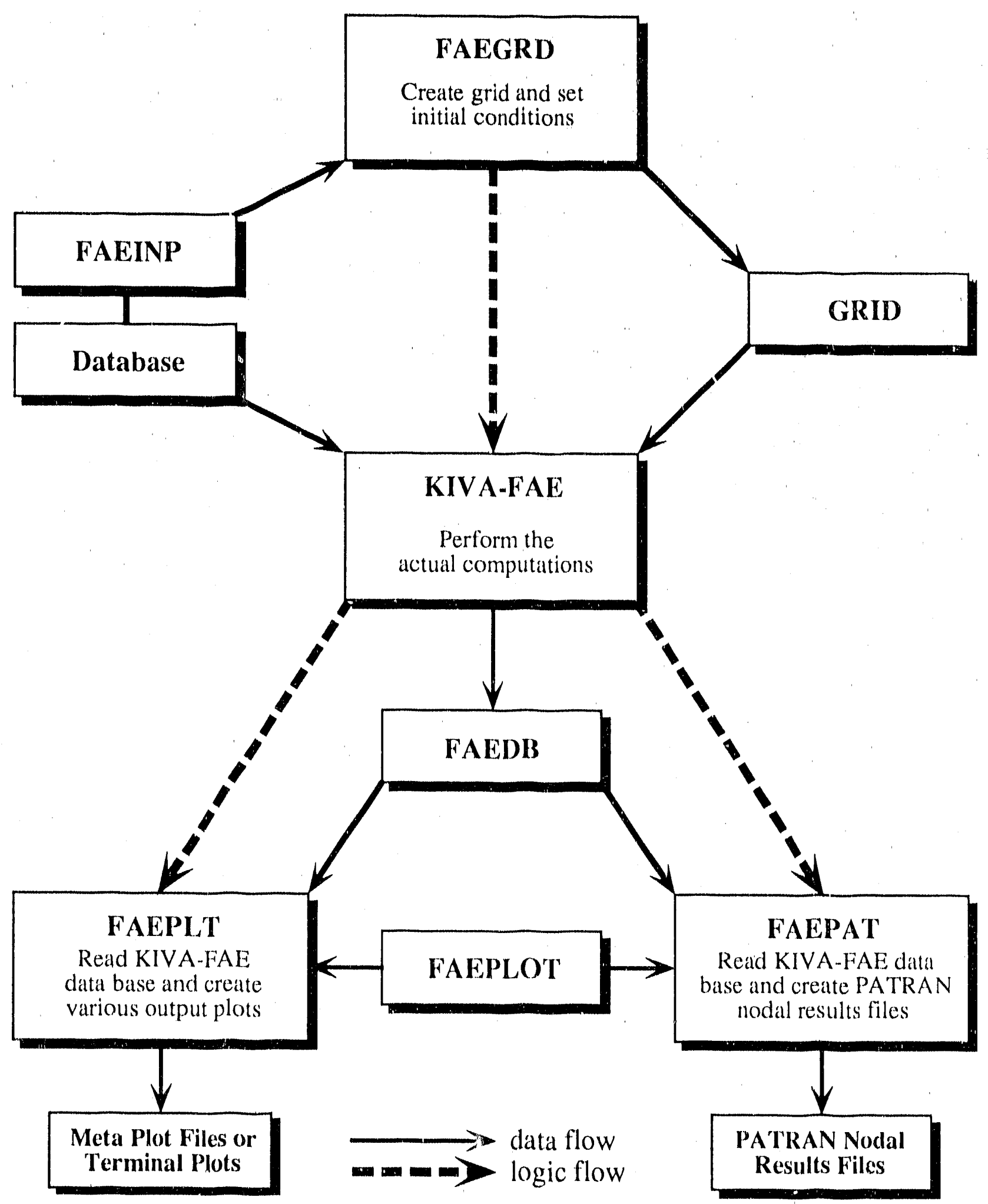

Figure 2: FAE far-field dispersal model flowchart. 


\subsection{Flaked Particle Drag Law}

There is considerable interest within the FAE community to investigate the suitability of flaked aluminum powder as a potential fuel. To model the dispersal of flaked aluminum, the fluid-particle interactions which are dependent upon the particle shape must be modified. In particular, an appropriate function for the particle drag was incorporated into KIVA-FAE. This was achieved by including a dynamic shape factor in the drag law [11]. The dynamic shape factor, $\beta$, is defined as the ratio of drag forces for a nonspherical particle and a sphere of equal volume moving at the same velocity. As expected, previous investigation into the aerodynamic drag on nonspherical particles reveals a heavy dependency upon the particle's orientation to the fluid flow $[11,12]$.

During low Reynold's number flow, disk shaped particles tend to exhibit a tumbling motion so it was assumed that an average correction factor could be applied to the drag law formulation. a ather than explicitly taking into account the particle's actual orientation. Cheng et al. [11] investigated disk shaped talc particles and showed that their experimentally determined dynamic shape factors closely matched those given by a theoretical analysis of oblate spheroids. Theoretical analysis for oblate spheroids yields the following expression for the dynamic shape factor if the particle moves along its polar axis,

$$
\beta_{\|}=\frac{\frac{4}{3}\left(1-q^{2}\right) q^{-1 / 3}}{\left(\frac{1-2 q^{2}}{\sqrt{1-q^{2}}}\right) \cos ^{-1} q+q}
$$

and the following if the particle moves perpendicular to its polar axis

$$
\beta_{\perp}=\frac{\frac{8}{3}\left(1-q^{2}\right) q^{-1 / 3}}{\left(\frac{3-2 q^{2}}{\sqrt{1-q^{2}}}\right) \cos ^{-1} q-q}
$$

where $\mathrm{q}$ is the aspect ratio of the spheriod. Thus for low Reynold's number flow, the average of Equations 23 and 24 is used as the dynamic shape factor for the flaked aluminum powder.

For high Reynold's number flow, disk shaped particles will tend to align themselves parallel with the flow and the dynamic shape factor approaches a constant value of 1.17 above a Reynold's 
number of 200 [13]. Thus the dynamic shape factor for flaked aluaninum powder was incorporated into KIVA-FAE as

$$
C_{D \text { flakes }}= \begin{cases}\frac{1}{2}\left(\beta_{\|}+\beta_{\perp}\right) C_{D \text { spheres }} & \text { Re }<200 \\ 1.17 & R e>200\end{cases}
$$




\section{Results}

This section provides some insight into the computational penalty each of the fluid-particle sub. models imposes upon KIVA-FAE, describes how the initial conditions were determined for further modeling of the fuel dispersal, and describes the results obtained from simulating the dispersal of decane, propylene oxide and flaked aluminum powder. Decane was chosen as a standard fuel for the majority of the simulations because there has been a strong emphasis, for safety reasons, on using low vapor pressure fuels in future FAE devices [14]. Decane was chosen as a representative model FAE fuel. A simulated dispersal of propylene oxide (PO) was conducted because $P O$ is used in current FAE devices [1] and was used in the DICE.FAE calculations [5]. Thus comparison to some previous data could be made. And finally, dispersal of a flaked aluminum powder was simulated because there is considerable interest in its potential as an advanced FAE fuel. All of the results presented here were two-dimensional, axi-symmetric: calculations. A typical computational mesh used in all of the calculations is shown in Figure 3. The following calculations included fuel evaporation and droplet breakup for the liquid fuels, droplet turbulence for all fuels, but neglected droplet coalescence. For the gas phase, the sub-grid turbulence model was used with the initial local turbulent kinetic energy based on $1 \%$ of the local gas velocity.

Because of the large number of figures present in this section, the plots from each case are all grouped together at the end of the section.

\subsection{Using KIVA-FAE}

Some preliminary calculations were performed with KIVA-FAE to a'sess its capabilities and to determine the effect of the various fluid-particle sub-models on the required computational times. A test problem was formulated that consisted of a cylinder of high temperature, high pressure gas (air in this instance) placed 1 metre above the ground plane. Within this cylinder, an annulus of decane was placed with the droplets having a $\chi$-squared size distribution. The high pressure gas was then allowed to freely expand into the ambient atmosphere, dispersing the fuel droplets. The geometry and spatial dimensions of this problem are shown in Figure 4. All of the calculations were performed on an identical two-dimensional, axi-symmetric computational mesh similar to Figure 3 but much courser with only $40 \times 40$ cells. The mesh physically represented a $20 \mathrm{~m}$ by 20 $\mathrm{m}$ spatial domain. Each of the calculations was carried out for a model time of $100 \mathrm{~ms}$. Fluid turbulence was neglested for this initial study and 2000 fuel parcels were used. 


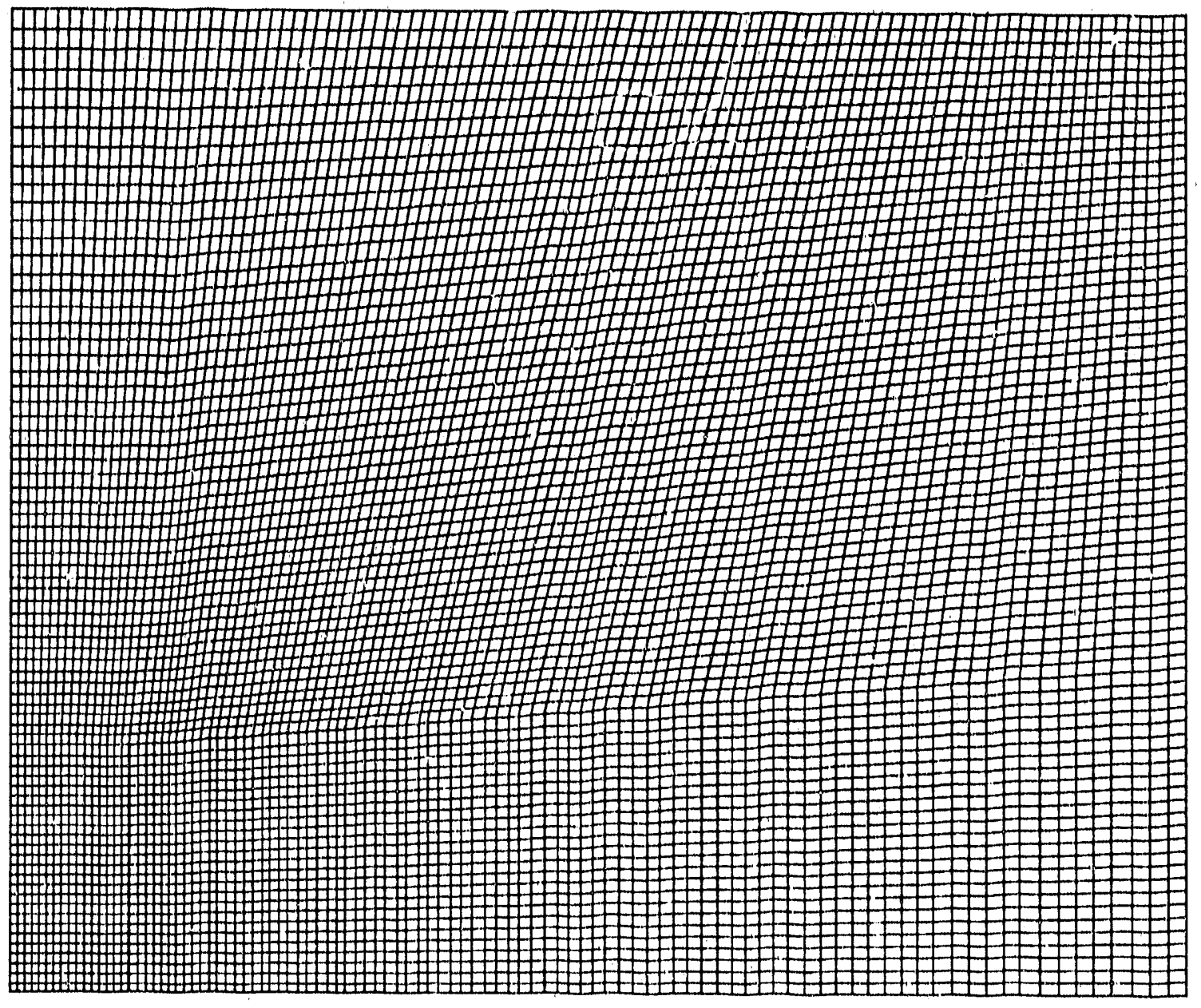

Figure 3: Typical computational mesh used in two-dimensional, axi-symmetric calculations 


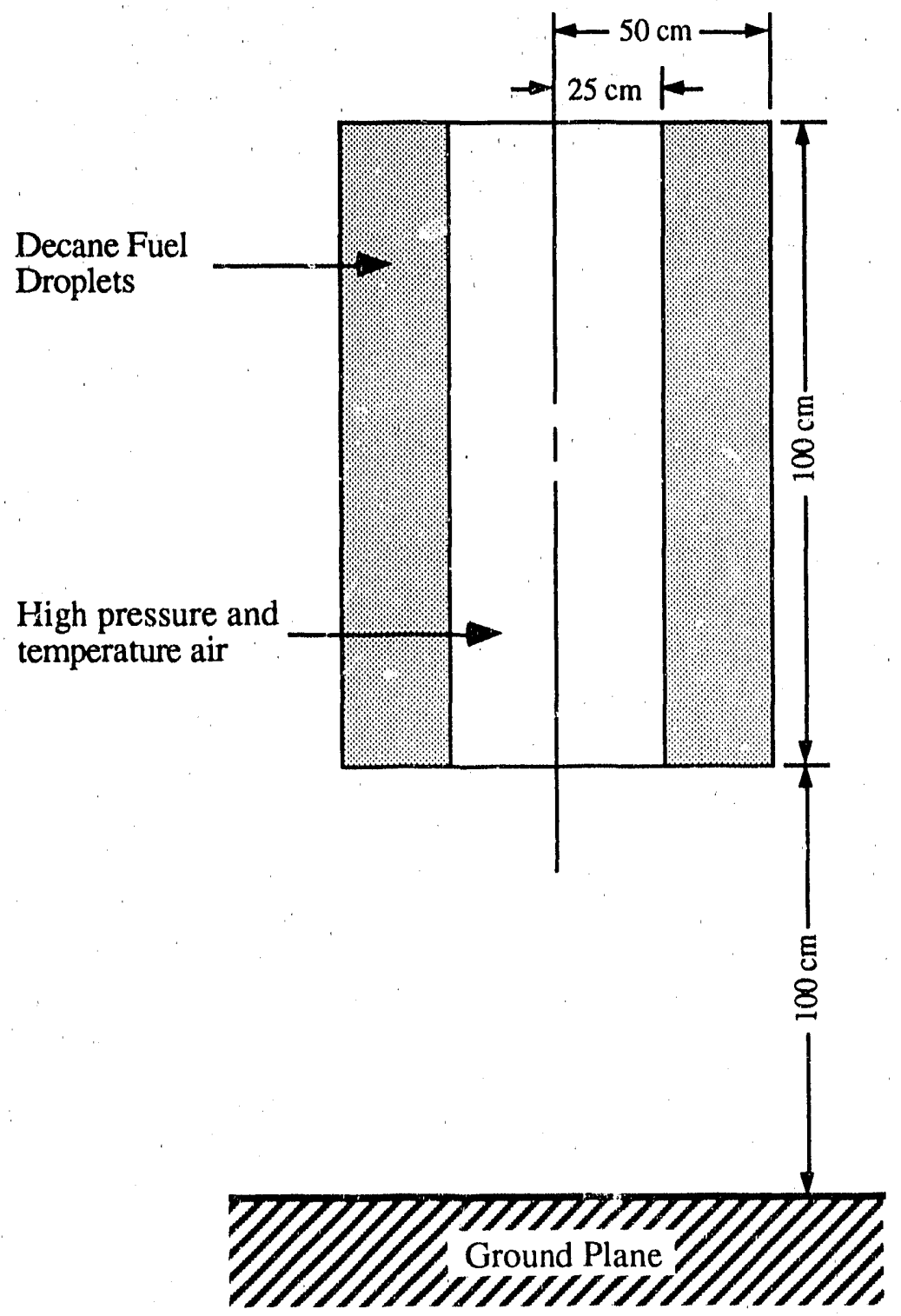

Figure 4: Schematic of initial configuration for dispersal model testing 
The timing results are shown in Table 2 . From this, we can see that the particle turbulence and evaporation models do not significantly add to the computational time of the code. The aerodynamic breakup model effectively doubles the time and the particle collision and coalescence model requires an 8 -fold increase in time. This clearly shows that the droplet coalescence submodel carnot be vectorized and to a lesser degree this is true of the breakup sub-model.

Table 2: CPU Timing Results for the Various Fluid-Particle Sub-Models

\begin{tabular}{|c|c|c|c|c|c|}
\hline & $\begin{array}{c}\text { Particle } \\
\text { Turbulence }\end{array}$ & $\begin{array}{c}\text { Droplet } \\
\text { Evaporation }\end{array}$ & $\begin{array}{c}\text { Aerodynamic } \\
\text { Breakup }\end{array}$ & $\begin{array}{c}\text { Droplet } \\
\text { Coalescence }\end{array}$ & $\begin{array}{c}\text { CRAY-XMP } \\
\text { CPU Timing }\end{array}$ \\
\hline \hline Case 1 & off & off & off & off & 6.0 min \\
\hline Case 2 & on & off & off & off & 6.0 \\
\hline Case 3 & on & on & off & off & 7.3 \\
\hline Case 4 & on & on & on & off & 14.5 \\
\hline Case 5 & on & on & on & on & 47.3 \\
\hline
\end{tabular}

* a fully $3 \mathrm{D}$ case with no fluid-particle sub-models took $\sim 2 \mathrm{hrs}$ CPU time.

\subsection{Initial Conditions for FAE Modeling}

For the purpose of evaluating KIVA-FAE's ability to model the far-field dispersal regime for FAE, a simple two-dimensional problem was formulated similar to the one used for the previous DICE-FAE calculations [5]. The geometry was chosen to resemble a FAE device after its burster charge had detonated and the fuel was partially dispersed and fully broken up into discrete droplets (i.e. at the beginning of the transition regime). This, of course, was just a rough estimate pending further progress in the near-field modeling effort. The near-field was sub-divided into three region as shown in Figure 5. Region I corresponds to the burster charge detonation products. For simplification, the detonation products were given the properties of air. Region II represents the main fuel mass. The fuel is assumed to have already undergone its initial breakup into discrete particles. Region III represents the transition to the ambient air. 


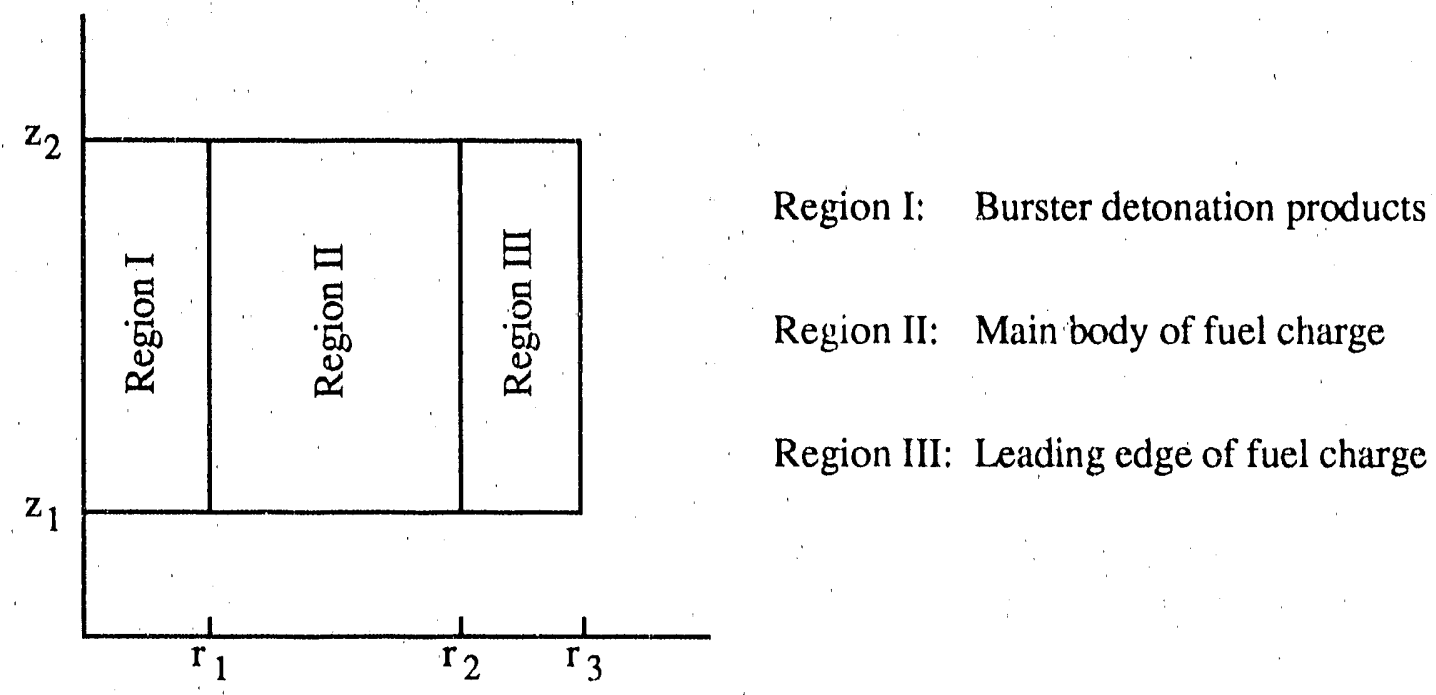

Figure 5: Initial configuration for FAE model.

If the device casing is neglected, the total energy available for the expansion phase is distributed between the gaseous detonation products and fuel droplets in the form of kinctic and internal energy. The relationship is given by

$$
\mathrm{M}_{\text {fucl }} \Delta \mathrm{H}_{\text {det }}=\left(\Delta \mathrm{KE}_{\text {fuel }}+\Delta \mathrm{KE}_{\mathrm{gas}}+\Delta \mathrm{IE}_{\mathrm{fuel}}+\Delta \mathrm{IE}_{\mathrm{gas}}\right)
$$

This energy was initially distributed as shown in Table 3 and is identical to the energy distribution used in the DICE-FAE calculations and for the same reasons [5].

Table 3: Initial Distribution of Energy from the Burster Charge Detonation

\begin{tabular}{|c|c|c|}
\hline & $\begin{array}{c}\text { Kinetic Energy } \\
\text { (percent) }\end{array}$ & $\begin{array}{c}\text { Internal Energy } \\
\text { (percent) }\end{array}$ \\
\hline \hline Fuel & 70 & 12 \\
\hline Gas & 3 & 15 \\
\hline
\end{tabular}


Fuel and Gas Radial 'elocity Profile

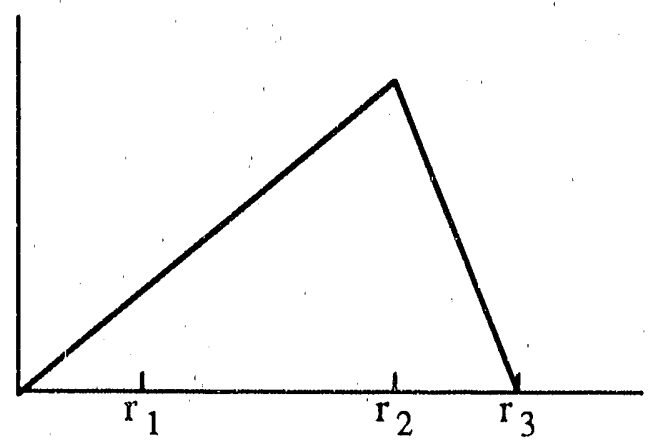

Fuel and Gas Longitudinal Velocity Profile

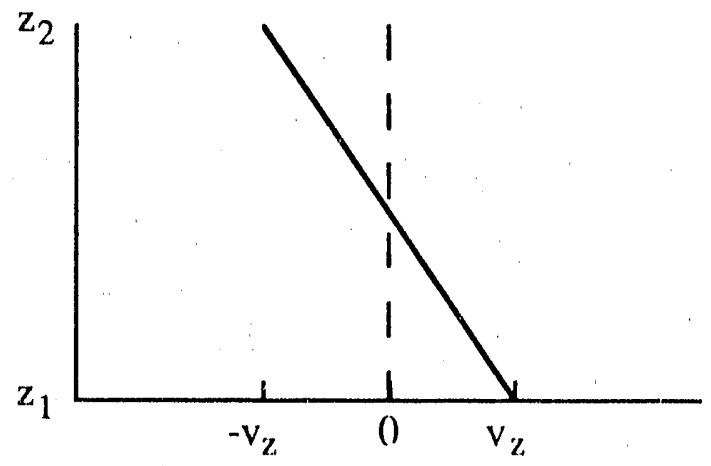

Gas Density and Temperature Profile

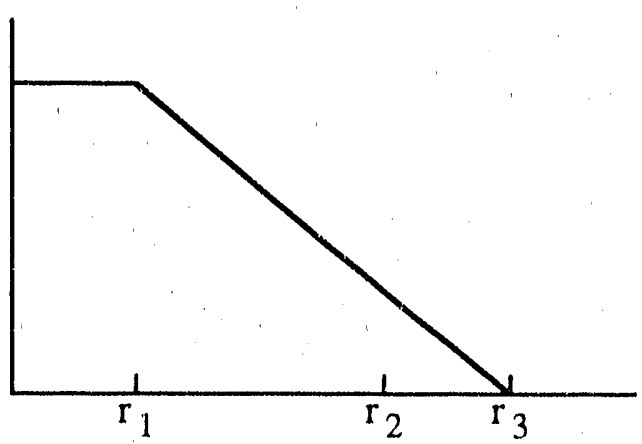

Fuel Density and Temperature Profile

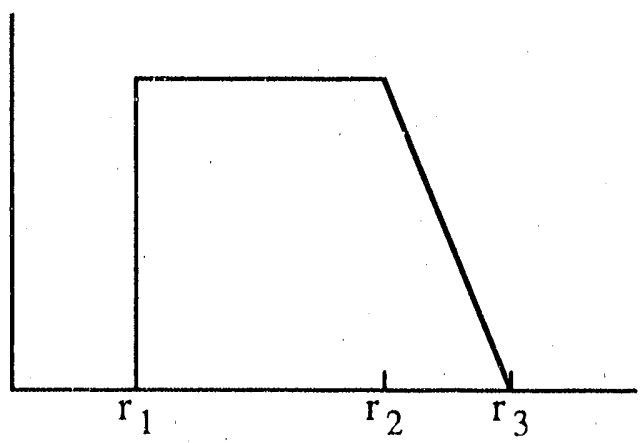

Figure 6: Initial velocity, temperature, and density profiles 
Assuming linear relationships for the profiles and interphase equilibrium as shown in Figure 6, the parameters for the linear functions can be determined by solving balance equations along with Equation 23. The parameters for the fuel and gas density profiles were determined first by solving Equations 24 and 25 below where $M_{\text {fuel }}$ the mass of the fuel present in the FAE device and $M_{\text {gas }}$ is the mass of the burster charge and the mass of ambient air that was originally present within the three regions.

$$
\begin{aligned}
& M_{\text {fucl }}=\int_{V} \rho_{\text {fuel }} d V=2 \pi \int_{z_{1}}^{z_{2}} \int_{r_{1}}^{r_{2}} \rho_{\text {fucl }} r d r d z \\
& M_{\text {gas }}=\int_{V} \rho_{\text {gas }} d V=2 \pi \int_{z_{1}}^{z_{2}} \int_{r_{1}}^{r_{2}} \rho_{\text {gas }} r d r d z
\end{aligned}
$$

The parameters for the temperature profiles were determined next by solving Equations 26 and 27 below. The initial temperature was assumed to be $300{ }^{\circ} \mathrm{K}$ and $\Delta$ IEs for each phase were determined from Equation 23 and Table 3.

$$
\begin{aligned}
\Delta \mathrm{IE}_{\text {fucl }} & =\int_{\mathrm{V}} \rho_{\text {fuel }} \mathrm{c}_{\mathrm{p}} \Delta \mathrm{T} \mathrm{dV}=2 \pi \int_{\mathrm{z}_{1}}^{\mathrm{z}_{2}} \int_{\mathrm{r}_{1}}^{\mathrm{r}_{2}} \rho_{\text {fuel }} \mathrm{c}_{\mathrm{p}} \Delta \mathrm{T} \mathrm{rdr} \mathrm{d} \mathrm{z} \\
\Delta \mathrm{IE}_{\text {gas }} & =\int_{\mathrm{V}} \rho_{\text {gas }} \mathrm{c}_{\mathrm{p}} \Delta \mathrm{T} \mathrm{dV}=2 \pi \int_{\mathrm{z}_{1}}^{\mathrm{z}_{2}} \int_{\mathrm{r}_{1}}^{\mathrm{r}_{2}} \rho_{\text {gas }} \mathrm{c}_{\mathrm{p}} \Delta \mathrm{T} \mathrm{rdr} \mathrm{dz}
\end{aligned}
$$

And finally, the parameters for the velocity distribution were calculated by solving Equations 28 and 29. The $\triangle \mathrm{KEs}$ for each phase were determined from Equation 23 and Table 3 . This is still not enough information to completely determine the velocity profiles. To provide closure, the maximum velocity in either the radial or longitudinal direction must be set to a specified value. For the purpose of these calculations, the maximum longitudinal velocity, $v_{z \text { max }}$ was set to $5500 \mathrm{~cm} / \mathrm{s}$ as it was in the DICE-FAE calculations. In typical FAE devices, the nose and tail assemblies limit the longitudinal expansion of the burster charge detonation, thus $v_{r \text { max }}$ will be much greater than $\mathrm{v}_{\mathrm{Z} \max }$ 


$$
\begin{aligned}
& \Delta \mathrm{KE}_{\text {fuel }}=\int_{\mathrm{V}} \frac{1}{2} \rho_{\text {fucl }} \mathrm{v}^{2} \mathrm{dV}=\pi \int_{\mathrm{z}_{1}}^{\mathrm{z}_{2}} \int_{\mathrm{r}_{1}}^{\mathrm{r}_{2}} \rho_{\text {fucl }}\left(v_{\mathrm{r}}^{2}+\mathrm{v}_{\mathrm{Z}}^{2}\right) \mathrm{rdr} \mathrm{dz} \\
& \Delta \mathrm{KE}_{\text {gas }}=\int_{V} \frac{1}{2} \rho_{\text {gas }} v^{2} \mathrm{dV}=\pi \int_{\mathrm{z}_{1}}^{\mathrm{z}_{2}} \int_{r_{1}}^{\mathrm{r}_{2}} \rho_{\text {gas }}\left(v_{\mathrm{r}}^{2}+v_{\mathrm{Z}}^{2}\right) \mathrm{rdr} \mathrm{dz}
\end{aligned}
$$

After the above calculations were performed, the parameters for the velocity, temperature, and density were used within the pre-processor to set the initial conditions for the FAE dispersal simulation. It was also assumed, in the case of a liquid fuel, that there was no evaporation of the fuel prior to the determination of the initial conditions for KIVA-FAE.

In the following calculations, the initial conditions were set to model a "jug" test typical of those which were to be carried out at the Naval Weapons Center. In such a test, a plastic 5 gallon jug is filled with fuel and a burster charge to simulate a FAE device. A fuel/burster charge mass ratio of 100:1 is typically used with PBX-9010 used as the burster charge [15]. With PBX-9010 as the burster charge, $\Delta \mathrm{H}_{\mathrm{det}}=5.7 \times 10^{10} \mathrm{ergs} / \mathrm{gm}[16]$. The burster charge mass was set to 137 gm and the fuel mass was set to $13700 \mathrm{gm}$, thus representing a lypical "jug" test. The distances defined in Figure 5 were specified as; $r_{1}=15 \mathrm{~cm}, r_{2}=60 \mathrm{~cm}, r_{3}=75 \mathrm{~cm}, \mathrm{z}_{1}=100 \mathrm{~cm}$, and $\mathrm{z}_{2}=$ $160 \mathrm{~cm}$. These values were obtained from the initial conditions used in the DICE-FAE calculations mentioned earlier. In such "jug" tests, the heavy support stand simulates the nose assembly and a heavy metal plate is placed on top of the jug to simulate the tail assembly.

In the following calculations, a $12 \times 10$ meter physical domain was represented with a $100 \times 75$ computational grid as was shown in Figure 3. Eight thousand computational particles were used to represent the dispersed fuel. Each calculation was carried out to simulate $75 \mathrm{~ms}$ and a typical computational time on the CRA Y/XM? using the CFT FORTRAN compiler was approximately 40 minutes.

\subsection{Dispersal of Decane}

Dispersal of decane was simulated for a total of 10 cases which are described in the following sections. Table 4 briefly summarizes the conditions for each case which will be referred to by the listed identifier code. 
Table 4: Summary of Decane Dispersal Conditions

\begin{tabular}{|c|c|c|c|c|}
\hline Identifier & $\mathrm{r}_{\text {sauter }}, \mathrm{cm}$ & Distribution & $\begin{array}{c}\text { Height-of-Burst, } \\
\mathrm{cm}\end{array}$ & $\begin{array}{c}\text { Delivery velocity, } \\
\mathrm{cm} / \mathrm{s}\end{array}$ \\
\hline Case 1 & 0.3 & monodisperse & 100 & 0 \\
\hline Case 2 & 1 & monodisperse & 100 & 0 \\
\hline Case 3 & 3 & monodisperse & 100 & 0 \\
\hline Case 4 & 1 & $\chi$-squared & 100 & 0 \\
\hline Case 5 & 2 & $\chi$-squared & 100 & 0 \\
\hline Case 6 & 3 & $\chi$-squared & 100 & 0 \\
\hline Case 7 & 3 & $\chi$-squared & 50 & 0 \\
\hline Case 8 & 3 & $\chi$-squared & 300 & 100 \\
\hline Case 9 & 3 & $\chi$-squared & 100 & 500 \\
\hline Case 10 & 3 & $\chi$-squared & 100 & 0 \\
\hline
\end{tabular}

\subsubsection{Effect of Initial Droplet Size and Mass Distribution}

Currently, one of the most difficult problems to model during the ejection regime is the initial breakup of the fuel mass. In the following calculations, the initial fuel droplet size and mass distribution were varied to determine the sensitivity of the final cloud on the initial droplet size parameters. It was hoped that the final cloud would be relatively insensitive to the initial fuel breakup so the near-field model could use a less rigorous approach to this problem.

Six cases were studied, three with a single droplet size present at the beginning of the calculations and three with a $\chi$-squared distribution present at the beginning. For the three cases with a sing droplet size, Sauter mean radii of $0.3,1$, and $3 \mathrm{~cm}$ were used and for the three cases with a $\chi$-squared distribution, Sauter mean radii of 1,2 , and $3 \mathrm{~cm}$ were used.

The results from these six cases are shown in Figures 7-46. In all the figures, only a $5 \times 4$ meter sub-region of the larger computational domain is shown. The contour plots shown also 
represent the same $4 \times 5$ meter sub-region but enlarged to improve clarity. The upper bound on the equivalence ratio contour plots for these and all other cases was limited to 3.6 in order to resolve the contour bands closer to 1.0. Therefore, the black band represents areas with an equivalence ratio of 3.2 or greater. Figures $7-12$ depict the fuel dispersal at $15 \mathrm{~ms}$ intervals for Case 1. For the remaining five cases, results are shown only at times of 60 and $75 \mathrm{~ms}$.

In all six cases the flow field is characterized by the development of vortices above and below the meridian plane of the device. However, it is also noted that the upper vortex becomes much stronger than the lower vortex as the initial droplet size was reduced. The vortices also serve to produce fuil rich zones within the cloud as shown by the density and equivalence ratio cortours.

The final droplet size distributions for all six cases were very similar with the majority of the fuel mass residing in the 5-20 $\mu \mathrm{m}$ size range. For Cases 4-6 where some larger particles were initially present, the final droplet size distribution showed only a few large droplets left but the mass-mean radius was similar in all cases. Though the final droplet size distribution was shown to be relatively insensitive to the initial droplet size distribution, the final cloud shape and concentration profile were sensitive to the initial droplet size distribution. A smaller initial droplet size produces a flatter cloud and the smaller drops flow with the gas, thus producing very concentrated regions at the vortices. As the initial droplet size distribution was set to larger droplet radii, the dispersal produced much less dense clouds that dispersed more in the longitudinal direction. Such a cloud's shape can also be characterized more as a torus rather than as a pancake. Such torus shaped clouds can be further characterized by fuel rich zones in the vortices and a fuel lean zone between the two vortices. In all six cases, the clouds were very fuel rich with equivalence ratios greater than 2 throughout a large portion of the cloud.

Varying the initial droplet size distribution also varies the droplet breakup times. It would seem that during the initial expansion of the cloud, the droplet breakup times play a significant role in effecting the final cloud characteristics.

The droplet size distribution also appears to have very little effect on the amount of fuel that is vaporized during the dispersal process. Approximately $1 \%$ of the initial fuel mass was vaporized in all six cases.

\subsubsection{Effect of Initial Height-of-Burst}

The distance above the ground plane at which the burster charge detonates is termed the heightof-burst. It is often varied according to the size of the FAE device and the desired shape of the cloud. In addition to the $1 \mathrm{~m}$ height-of-burst cases calculated above, two additional cases, Cases 7 and 8 , were calculated with a height-of-burst of 0.5 and $3 \mathrm{~m}$ respectively. Comparing the results from cases 6, 7 and 8 (Figures 41-58), it is seen that the height-of-burst can effect the cloud development if the height-of-burst is low enough such that the gas flow field strongly interacts 
with the ground plane. Comparison of Case 7 to Case 6 shows that ground effects are significant in Case 7. In Case 7, the lower vortex has been eliminated from the flow field and fuel cloud appears to run along the ground plane and hence is nore concentrated along the ground as compared to the other cases. Case 8 shows almost identical cloud characteristics as Case 5 indicating that ground effects were negligible for both cases.

\subsubsection{Effect of Device Delivery Velocity}

The velocity of a FAE device at the time the burster charger detonates spans a very wide range. The vast majority of FAE experimental programs utilize static testing where the test device is resting on a stand at the time the burster charge is detonated. First-generation FAE weapons typically employed a parachute delivery system so their initial velocity was quite low and the delivery was normal to the ground plane. Second-generation FAE weapons often utilize a low angle, high-speed delivery.

Two additional cases, Cases 9 and 10, were used to investigate the effect the delivery velocity has on the fuel cloud. Along with a static calculation from above, Case 6, cases with initial velocities of $\left.10^{\prime}\right)$ and $500 \mathrm{~cm} / \mathrm{s}$ were also calculated. The velocities were limited to low values representative of a parachute delivery because the high-speed delivery velocities of second generation FAE weapons are limited to acute delivery angles which would require a threedimensional calculation which is beyond the scope of this present study.

Results from these two cases, along with a comparison to Case 6, show that the delivery velocity for a simulated parachute delivery system has a negligible effect upon the FAE cloud.

\subsection{Dispersal of Propylene Oxide}

Propylene oxide (PO) has been widely used in previous FAE weapons and is still widely used today in test devices used to study FAE blast effects. Because of its wide use, a simulated dispersal of PO was conducted, Case 11, to provide a reference to existing experimental data in order to gauge the accuracy of the KIVA-FAE results.

Results from Case 11 are shown in Figures 71-76. The PO dispersal shows a cloud shape very similar to one produced with decane under identical conditions (Case 6). The PO cloud is slightly more uniform than the decane cloud, especially when comparing the equivalence ratio contours. Additionally, almost $3 \%$ of the initial fuel mass was vaporized during the dispersal process as compared to approximately $1 \%$ for previous cases with decane as the fuel. 


\subsection{Dispersal of Flaked Aluminum}

To demonstrate the ability of KIVA-FAE to model the dispersal of solid fuels, a flaked aluminum powder was chosen because there has been considerable interest in its potential as an advanced FAE fuel. The flakes were assumed to be thin disks $1 \mu \mathrm{m}$ in thickness and $10 \mu \mathrm{m}$ in diameter [17]. Several assumptions were made about the solid dispersal process. These were: (1) there was no agglomeration of the flakes; (2) shock heating of the flakes did not cause any of the flakes to fuse; and (3) there was no mechanical breakup of the flakes. A 1 meter height-of-burst was also used for this calculation.

The results of the aluminum dispersal, Case 12, are shown in Figures 77-86. The results show that the cloud is much flatter, representing a pancake more than a torus, than those obtained from licyuid fuels and appears to be much more uniform in the radial direction. 


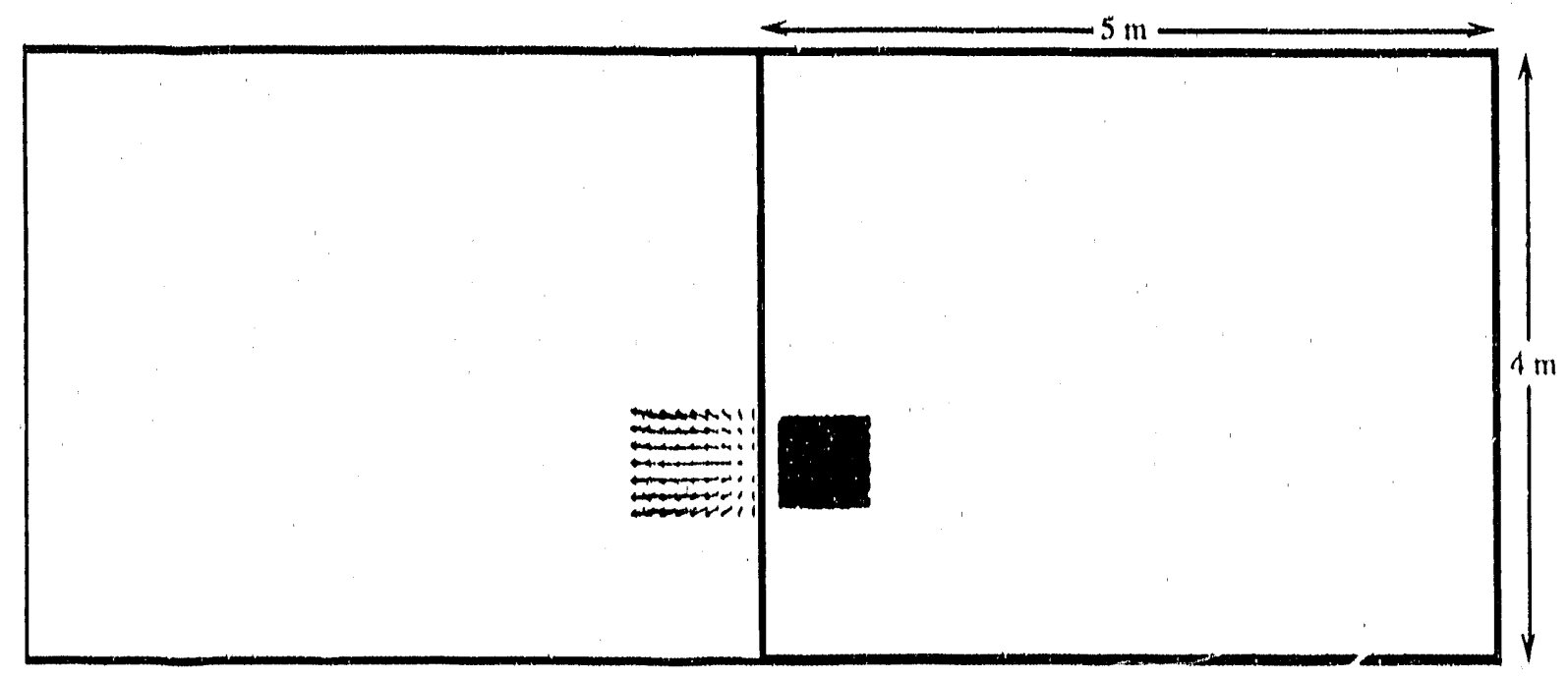

Figure 7: Velocity profile and fuel parcel positions at $t=6$ ans, Case 1. $v_{\max }=273(0) \mathrm{cm} / \mathrm{s}$

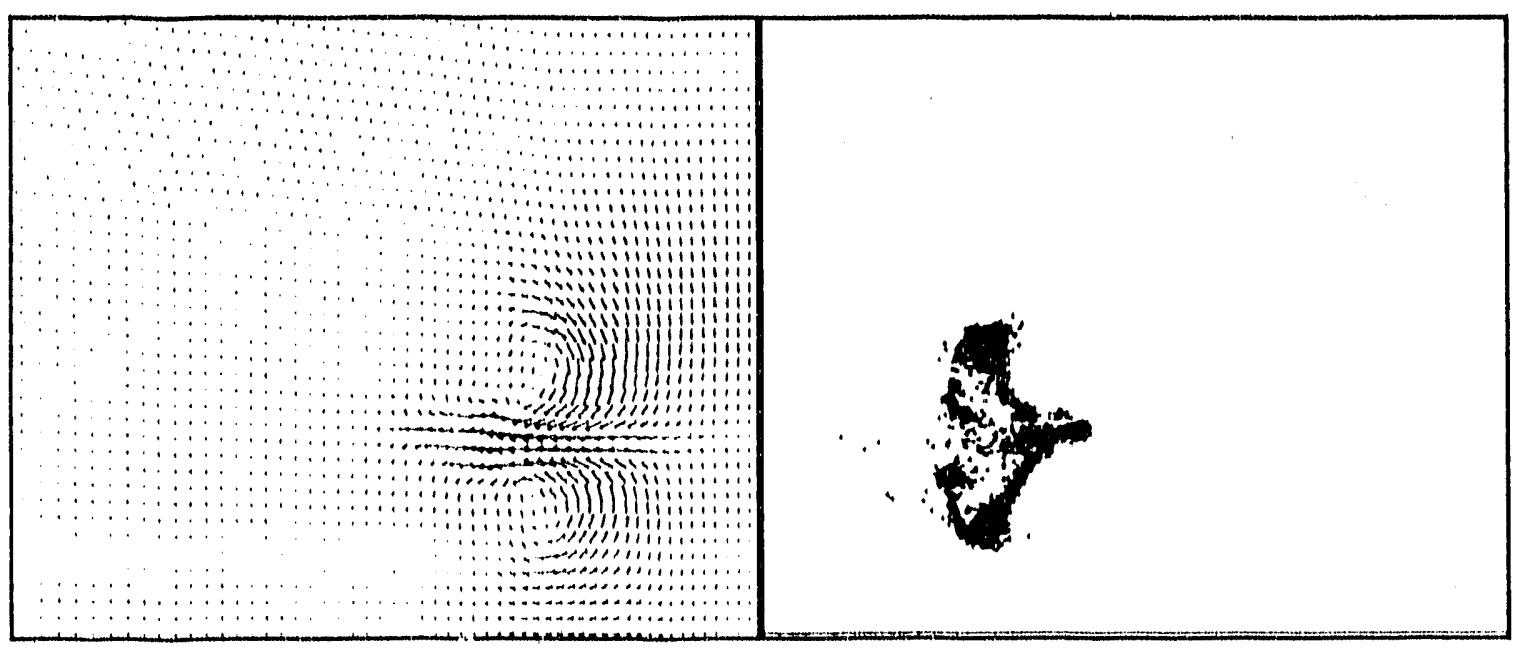

Figure 8: Velocity protile and fuel parcel positions at $t=15 \mathrm{~ms}$, Case 1. $v_{\text {max }}=16200 \mathrm{~cm} / \mathrm{s}$ 


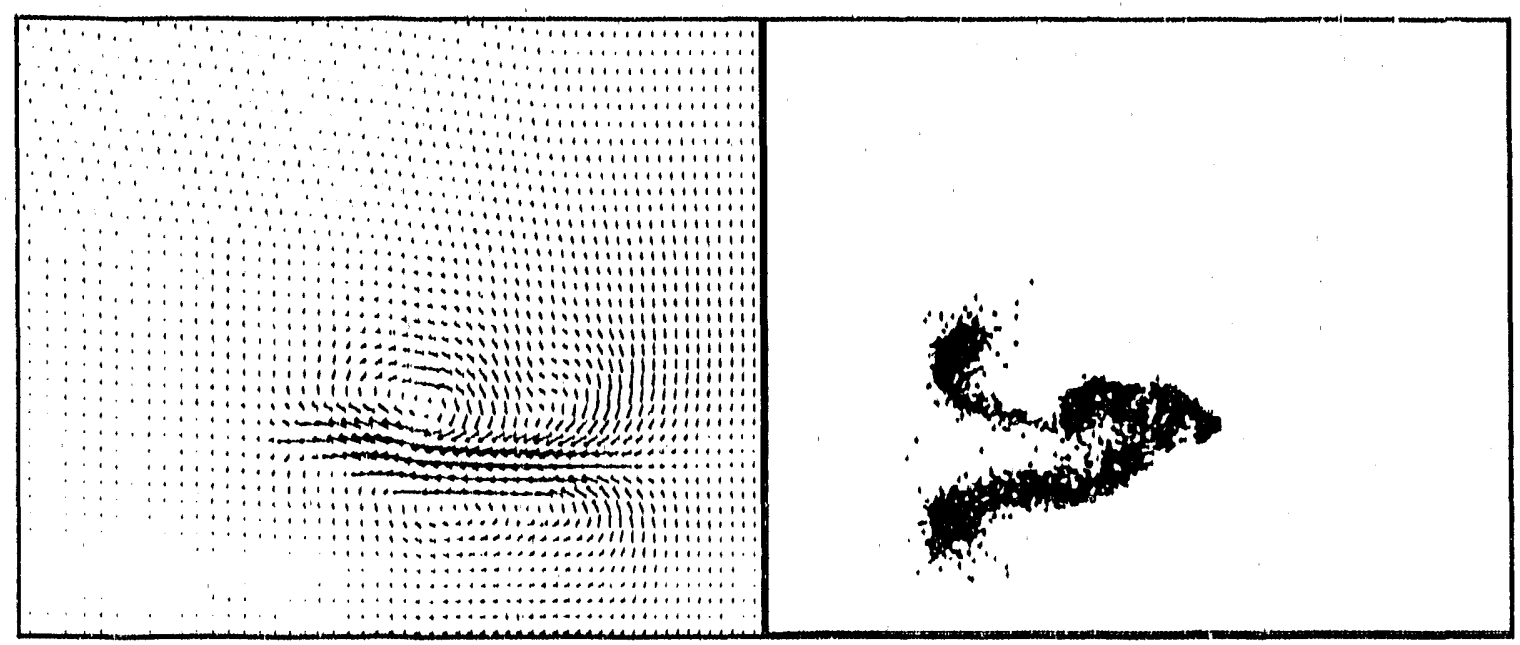

Figure 9: Velocity profile and fuel parcel positions at $t=30 \mathrm{~ms}$, Case 1. $v_{\max }=9170 \mathrm{~cm} / \mathrm{s}$

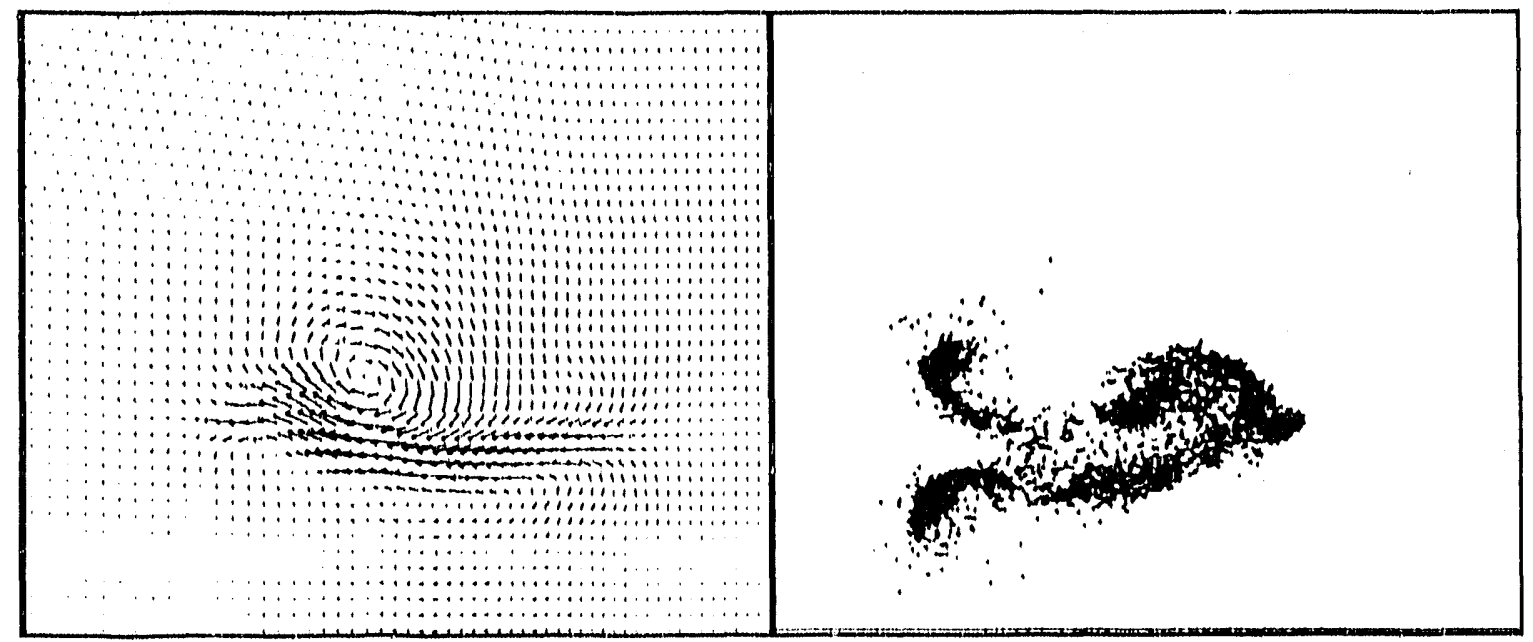

Figure 10: Velocity profile and fuel parcel positions at $\mathrm{t}=4.5 \mathrm{~ms}$, Case 1 . $v_{\text {max }}=6300 \mathrm{~cm} / \mathrm{s}$ 


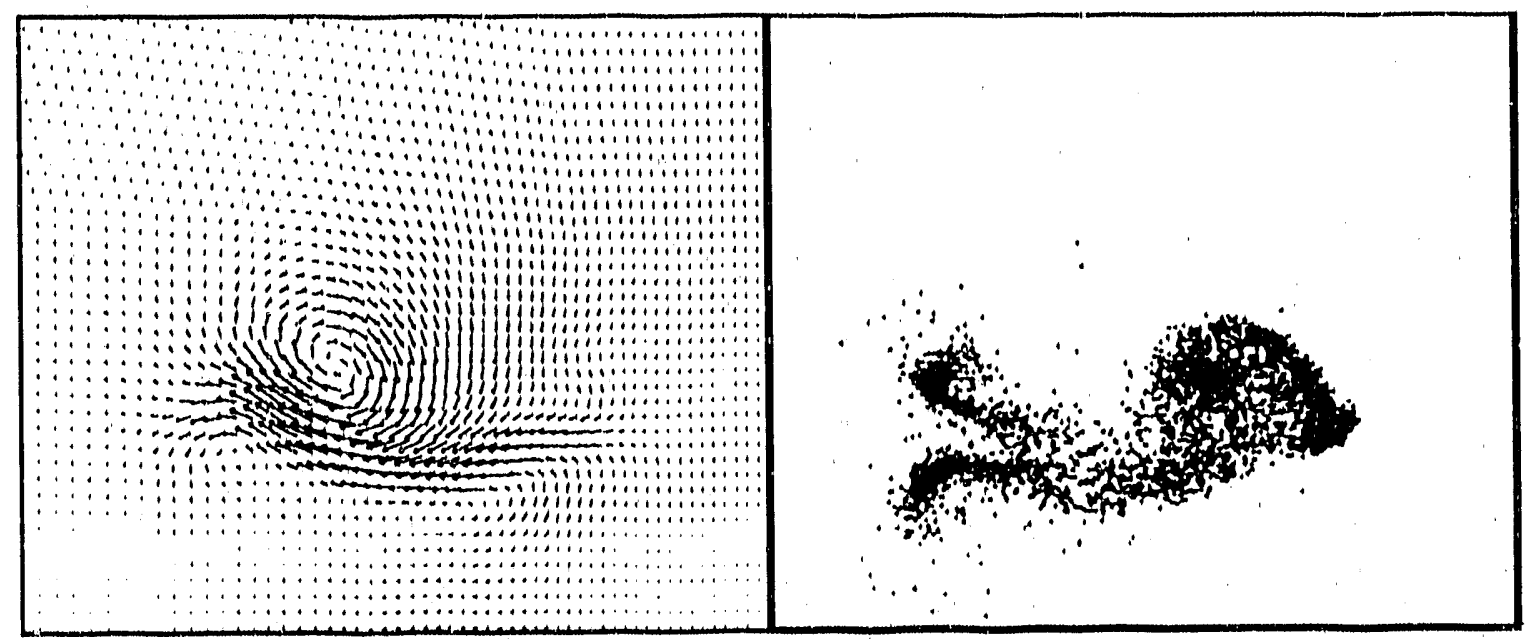

Figure 11: Velocity profile and fuel parcel positions at $t=60 \mathrm{~ms}$, Case 1 .

$\mathrm{v}_{\max }=4380 \mathrm{~cm} / \mathrm{s}$

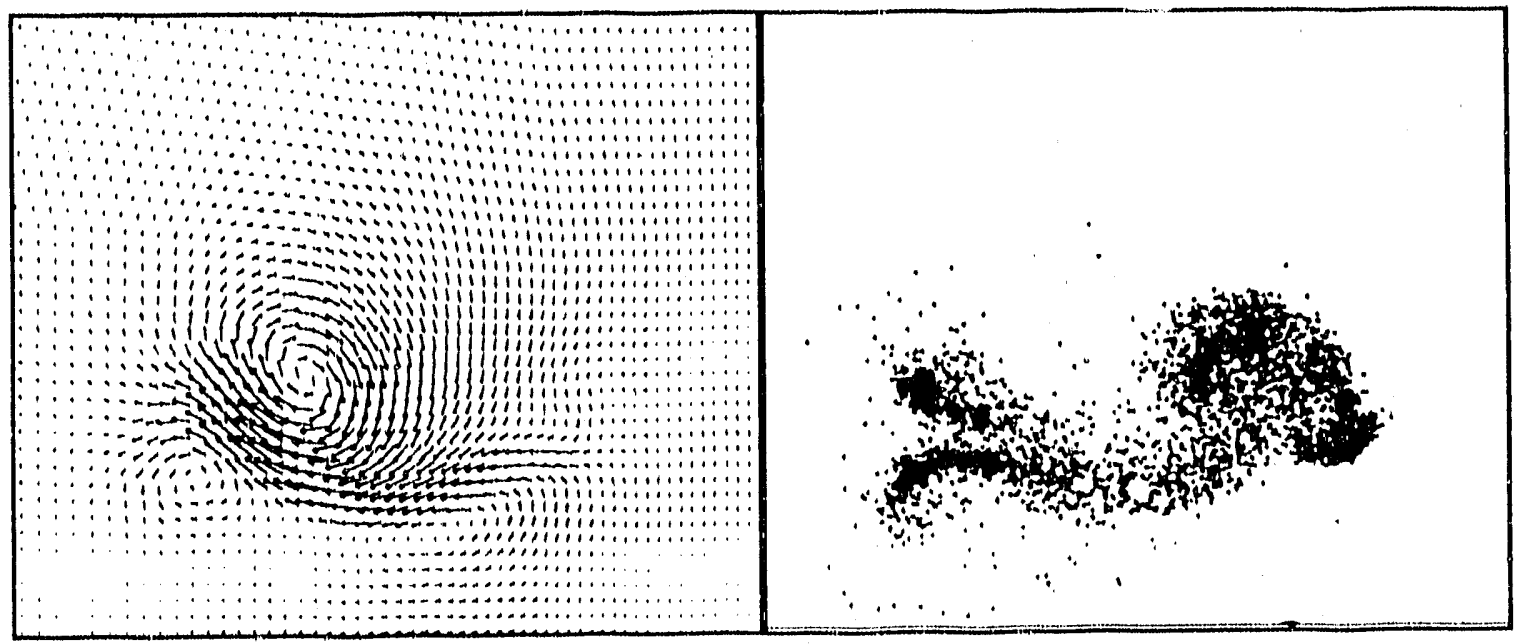

Figure 12: Velocity profile and fuel parcel positions at $\mathrm{t}=75 \mathrm{~ms}$, Case 1 . $v_{\max }=3360 \mathrm{~cm} / \mathrm{s}$ 


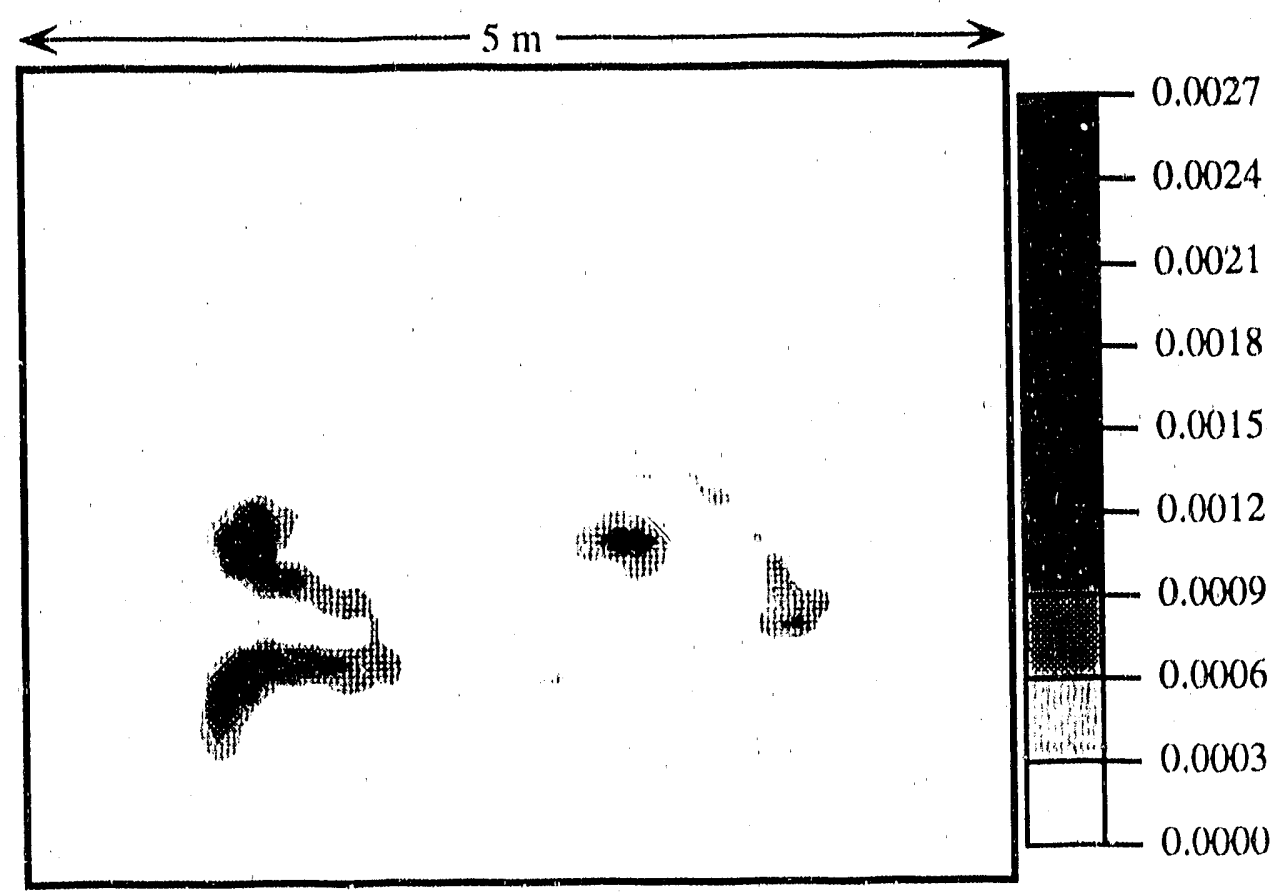

Figure 13: Fuel density profile at $\mathrm{t}=60 \mathrm{~ms}$, Case 1 .

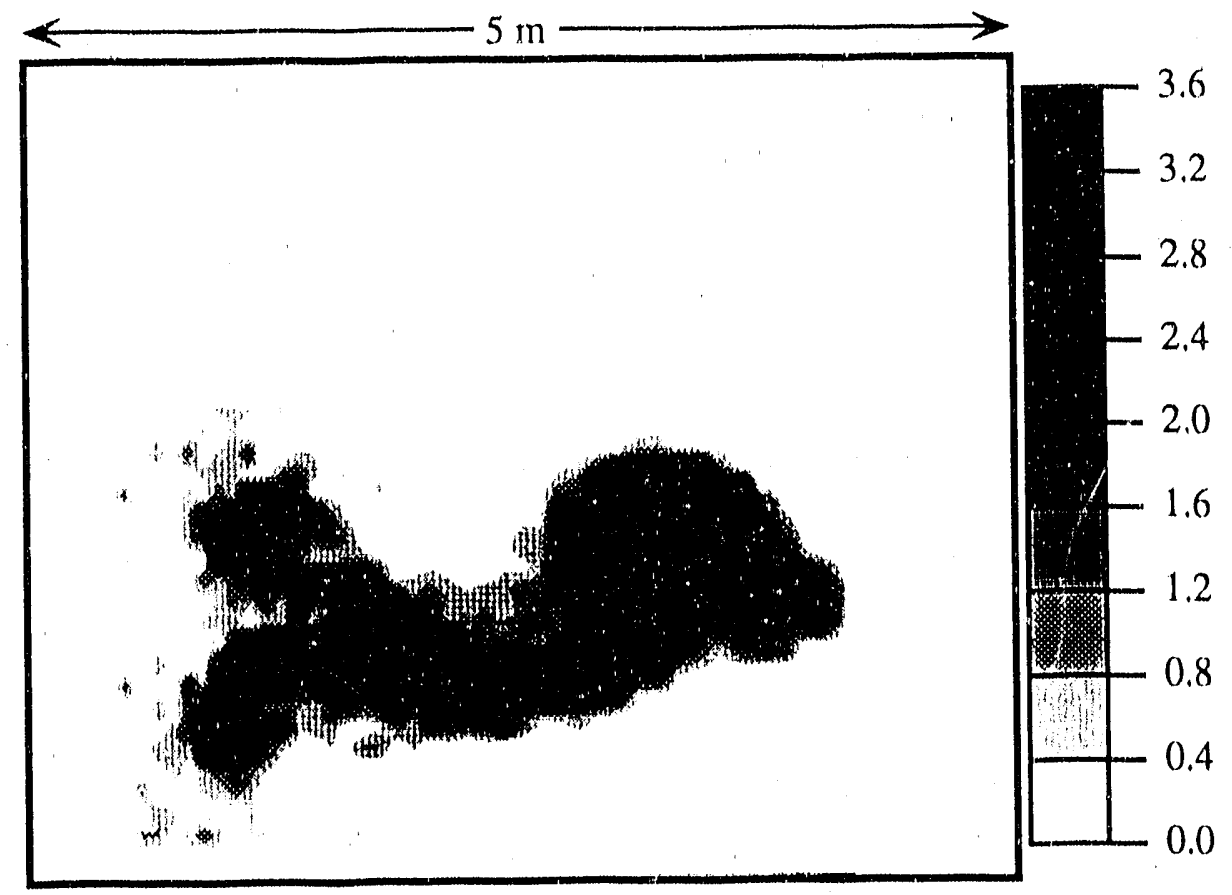

Figure 14: Equivalence ratio profile at $\mathrm{t}=60 \mathrm{~ms}$, Case 1 . 


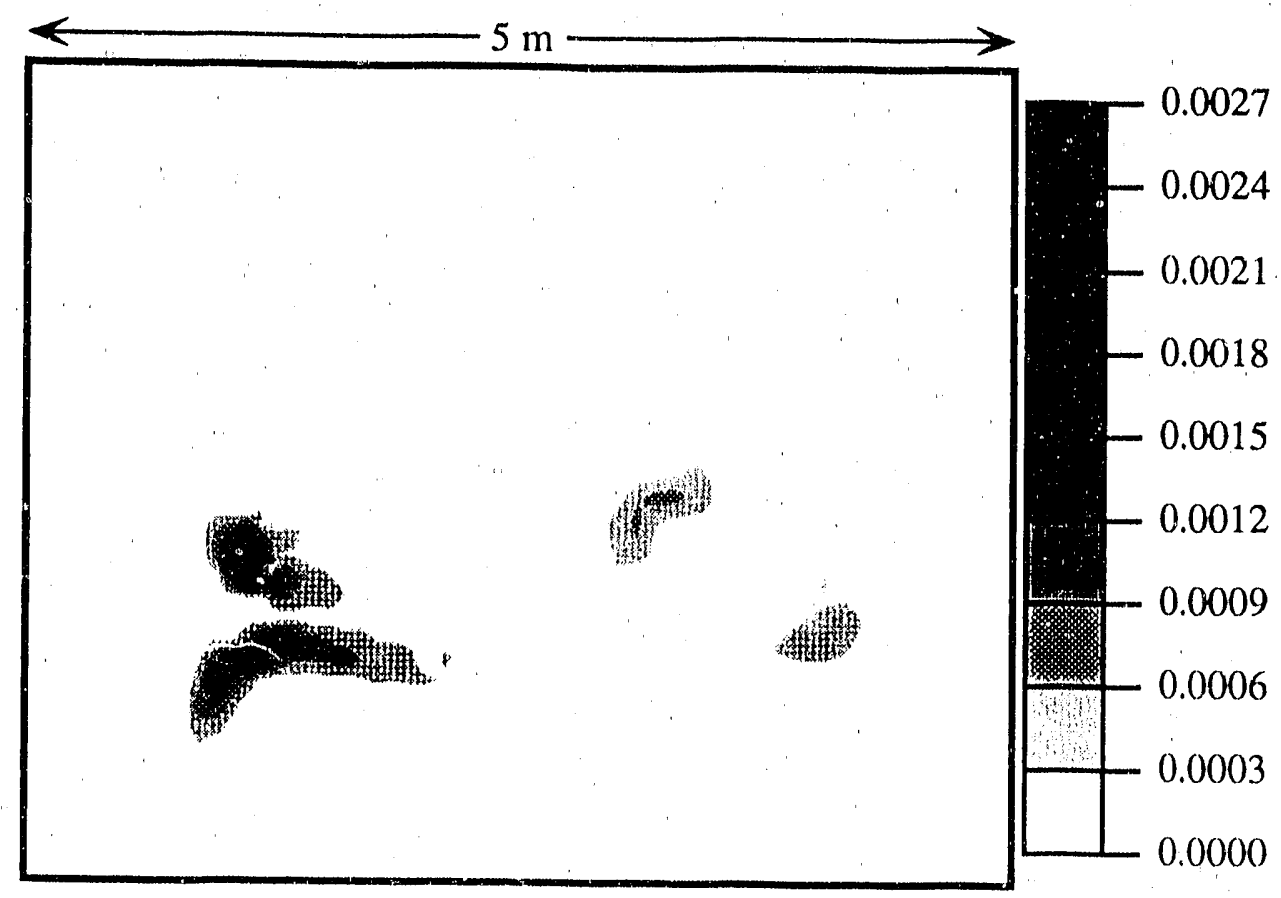

Figure 15: Fuel density profile at $\mathrm{t}=75 \mathrm{~ms}$, Case 1 .

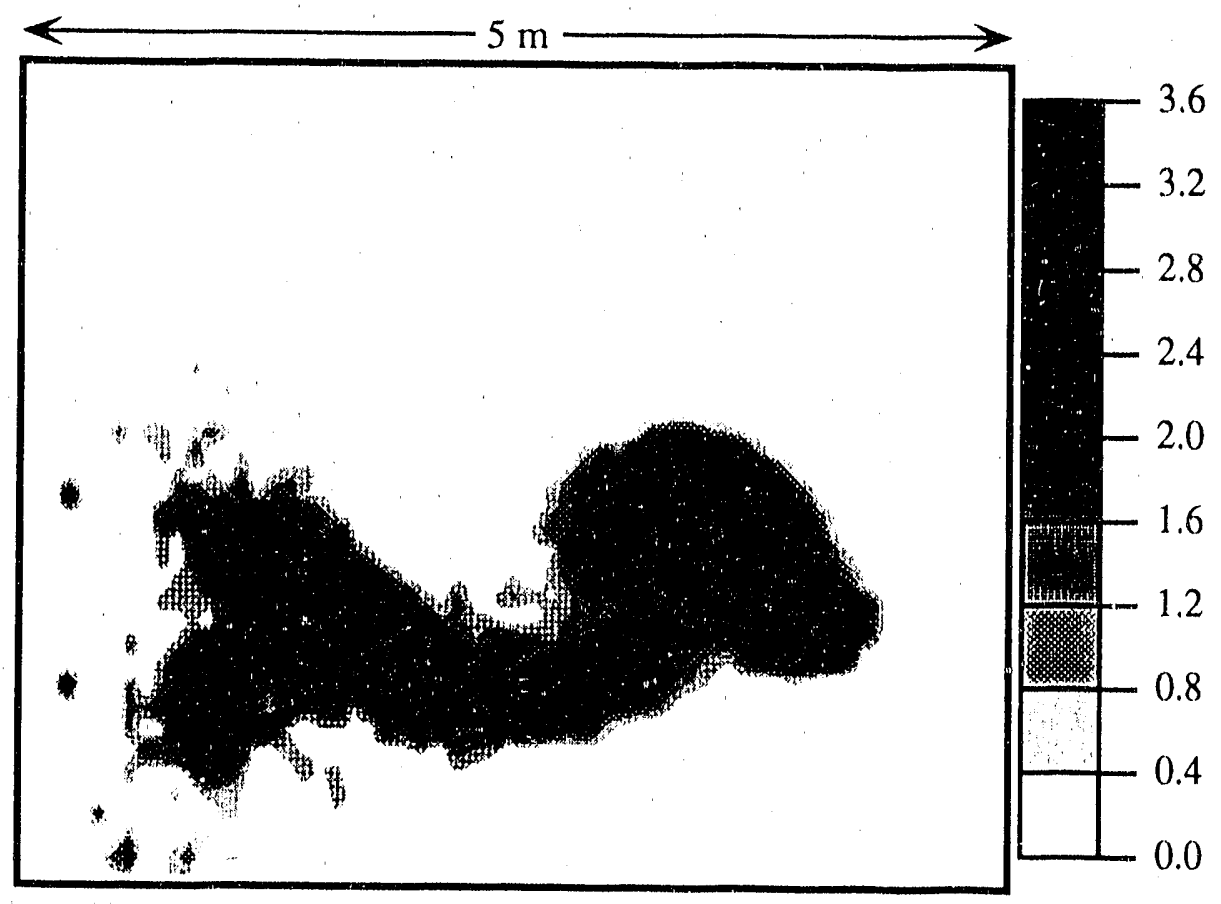

Figure 16: Equivalence ratio profile at $t=75 \mathrm{~ms}$, Case 1 . 


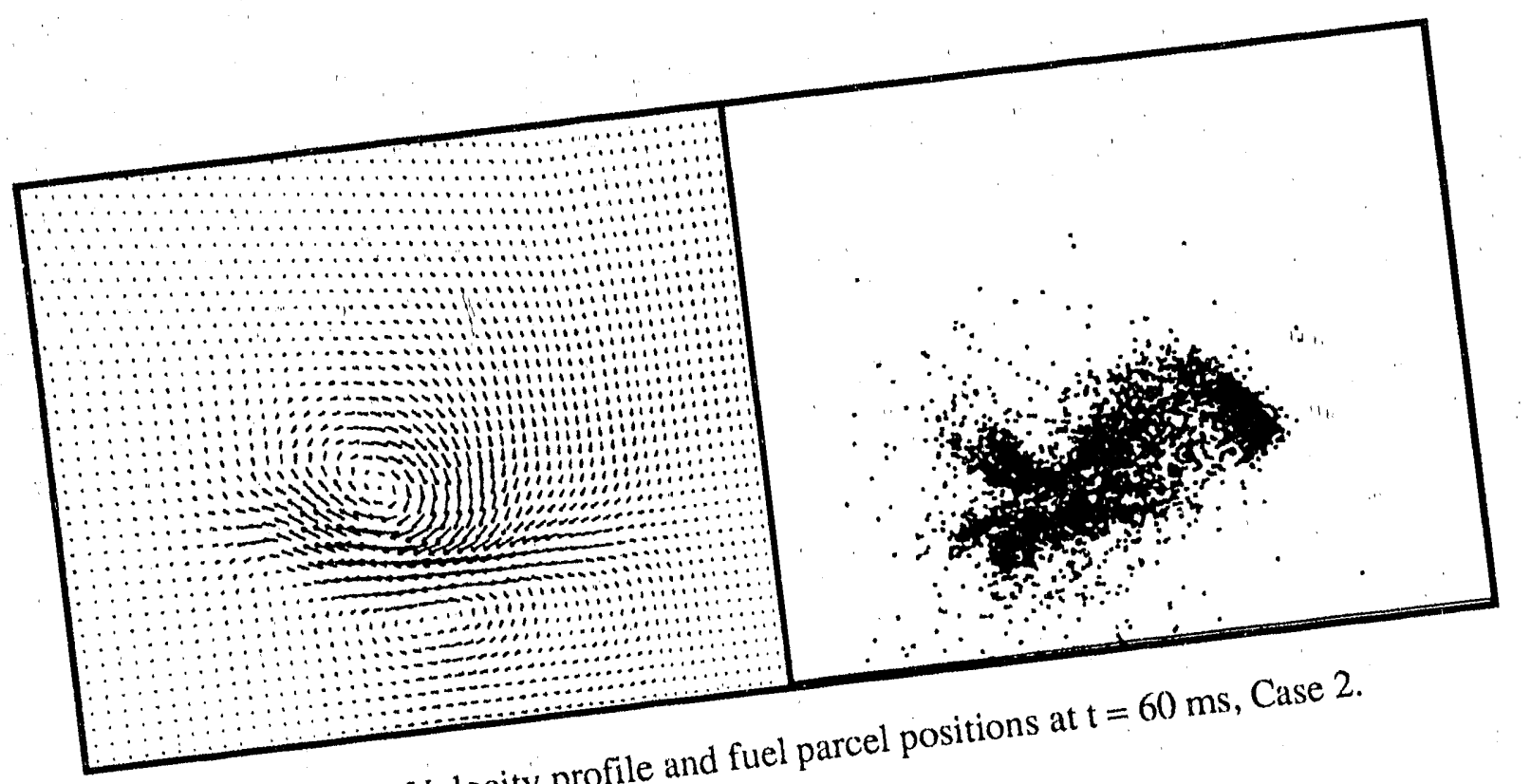

Figure 17: Velocity profile and

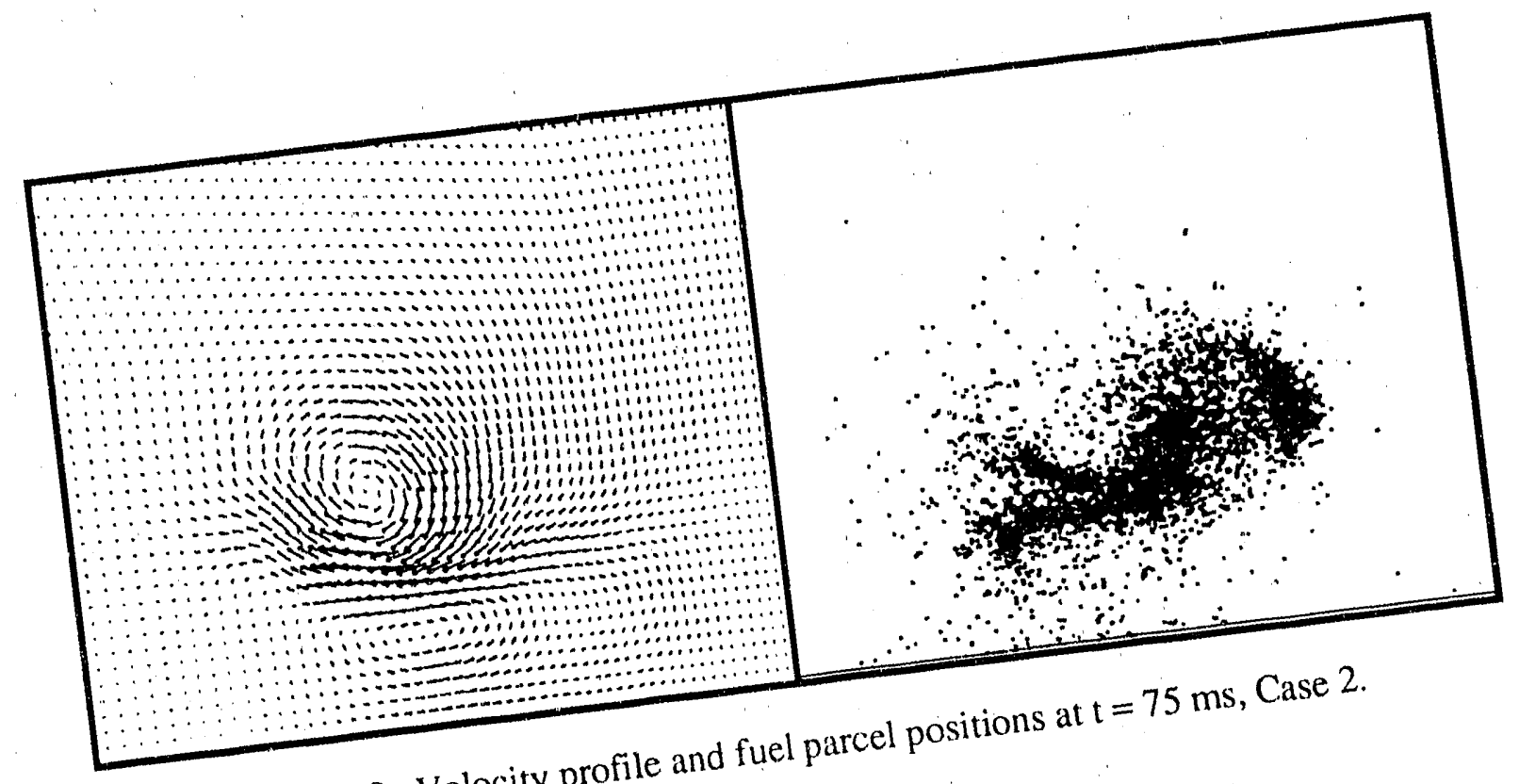

Figure 18: Velocity profile $\begin{aligned} & \text { am/s } \\ & v_{\max }=3740 \mathrm{~cm}\end{aligned}$ 


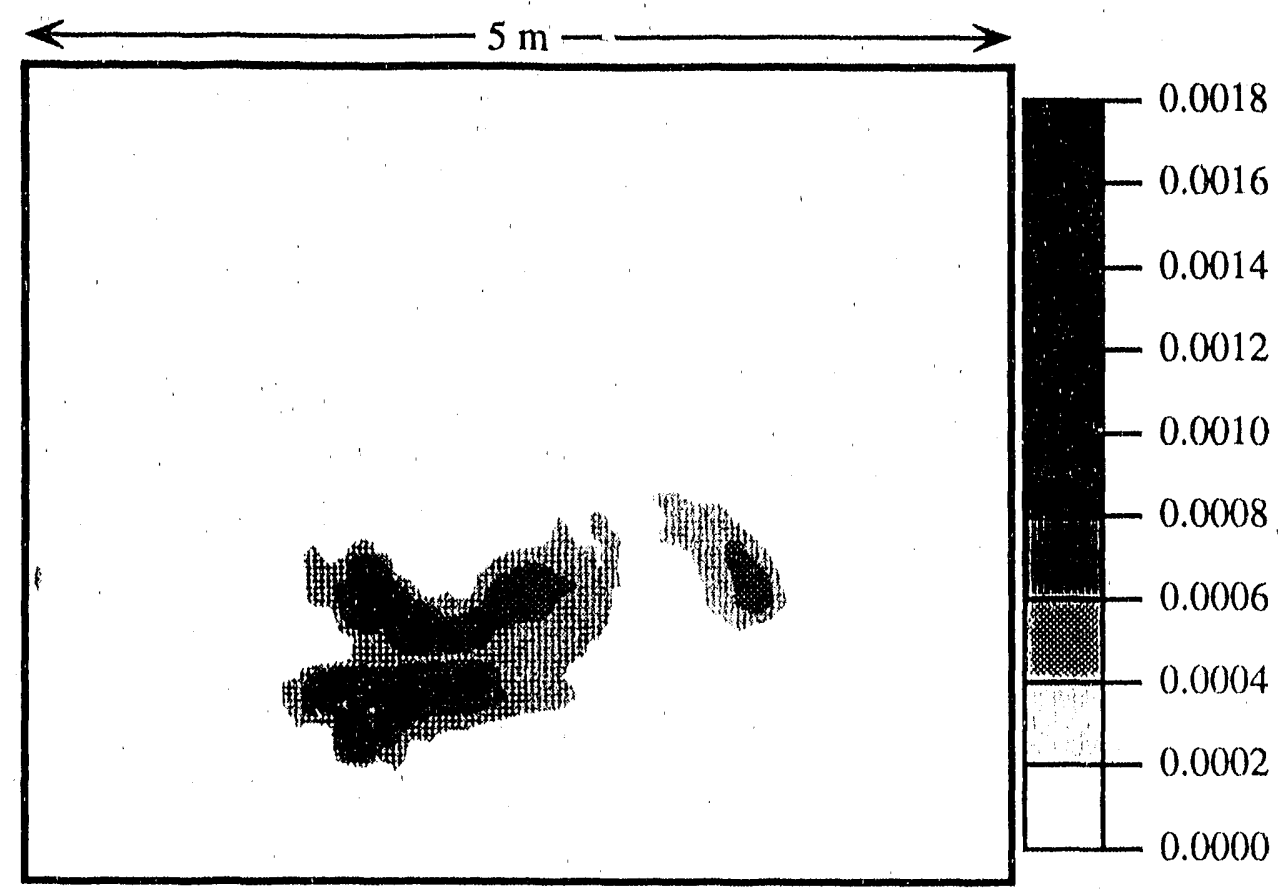

Figure 19: Fuel density profile at $\mathrm{t}=60 \mathrm{~ms}$, Case 2 .

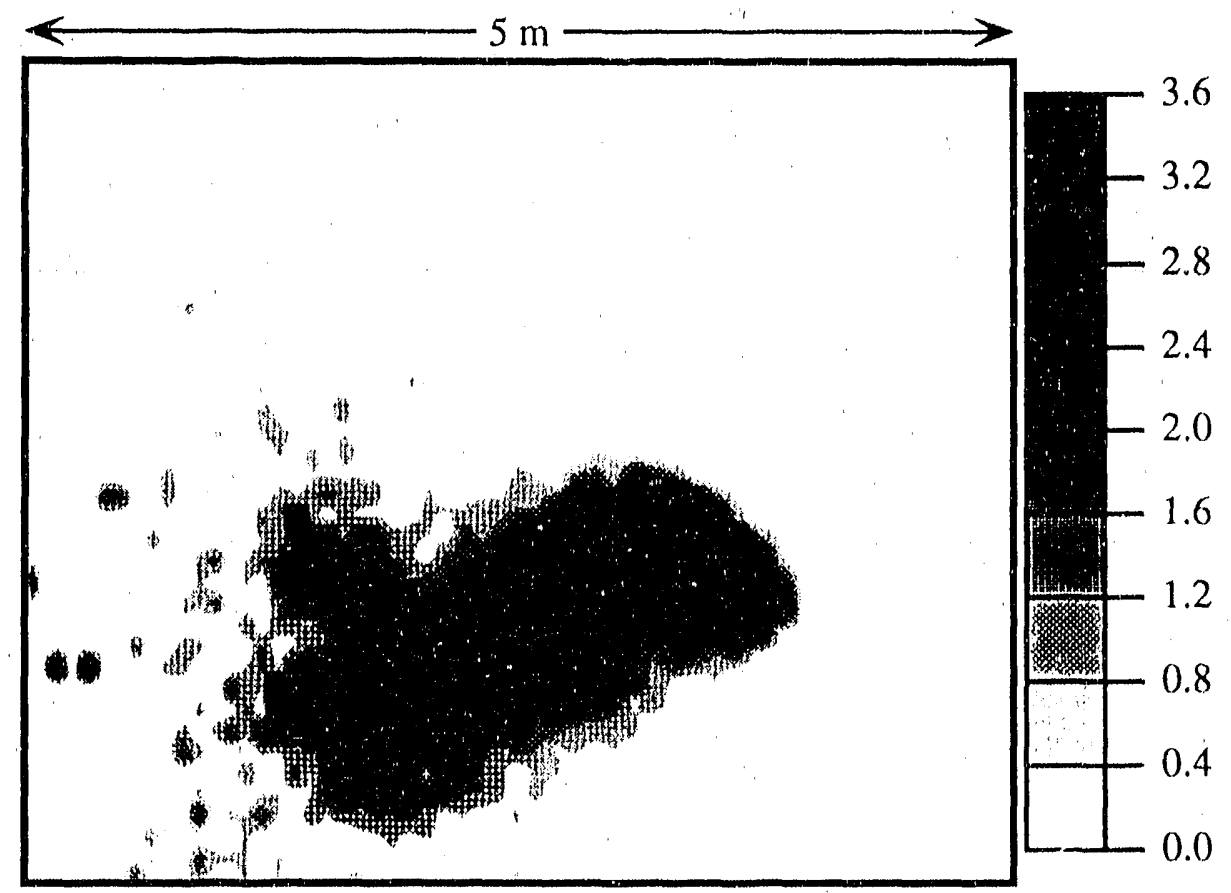

Figure 20: Equivalence ratio profile at $\mathrm{t}=60 \mathrm{~ms}$, Case 2 . 


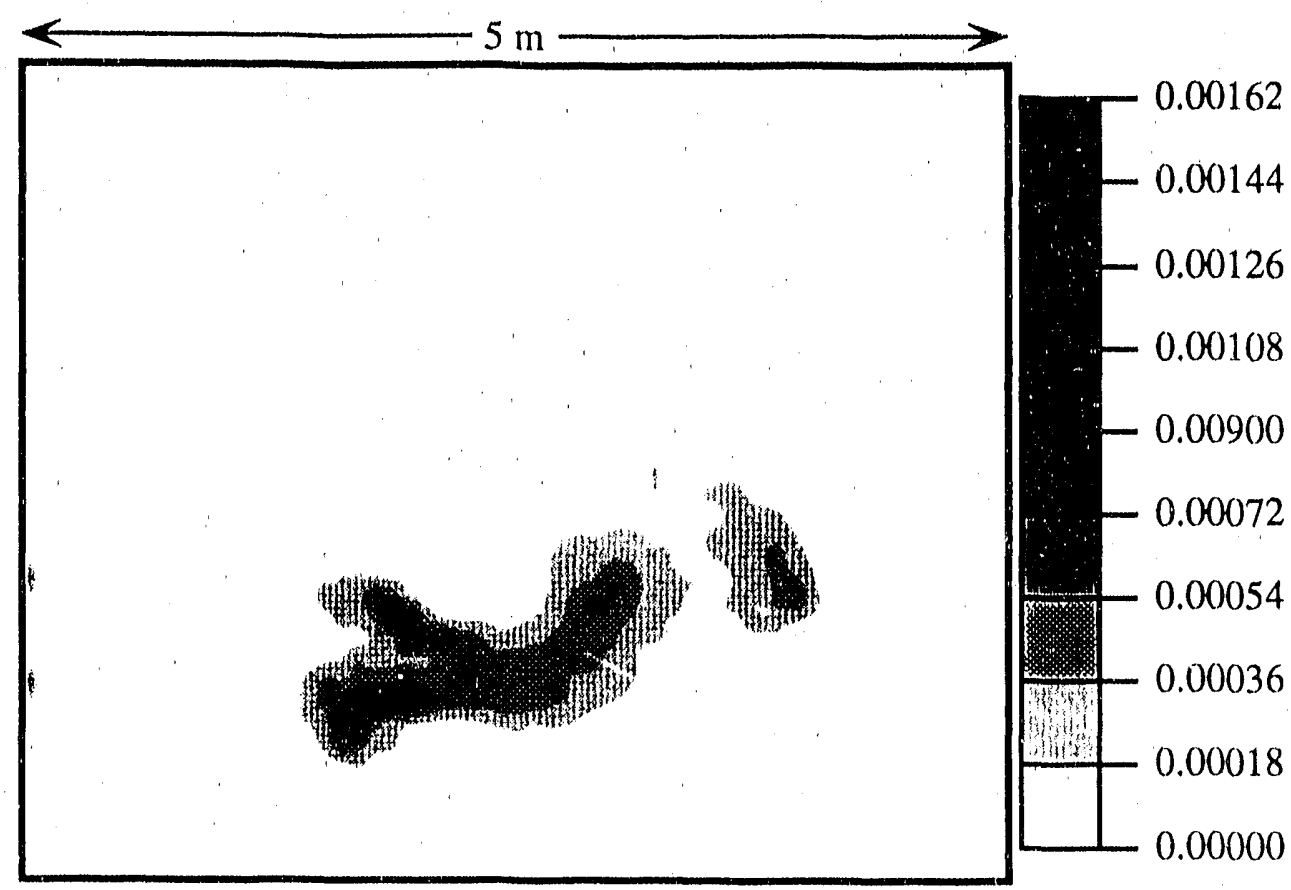

Figure 21: Fuel density profile at $t=75 \mathrm{~ms}$, Case 2.

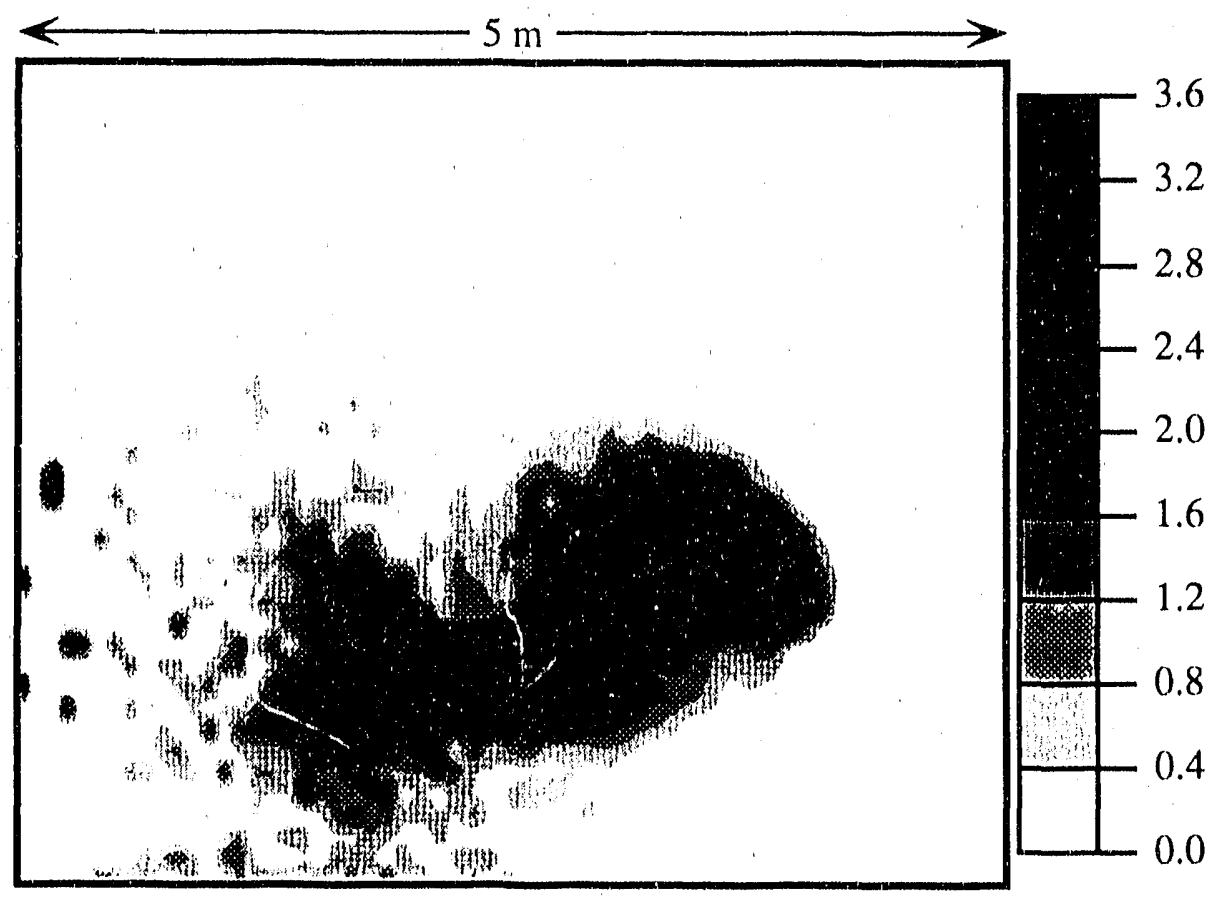

Figure 22: Equivalence ratio profile at $\mathrm{t}=75 \mathrm{~ms}$, Case 2 . 


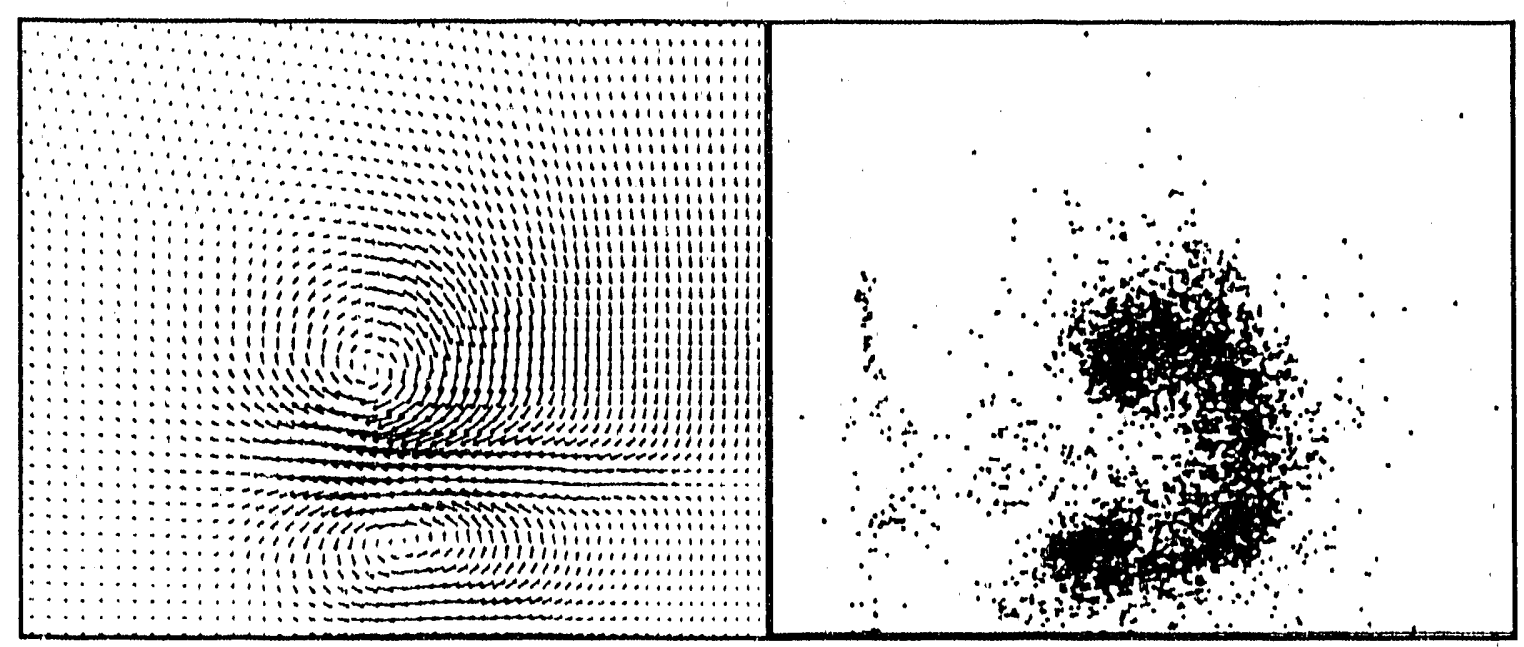

Figure 23: Velocity profile and fuel parcel positions at $t=60 \mathrm{~ms}$, Case 3 . $\mathrm{v}_{\max }=4190 \mathrm{~cm} / \mathrm{s}$

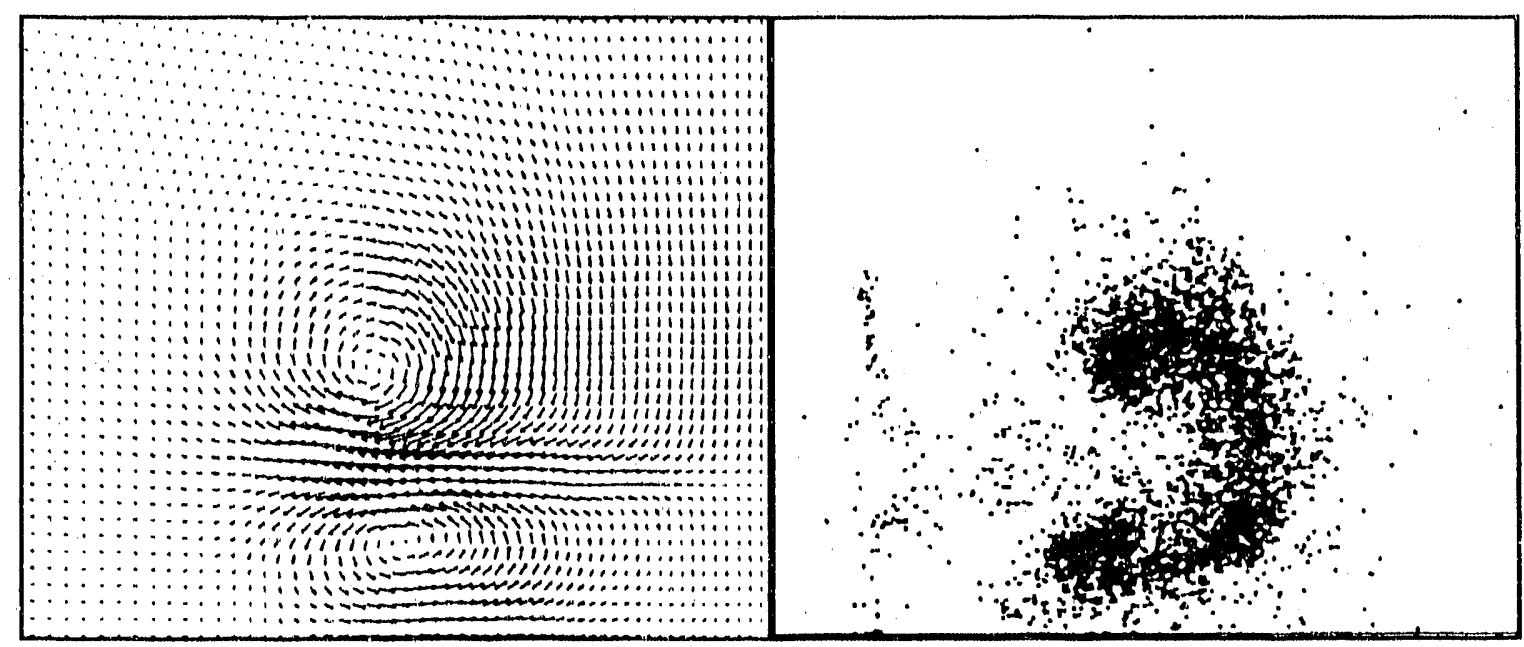

Figure 24: Velocity profile and fuel parcel positions at $\mathrm{t}=75 \mathrm{~ms}$, Case 3 . $v_{\max }=3880 \mathrm{~cm} / \mathrm{s}$ 


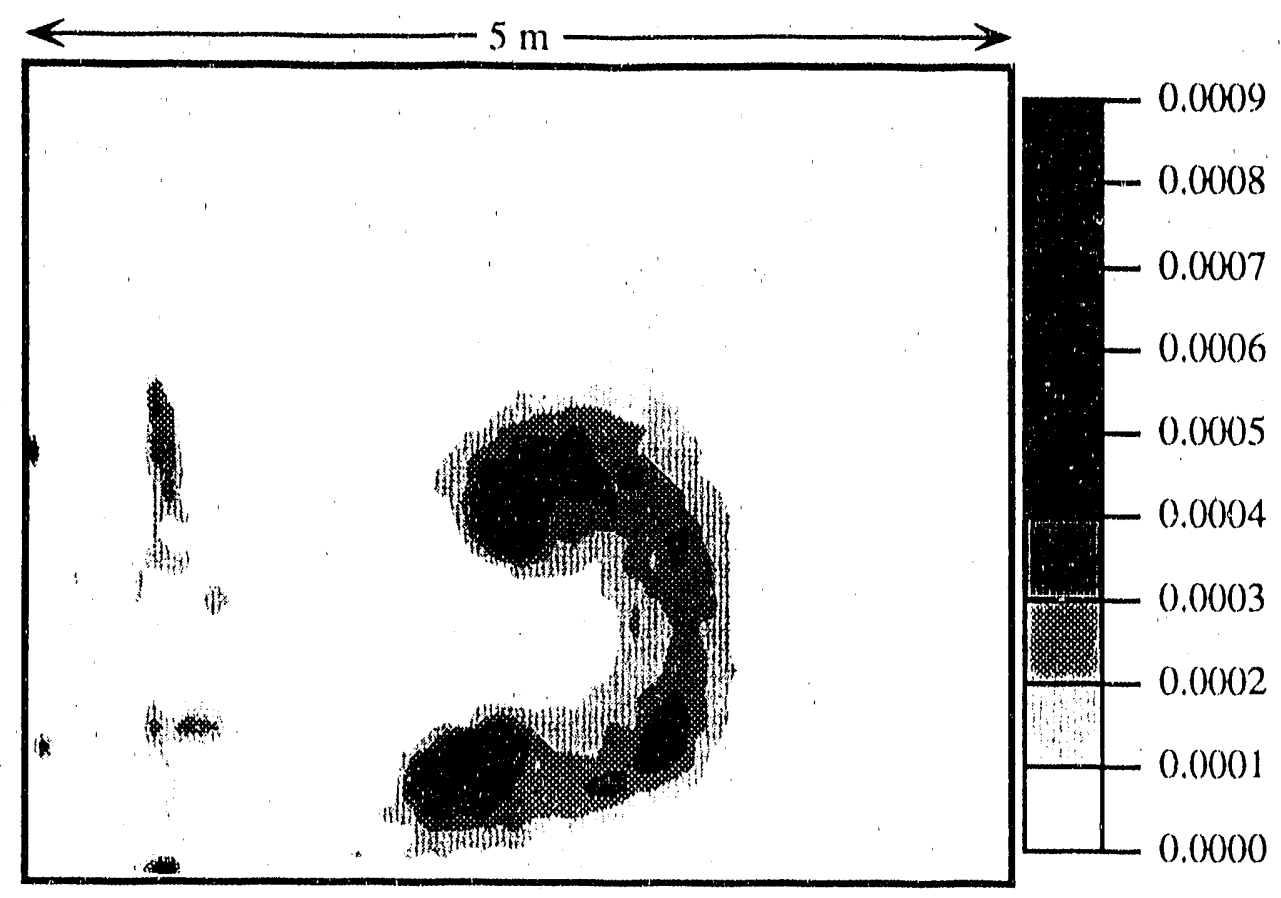

Figure 25: Fuel density profile at $\mathrm{t}=60 \mathrm{~ms}$, Case 3.

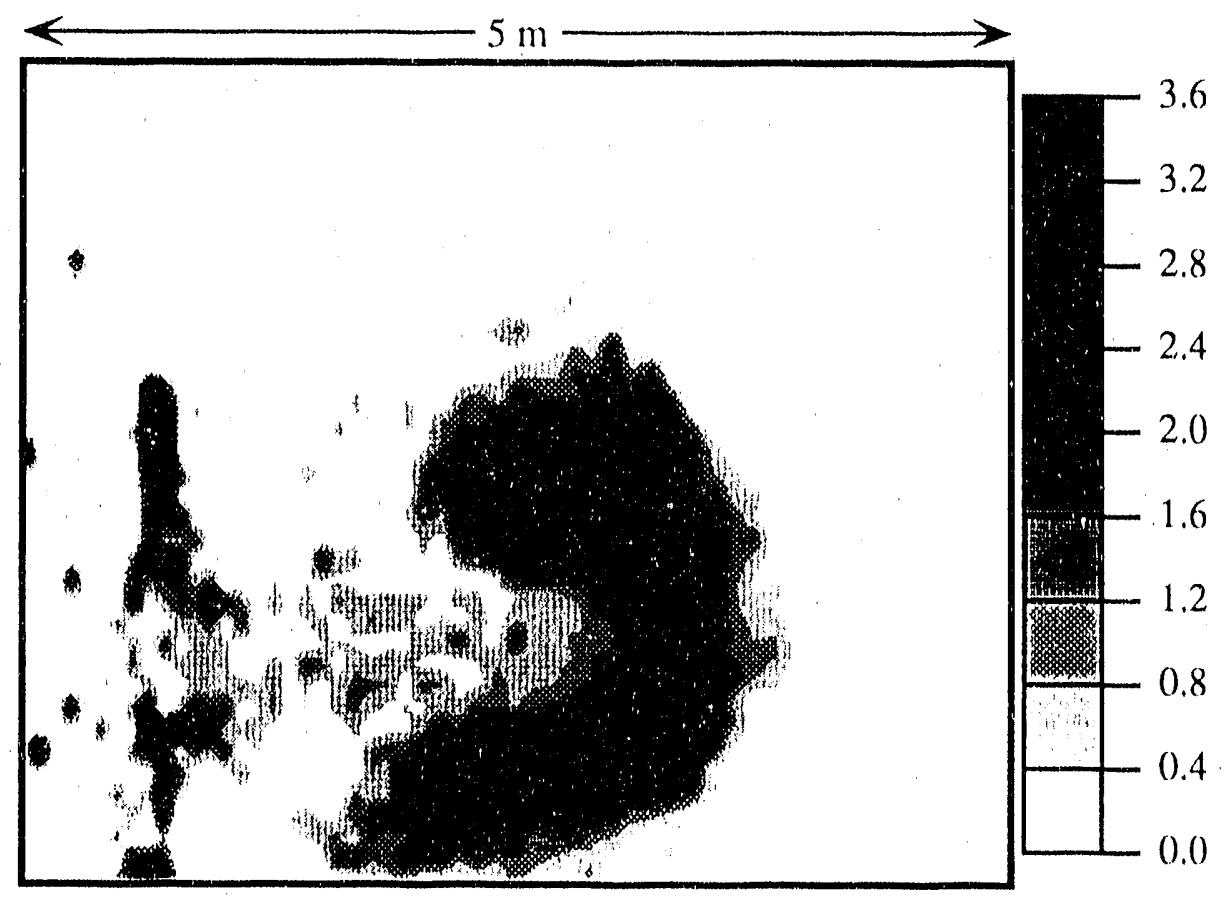

Figure 26: Equivalence ratio profile at $\mathrm{t}=60 \mathrm{~ms}$, Case 3 . 


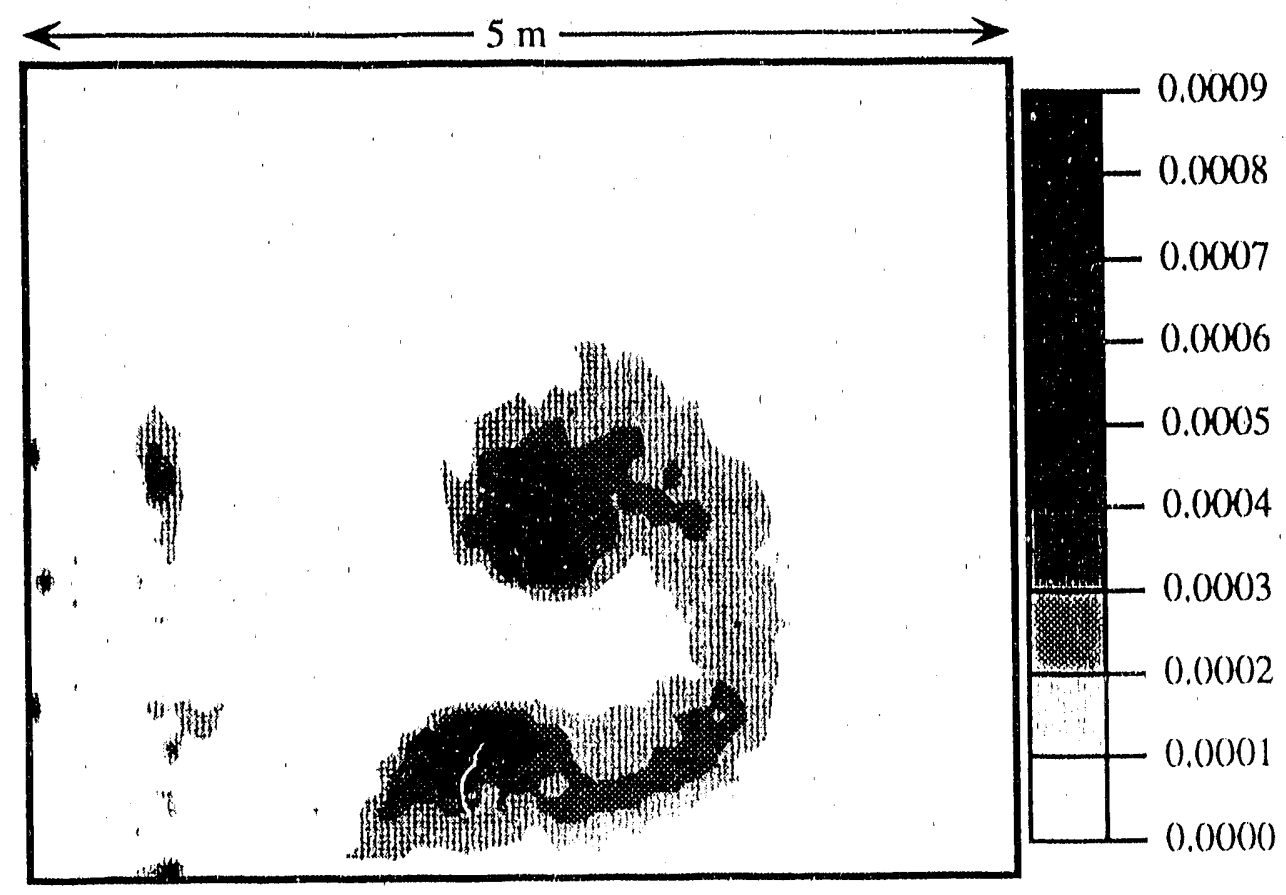

Figure 27: Fuel density profile at $\mathrm{t}=75 \mathrm{~ms}$, Case 3 .

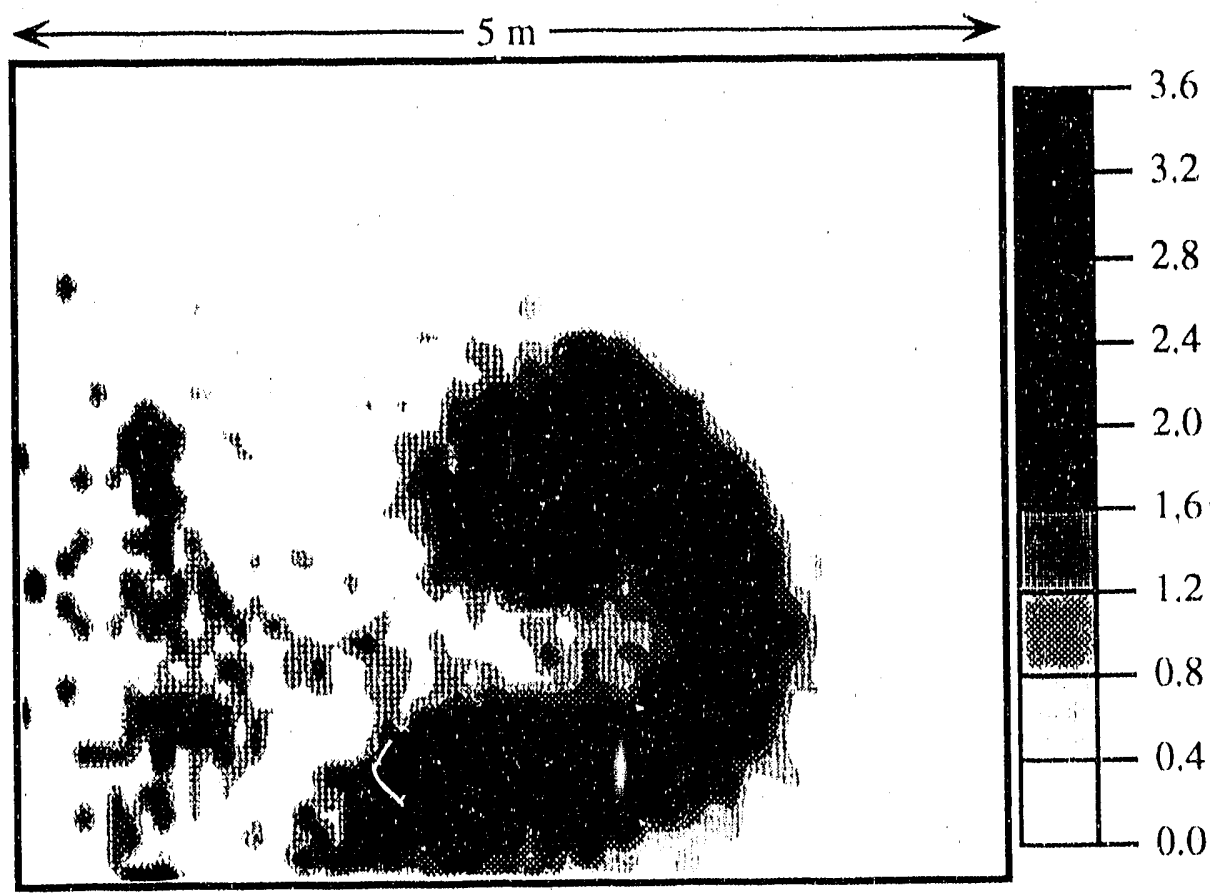

Figure 28: Equivalence ratio profile at $t=75 \mathrm{~ms}$, Case 3 . 


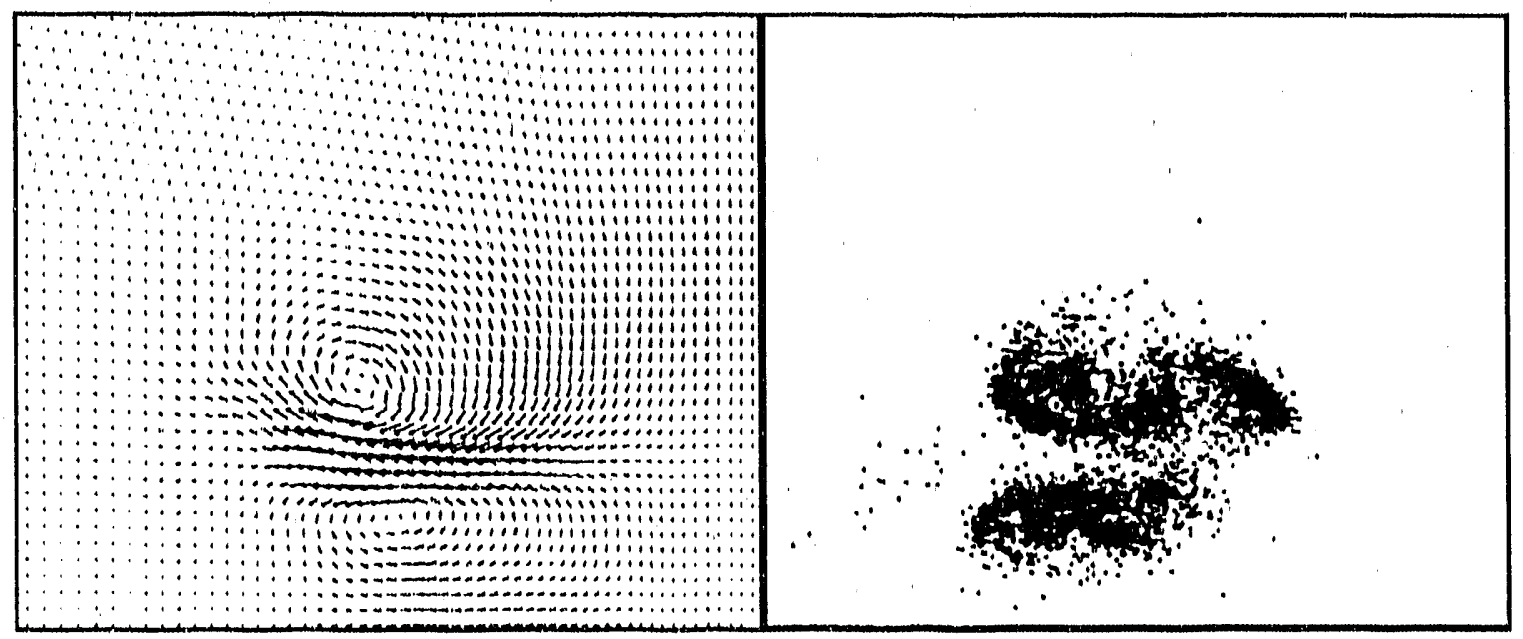

Figure 29: Velocity profile and fuel parcel positions at $t=60 \mathrm{~ms}$, Case 4 . $\mathrm{v}_{\max }=5320 \mathrm{~cm} / \mathrm{s}$

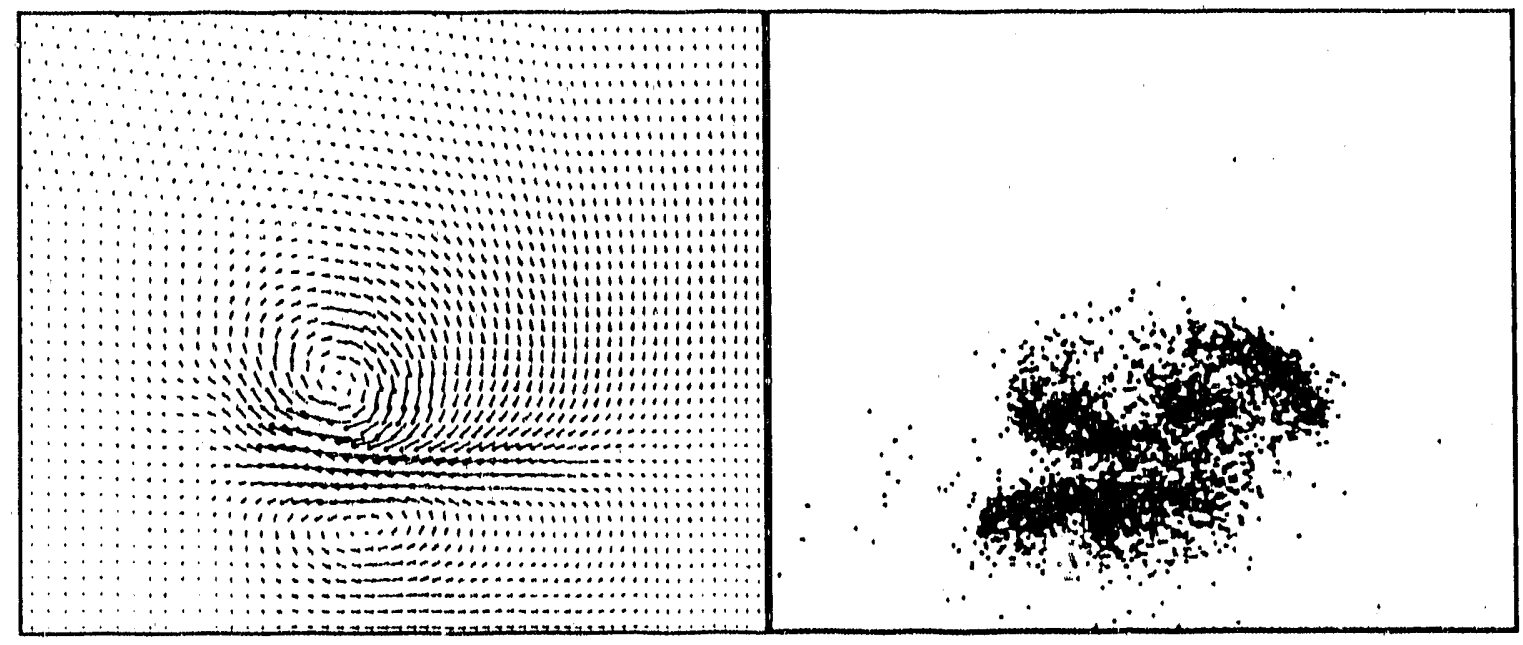

Figure 30: Velocity profile and fuel parcel positions at $t=75 \mathrm{~ms}$, Case 4 . $v_{\max }=4250 \mathrm{~cm} / \mathrm{s}$ 


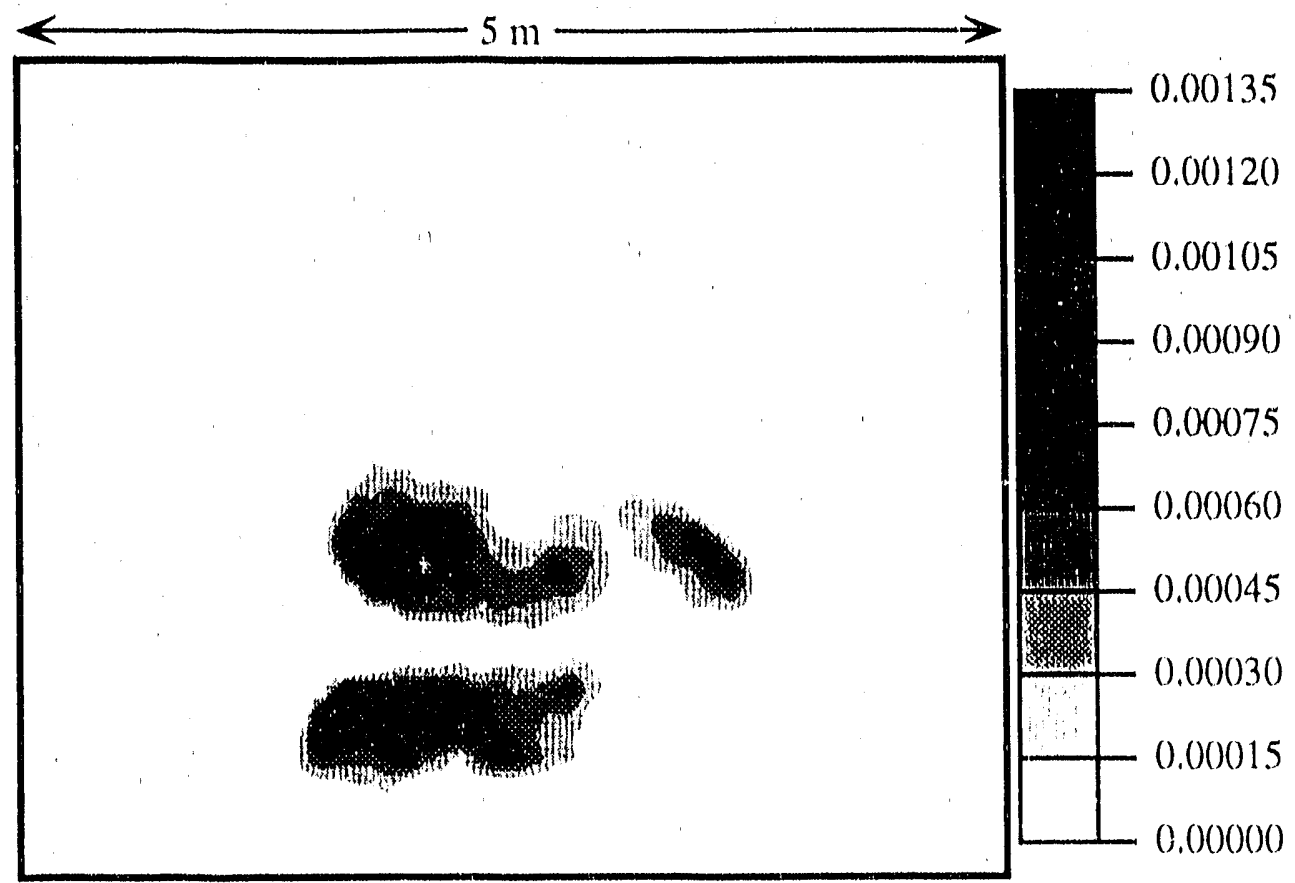

Figure 31: Fuel density profile at $t=60 \mathrm{~ms}$, Case 4 .

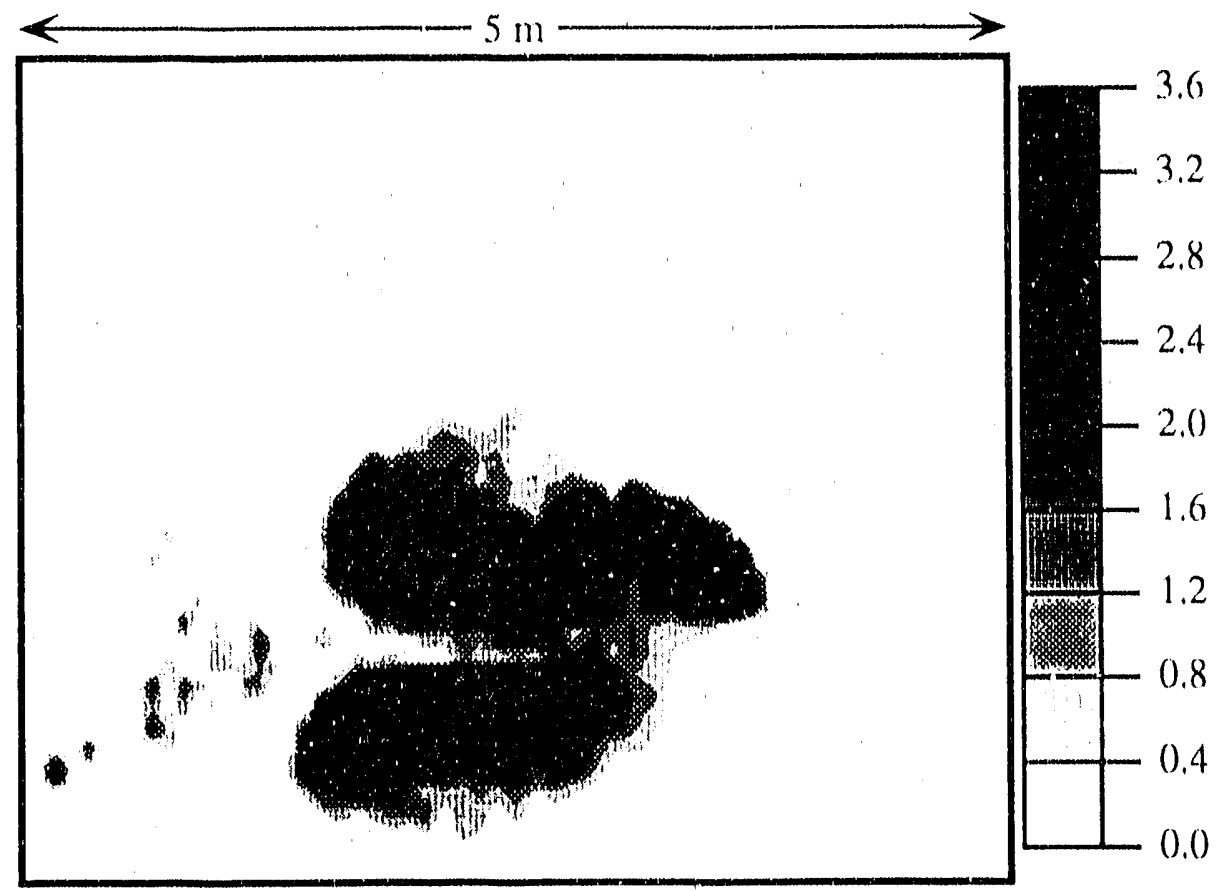

Figure 32: Equivalence ratio profile at $t=60 \mathrm{~ms}$, Case 4 . 


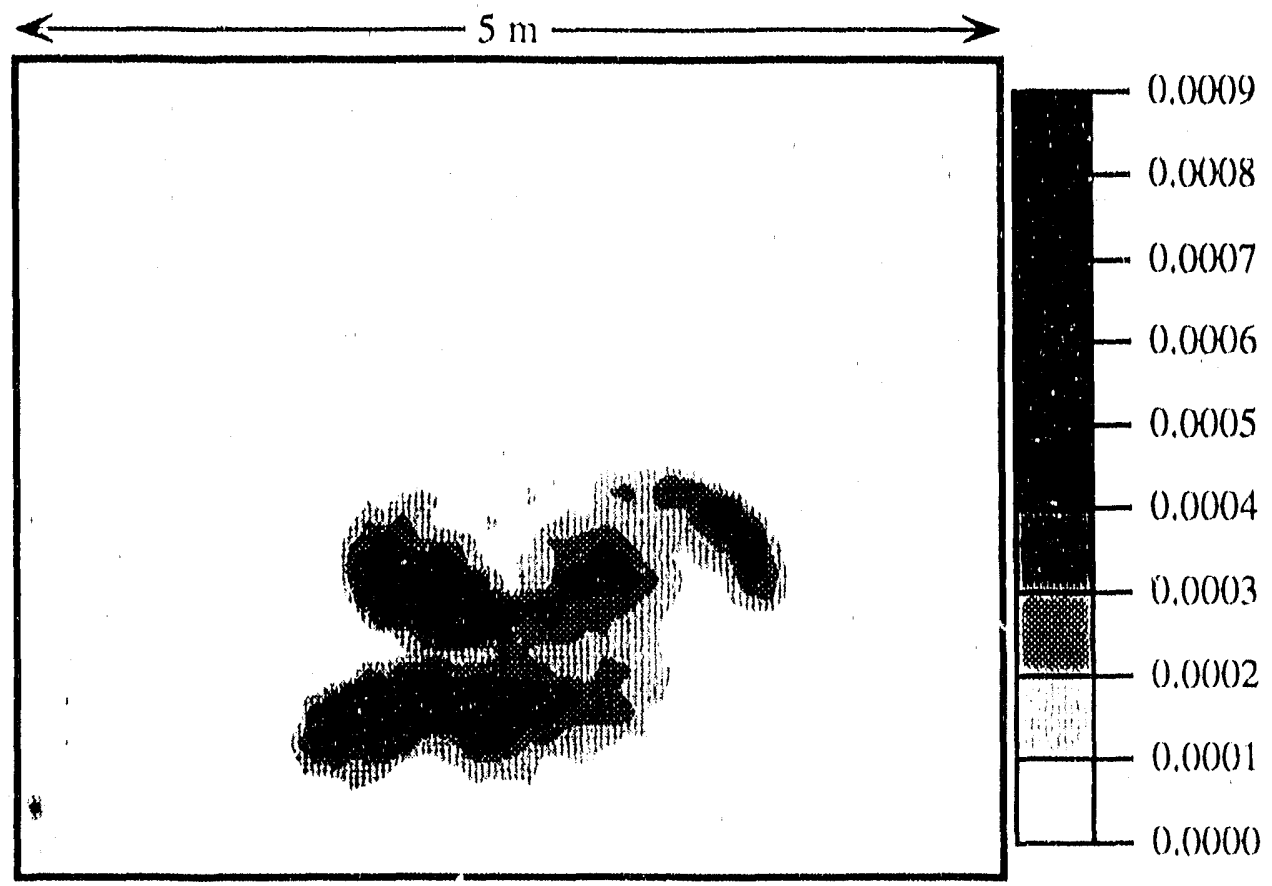

Figure 33: Fuel density profile at $t=75 \mathrm{~ms}$, Case 4 .

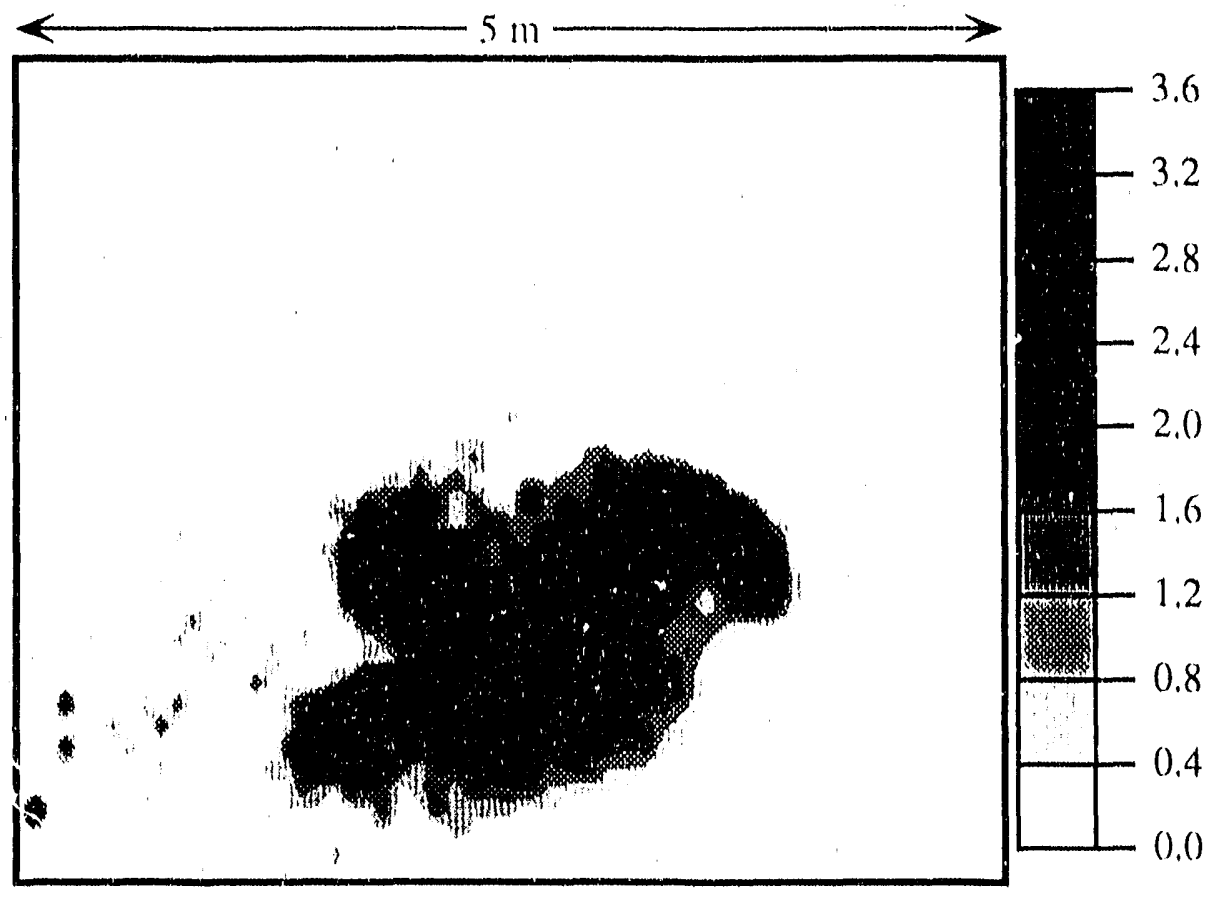

Figure 34: Equivalence ratio profile at $t=75 \mathrm{~ms}$, Case 4 . 


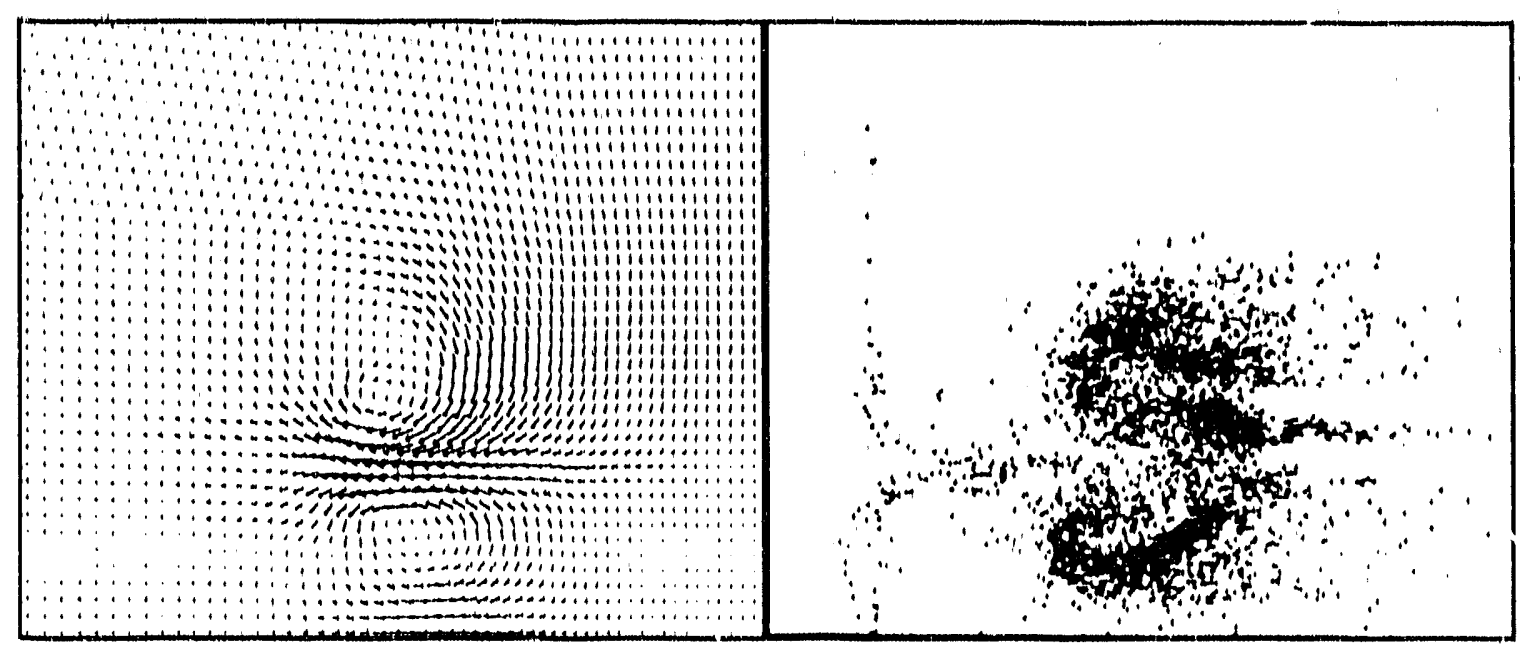

Figure 35: Velocity profile and fuel parcel positions at $t=60 \mathrm{~ms}$, Case 5.

$v_{\max }=566() \mathrm{cm} / \mathrm{s}$

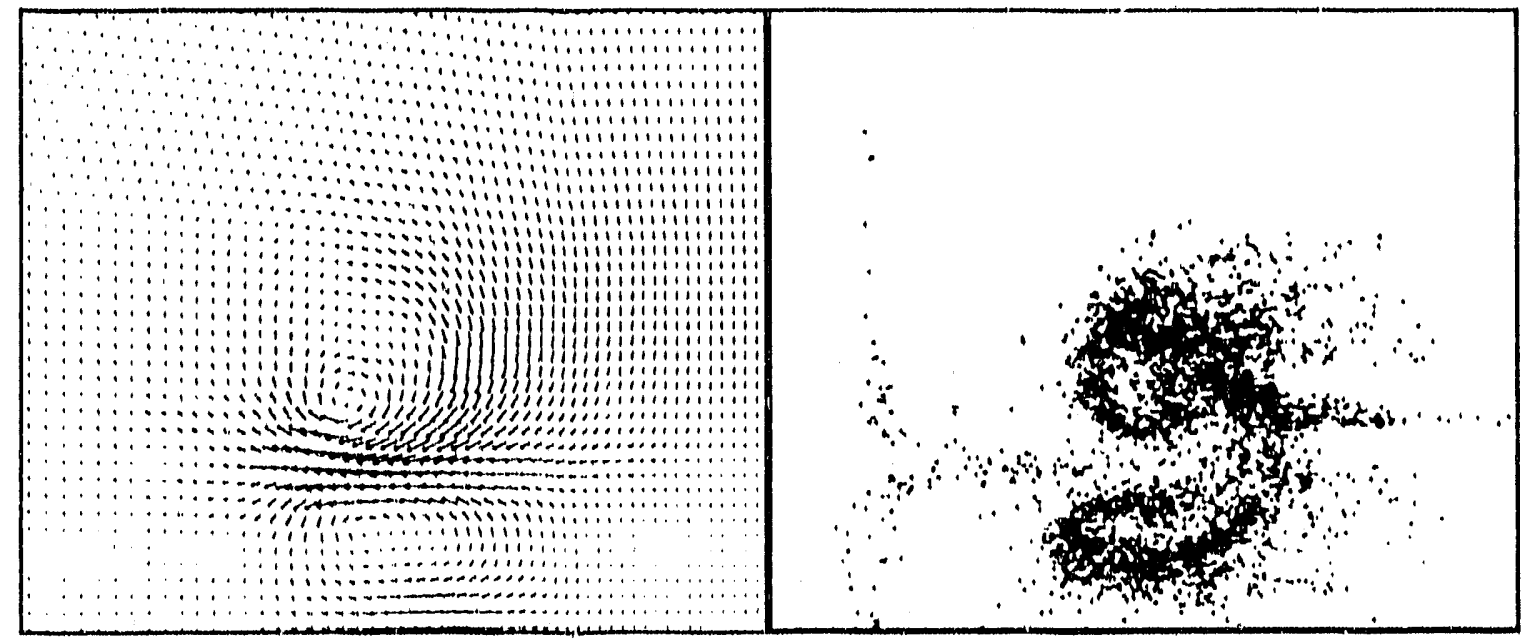

Figure 36; Velocity profile and fuel parcel positions at $\mathrm{t}=75 \mathrm{~ms}$, Case 5 .

$\mathrm{v}_{\max }=5260 \mathrm{~cm} / \mathrm{s}$ 


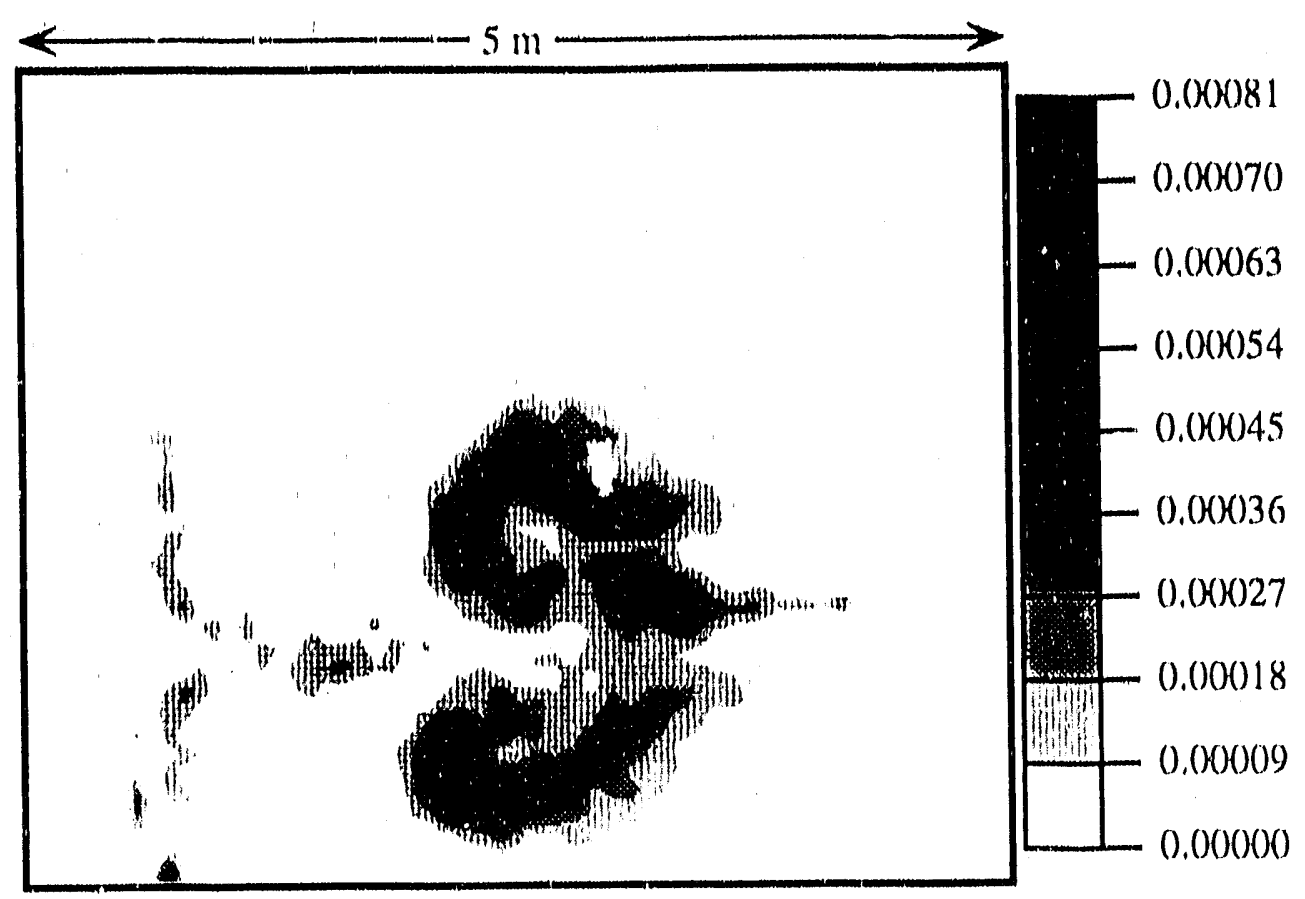

Figure 37: Fuel density profile at $\mathrm{t}=60 \mathrm{~ms}$, Case 5 .

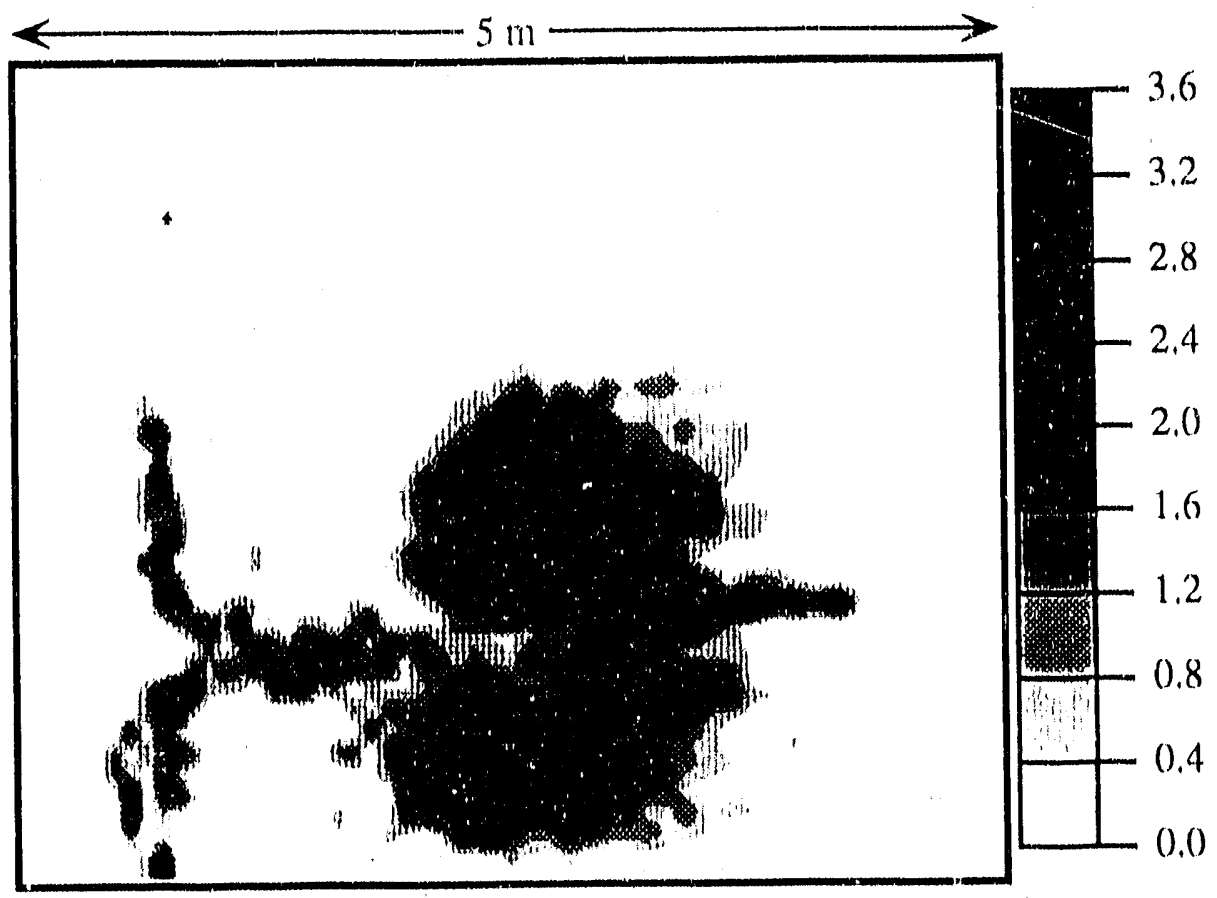

Figure 38: Equivalence ratio profile at $\mathrm{t}=60 \mathrm{~ms}$, Case 5 . 


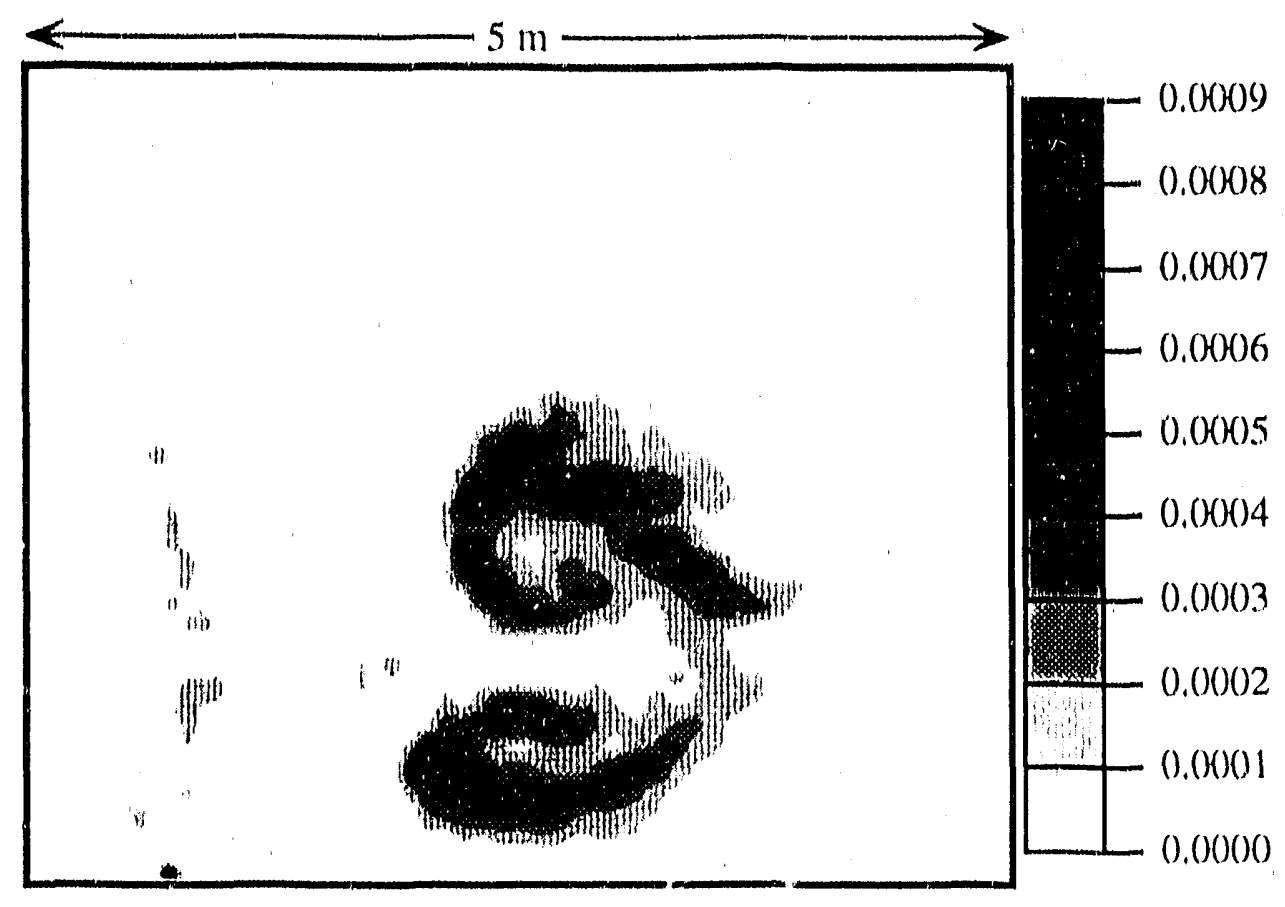

Figure 39: Fuel density profile at $t=75 \mathrm{~ms}$, Case 5 .

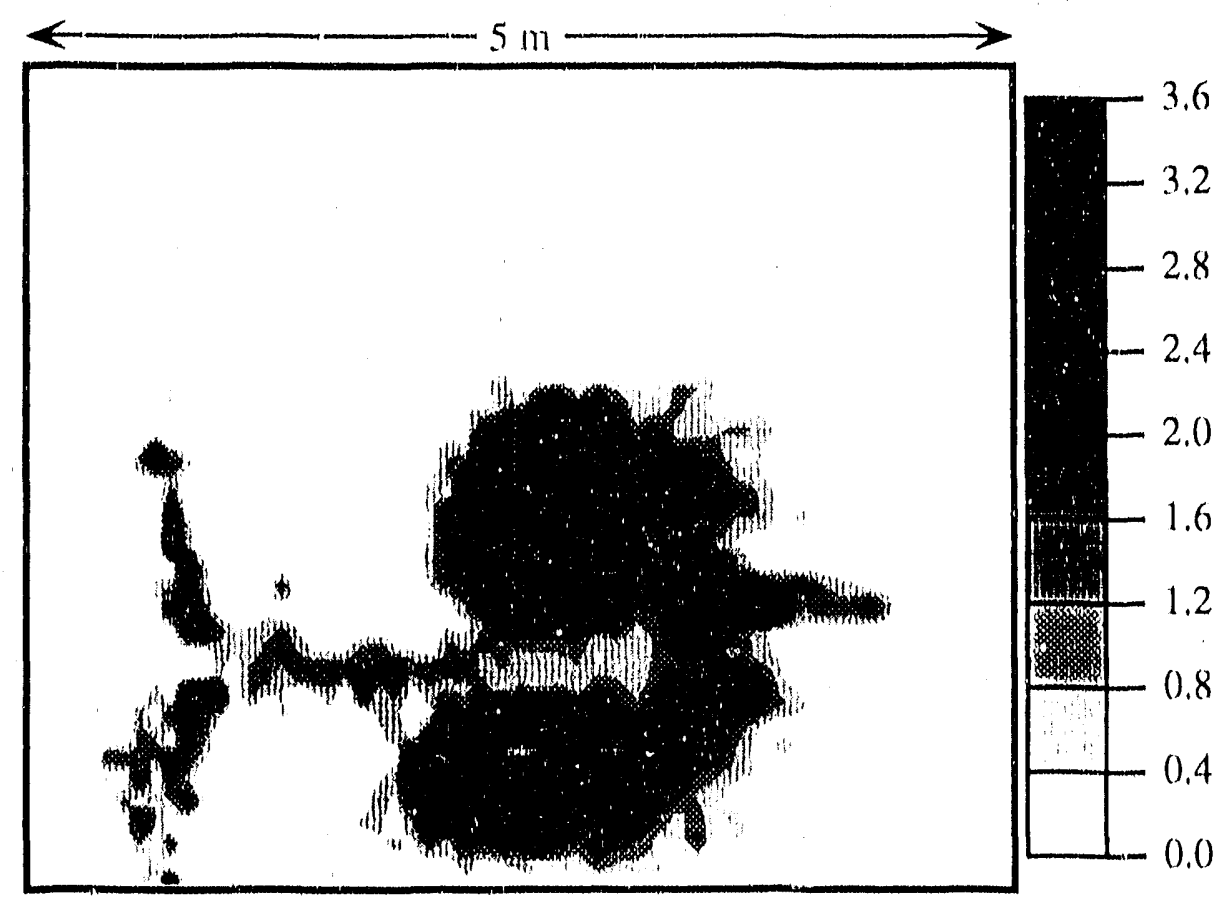

Figure 40: Equivalence ratio profile at $\mathrm{t}=60 \mathrm{~ms}$, Case 5 . 


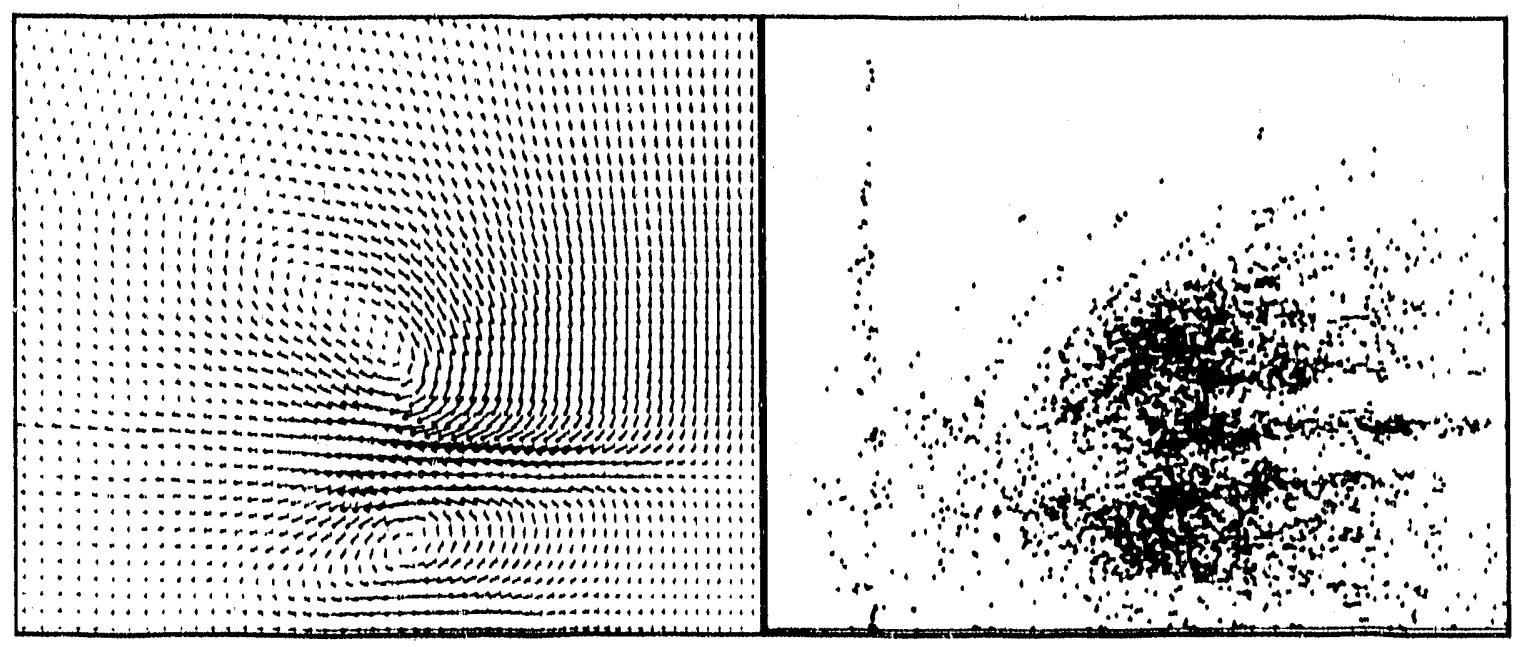

Figure 41: Velocity profile and fuel parcel positions at $t=60 \mathrm{~ms}$, Case 6 . $v_{\max }=3280 \mathrm{~cm} / \mathrm{s}$

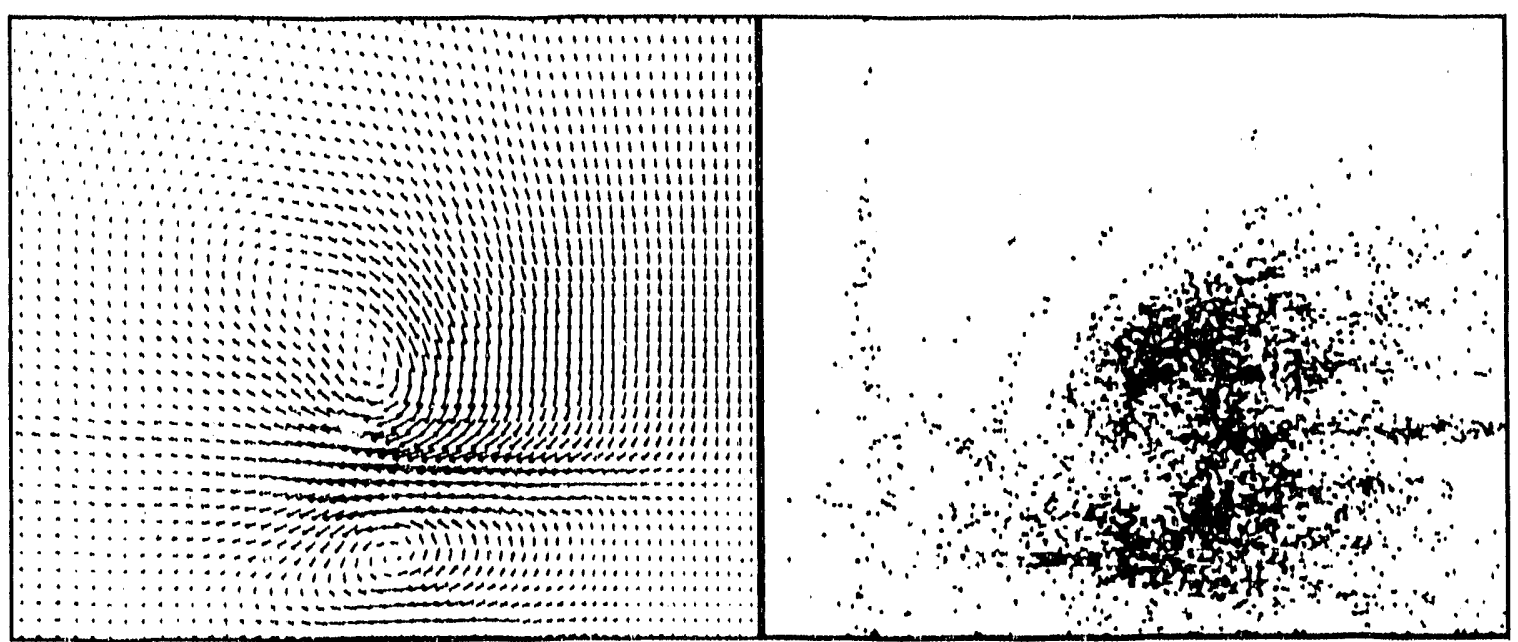

Figure 42: Velocity profile and fuel parcel positions at $t=75 \mathrm{~ms}$, Case 6 . $v_{\max }=3150 \mathrm{~cm} / \mathrm{s}$ 


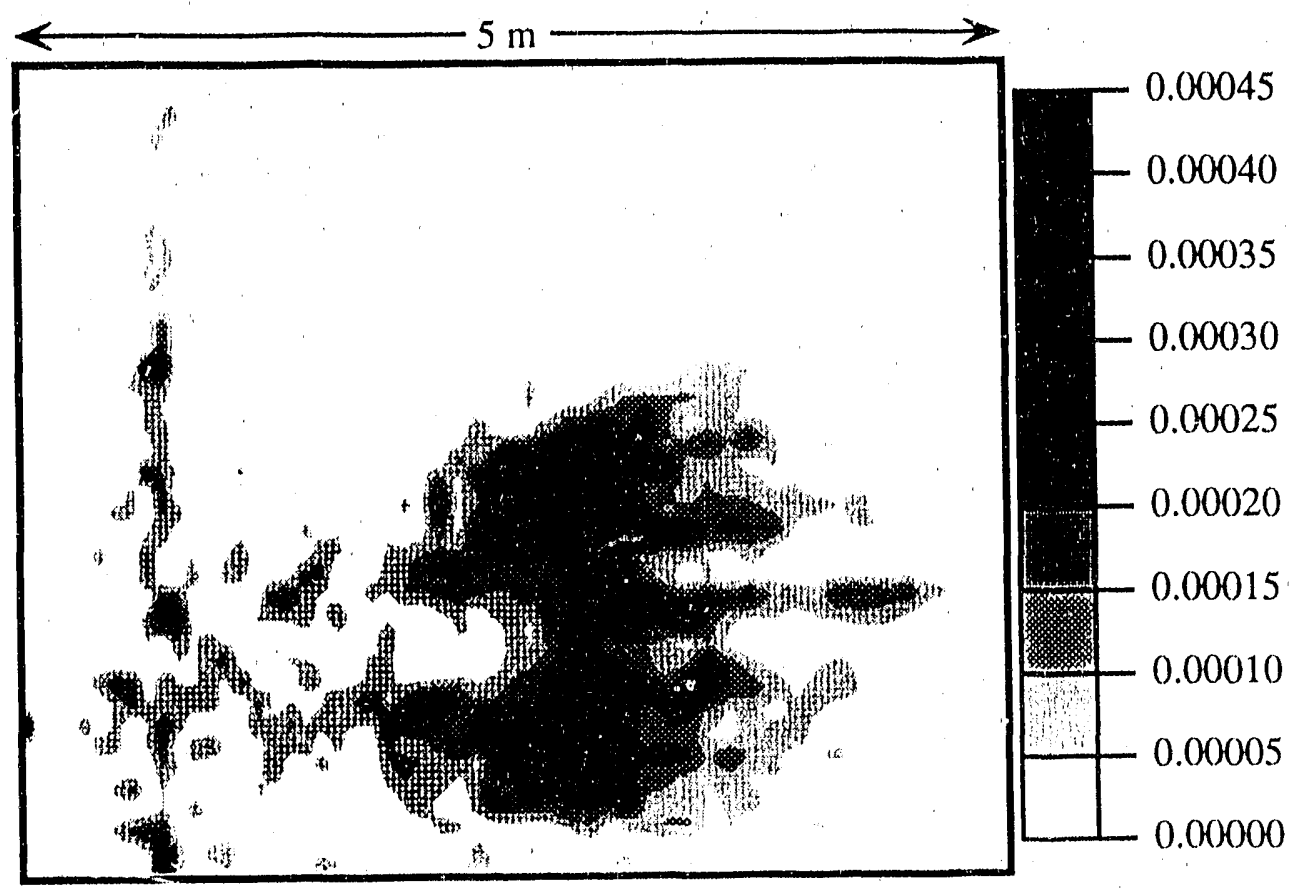

Figure 43: Fuel density profile at $\mathrm{t}=60 \mathrm{~ms}$, Case 6 .

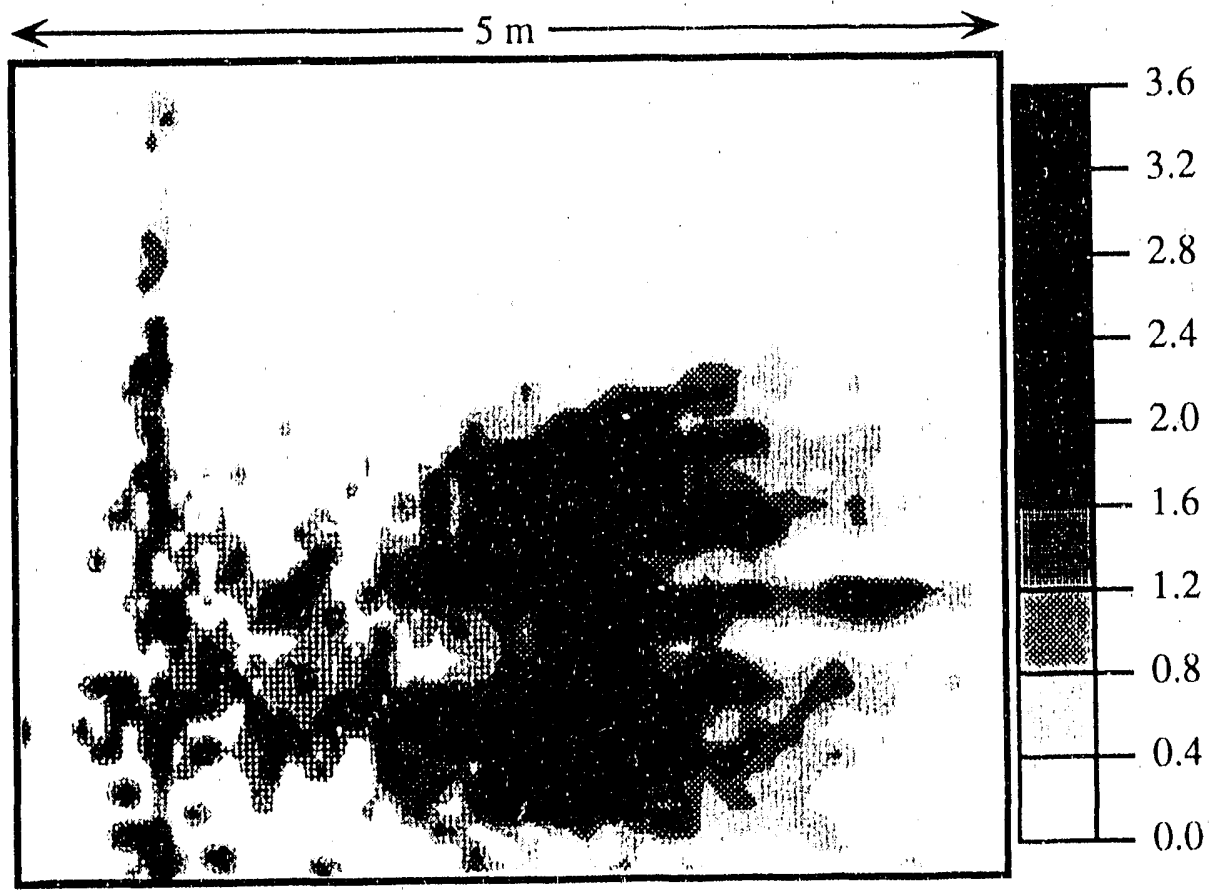

Figure 44: Equivalence ratio profile at $t=60 \mathrm{~ms}$, Case 6 . 


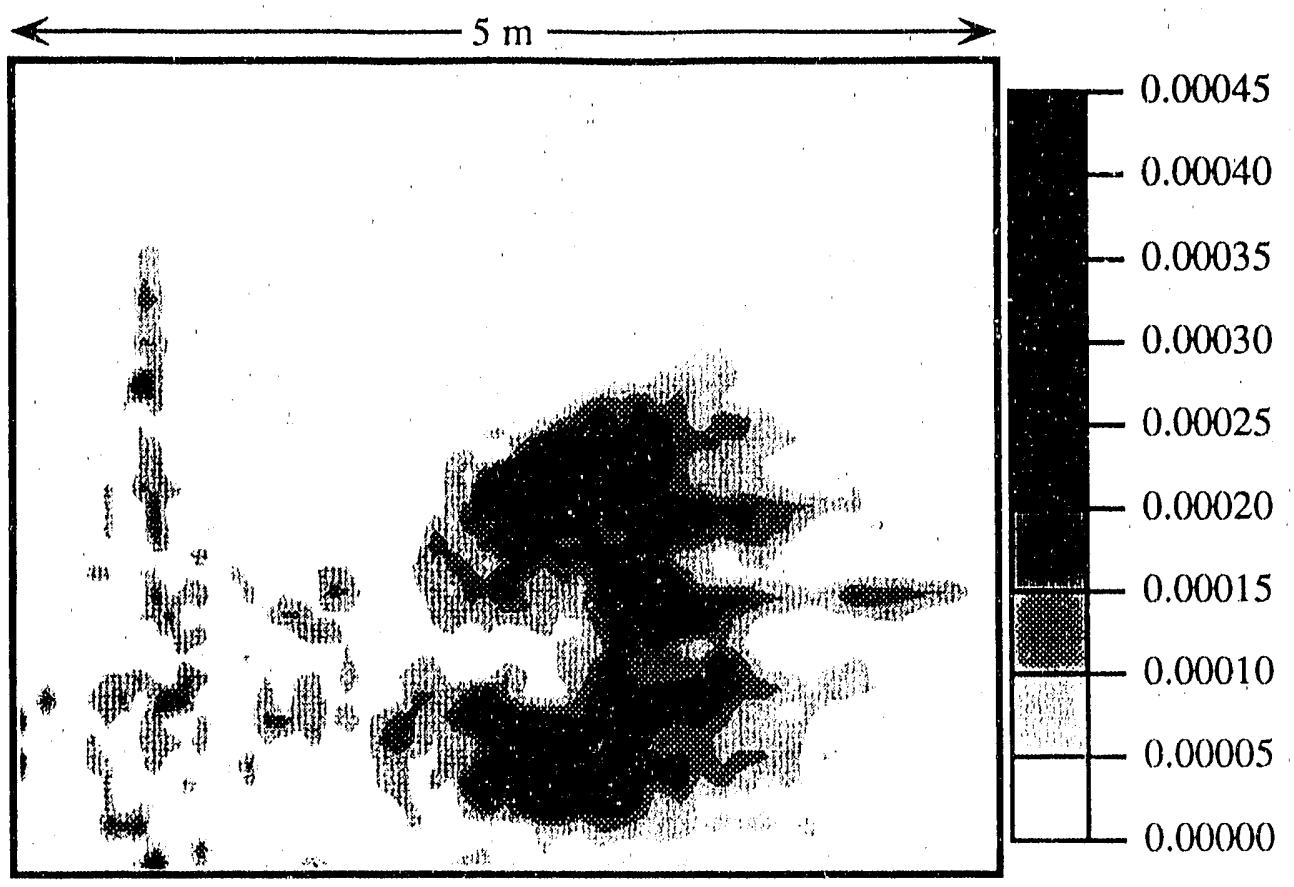

Figure 45: Fuel density profile at $t=75 \mathrm{~ms}$, Case 6 .

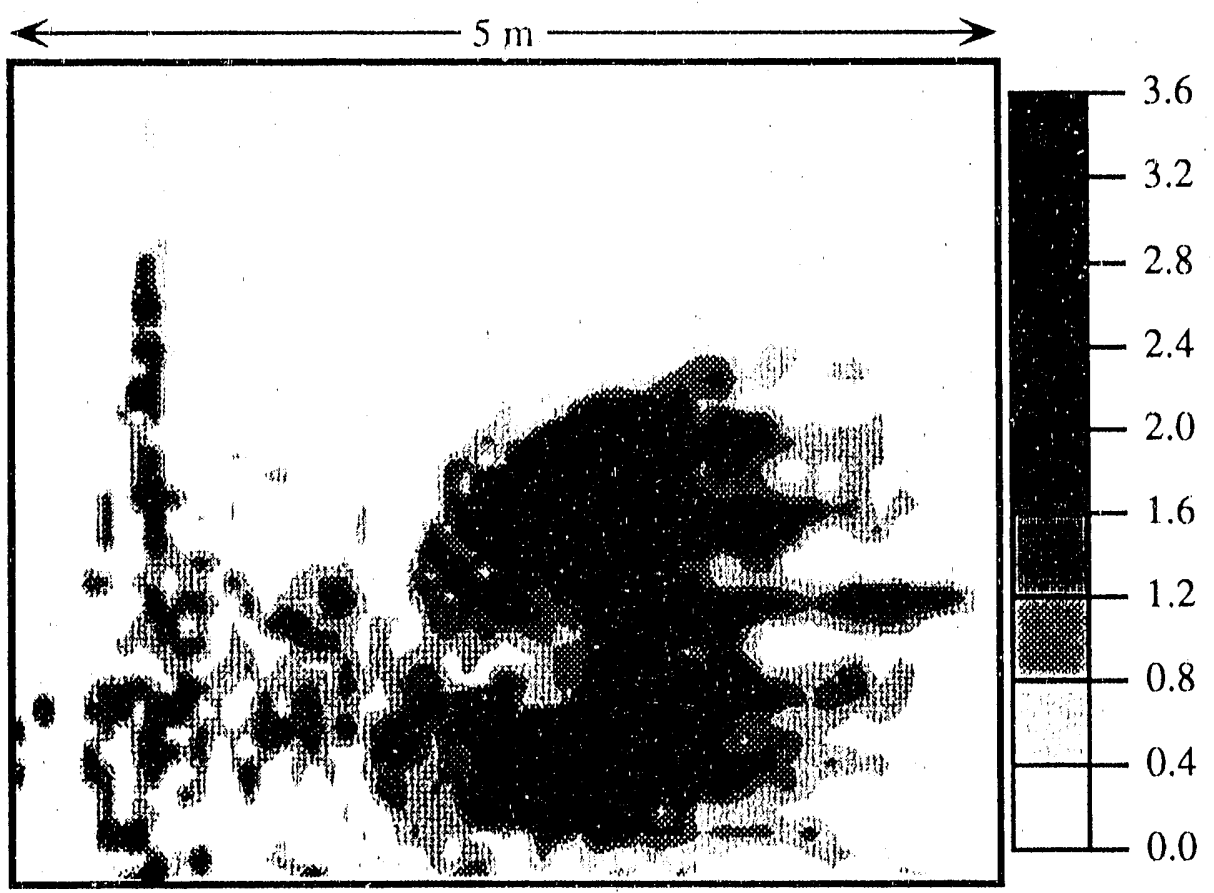

Figure 46: Equivalence ratio profile at $t=75 \mathrm{~ms}$, Case 6 . 


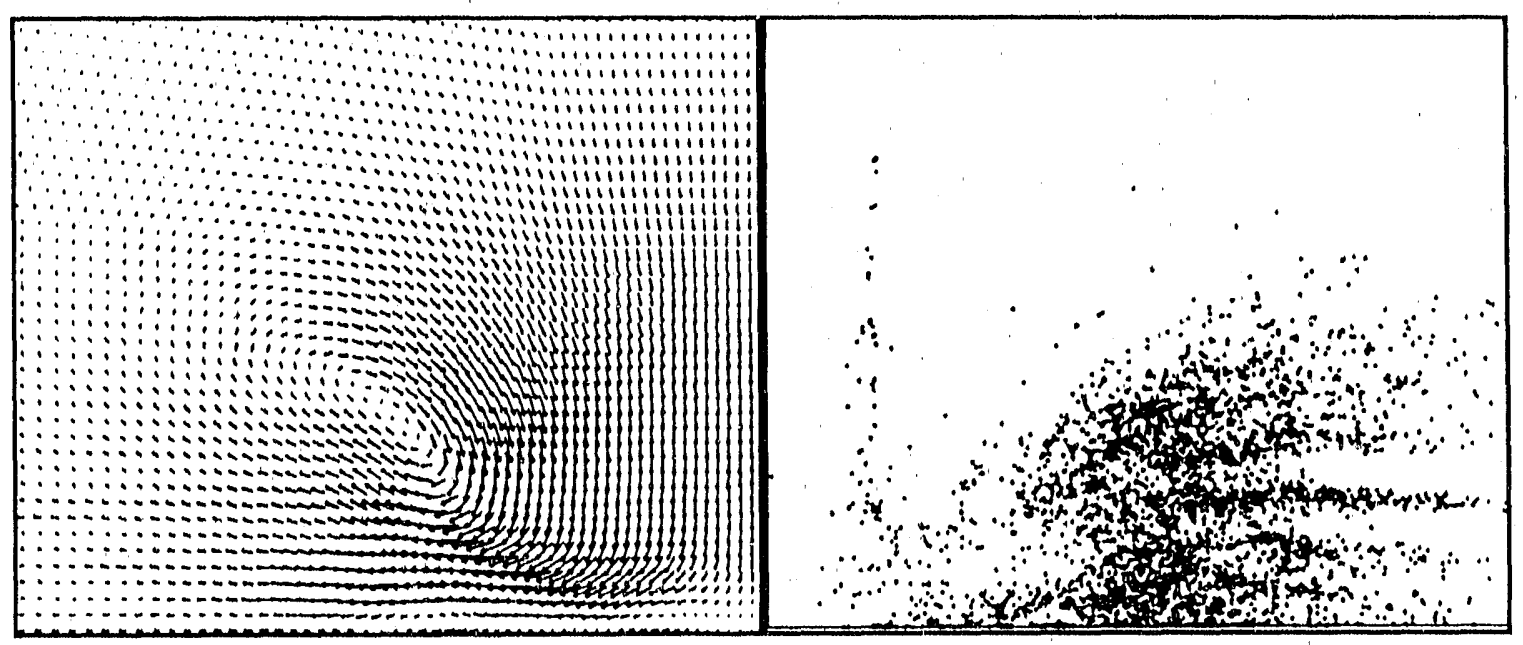

Figure 47: Velocity profile and fuel parcel positions at $\mathrm{t}=60 \mathrm{~ms}$, Case 7 .

$\mathrm{v}_{\max }=2620 \mathrm{~cm} / \mathrm{s}$

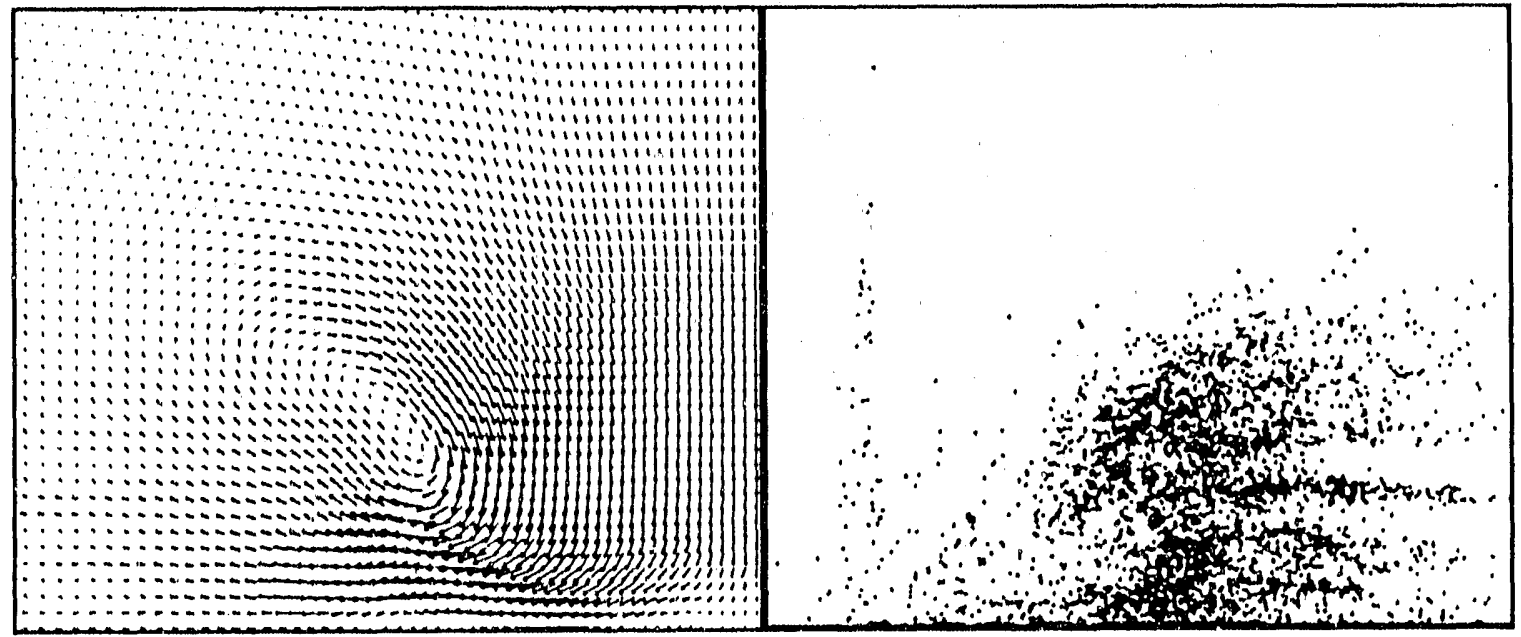

Figure 48: Velocity profile and fuel parcel positions at $\mathrm{t}=75 \mathrm{~ms}$, Case 7 .

$\mathrm{v}_{\max }=2590 \mathrm{~cm} / \mathrm{s}$ 


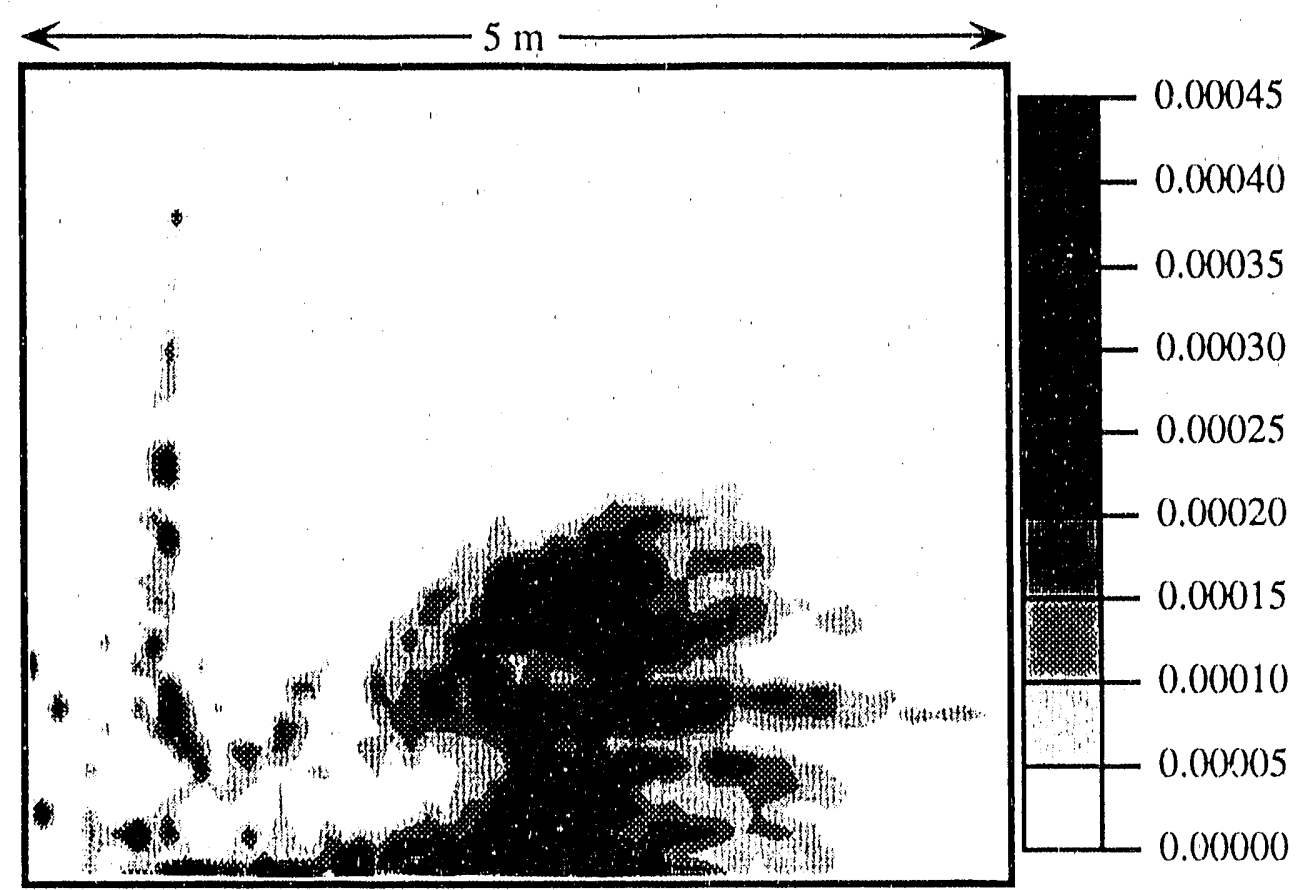

Figure 49: Fuel density profile at $\mathrm{t}=60 \mathrm{~ms}$, Case 7.

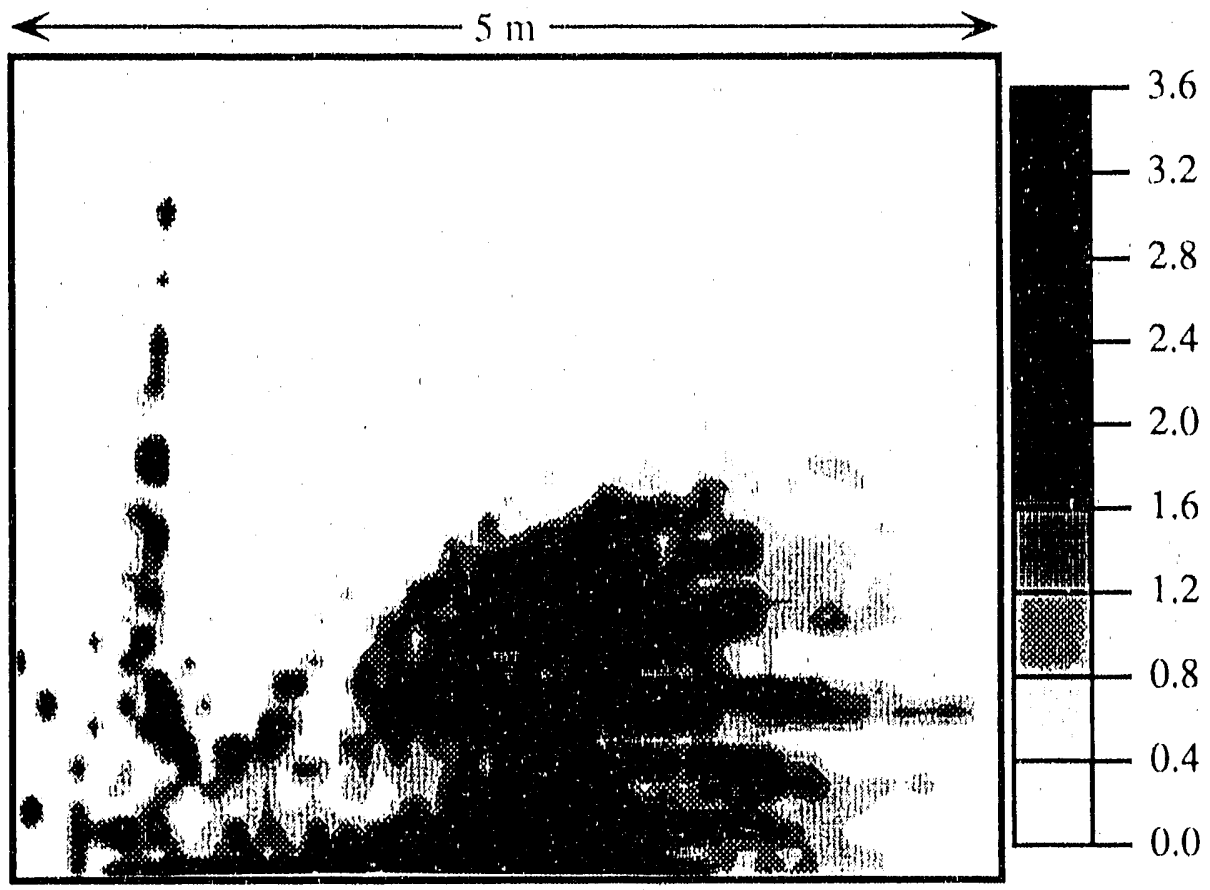

Figure 50: Equivalence rutio profile at $t=60 \mathrm{~ms}$, Case 7 . 


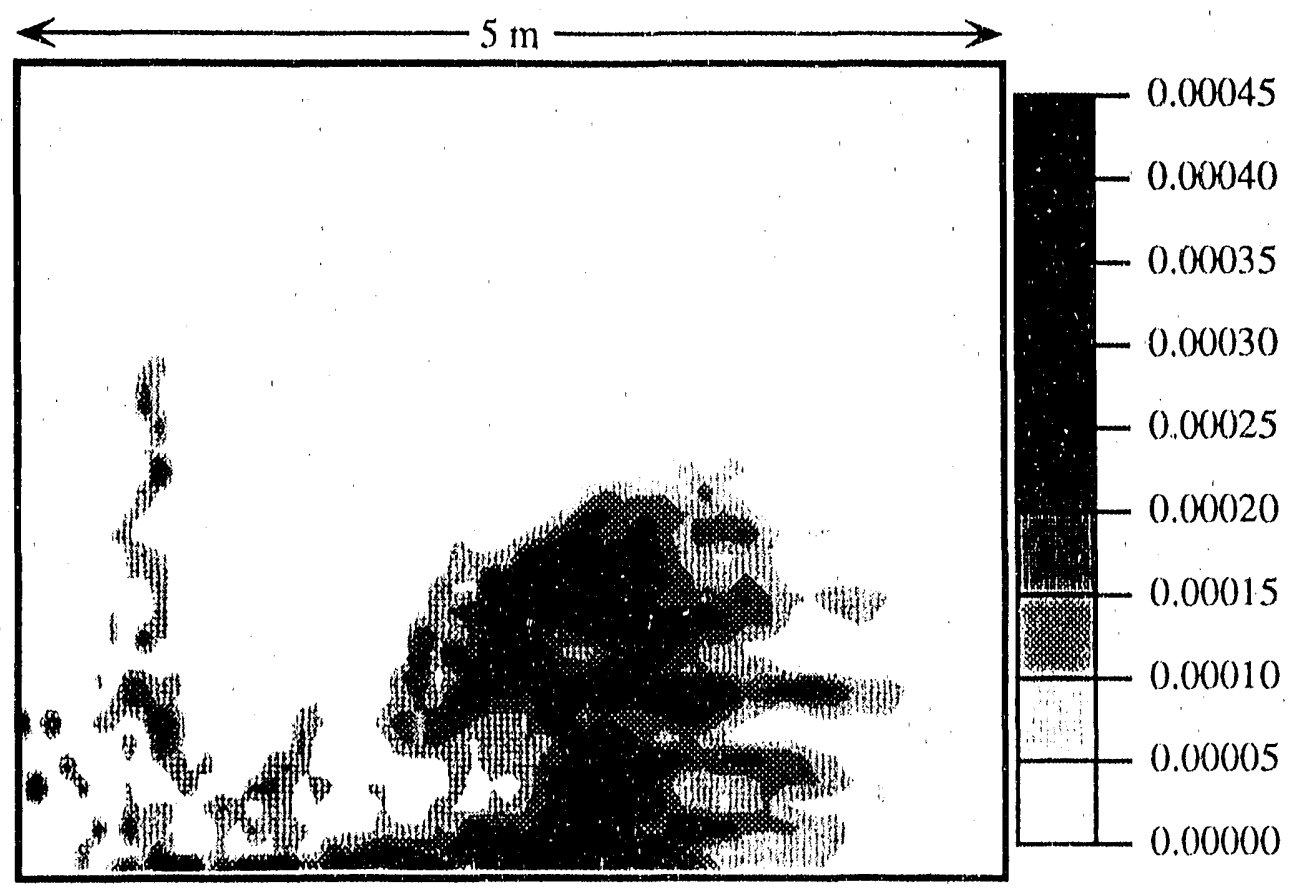

Figure 51: Fuel density profile at $\mathrm{t}=75 \mathrm{~ms}$, Case 7 .

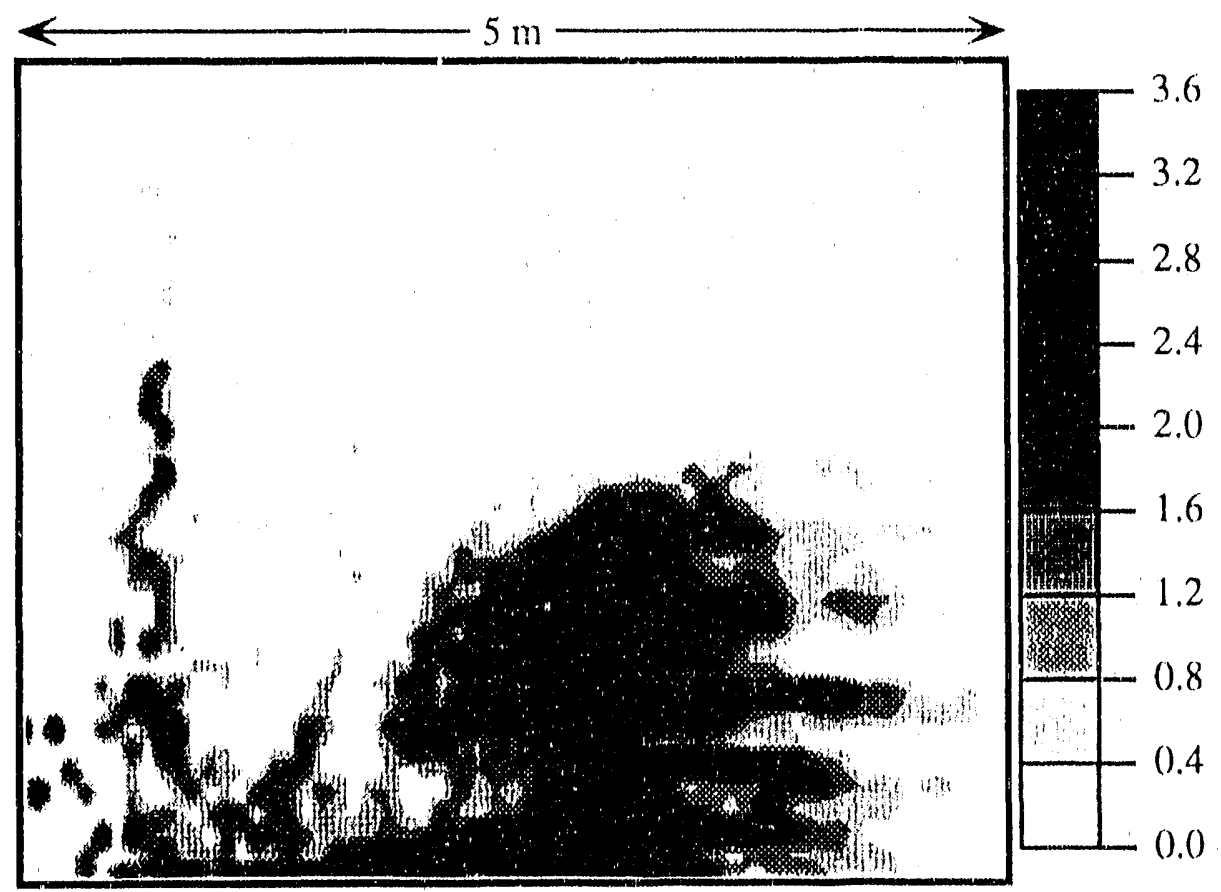

Figure 52: Equivaience ratio profiie at $1=75 \mathrm{~ms}$, Case 7 . 


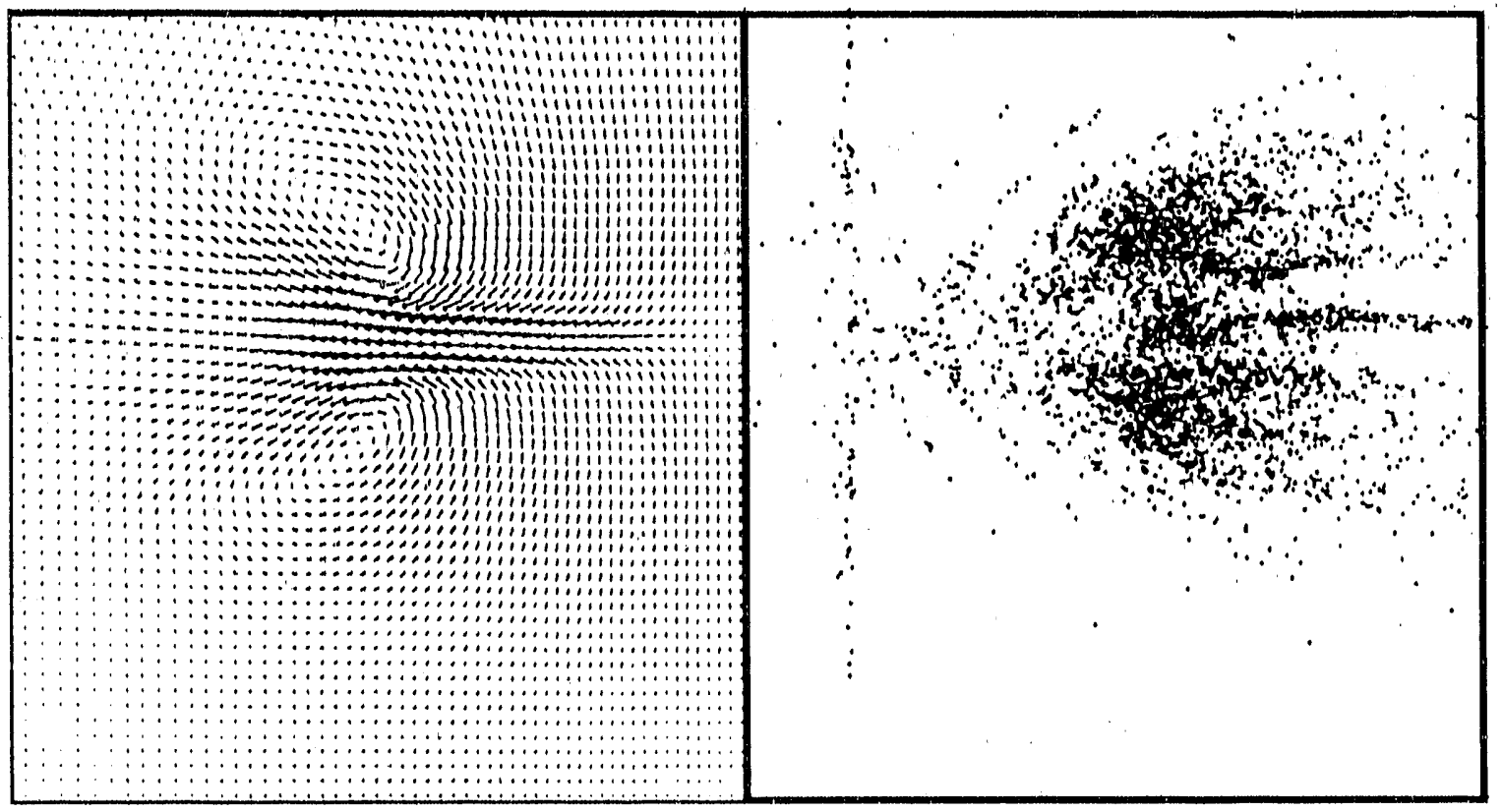

Figure 53: Velocity profile and fuel parcel positions at $t=60 \mathrm{~ms}$, Case 8 . $\mathrm{v}_{\max }=3540 \mathrm{~cm} / \mathrm{s}$

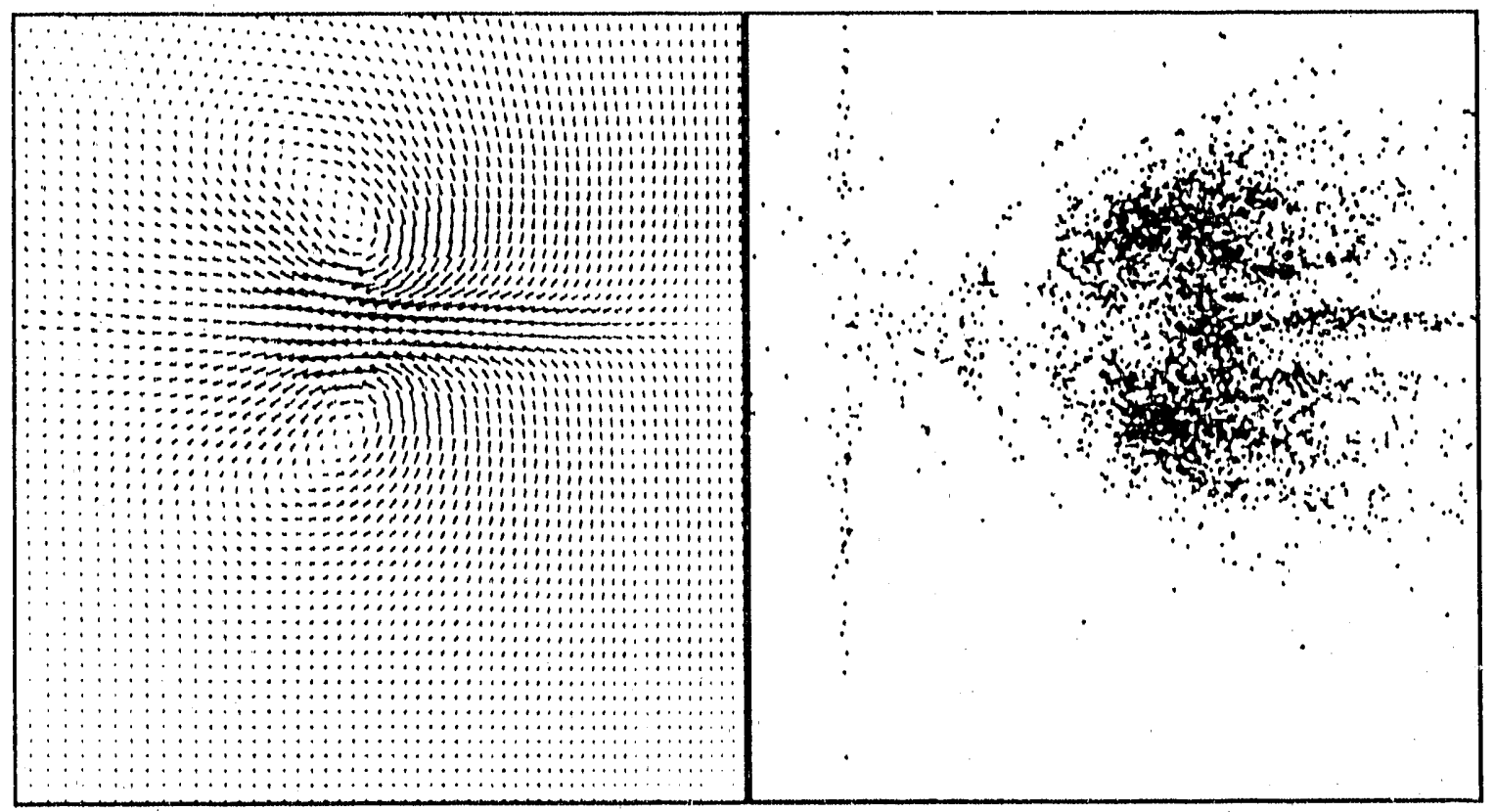

Figure 54: Velocity profile and fuel parcel positions at $\mathrm{t}=75 \mathrm{~ms}$, Case 8 . $v_{\text {inax }}=3440 \mathrm{~cm} / \mathrm{s}$ 


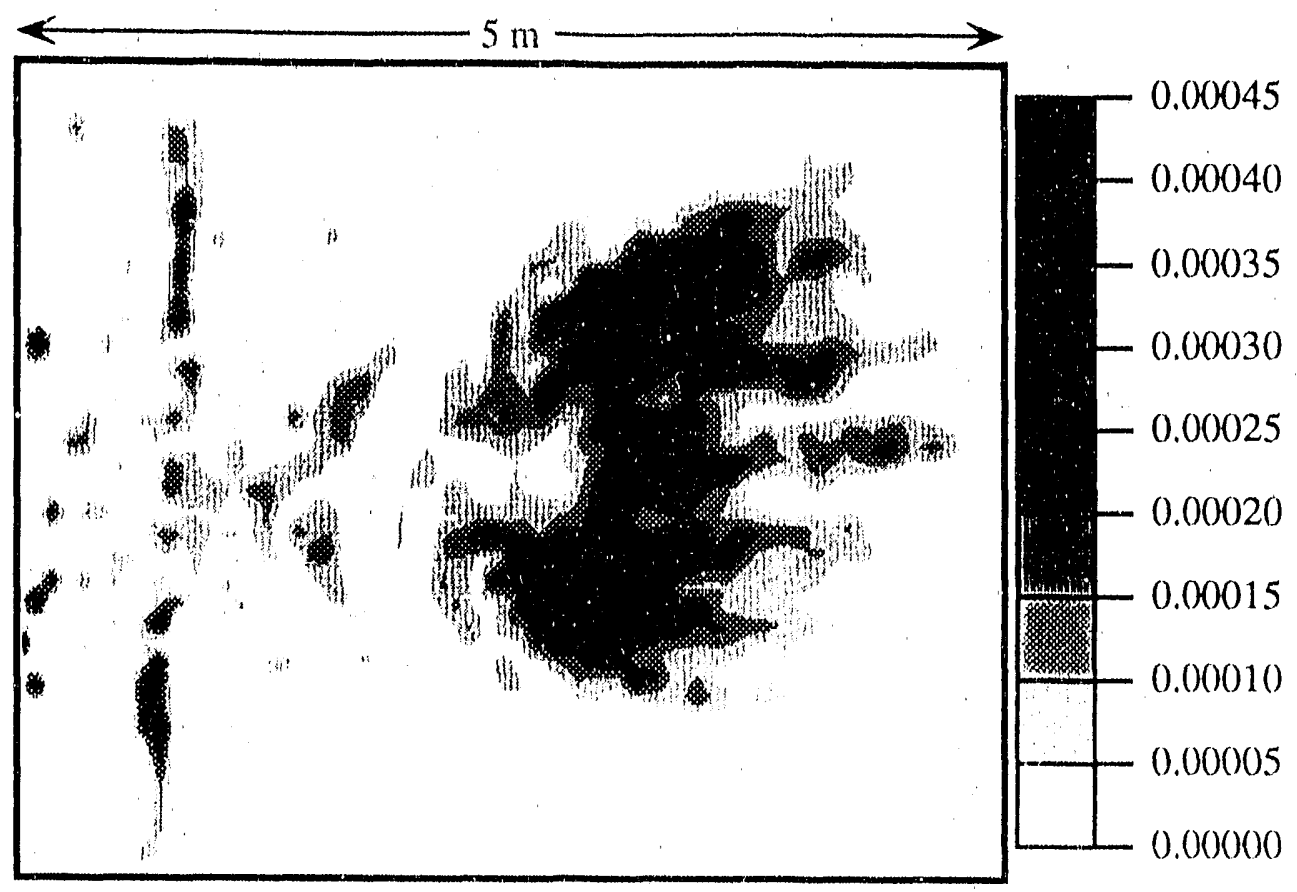

Figure 55: Fuel density profile at $\mathrm{t}=60 \mathrm{~ms}$, Case 8 .

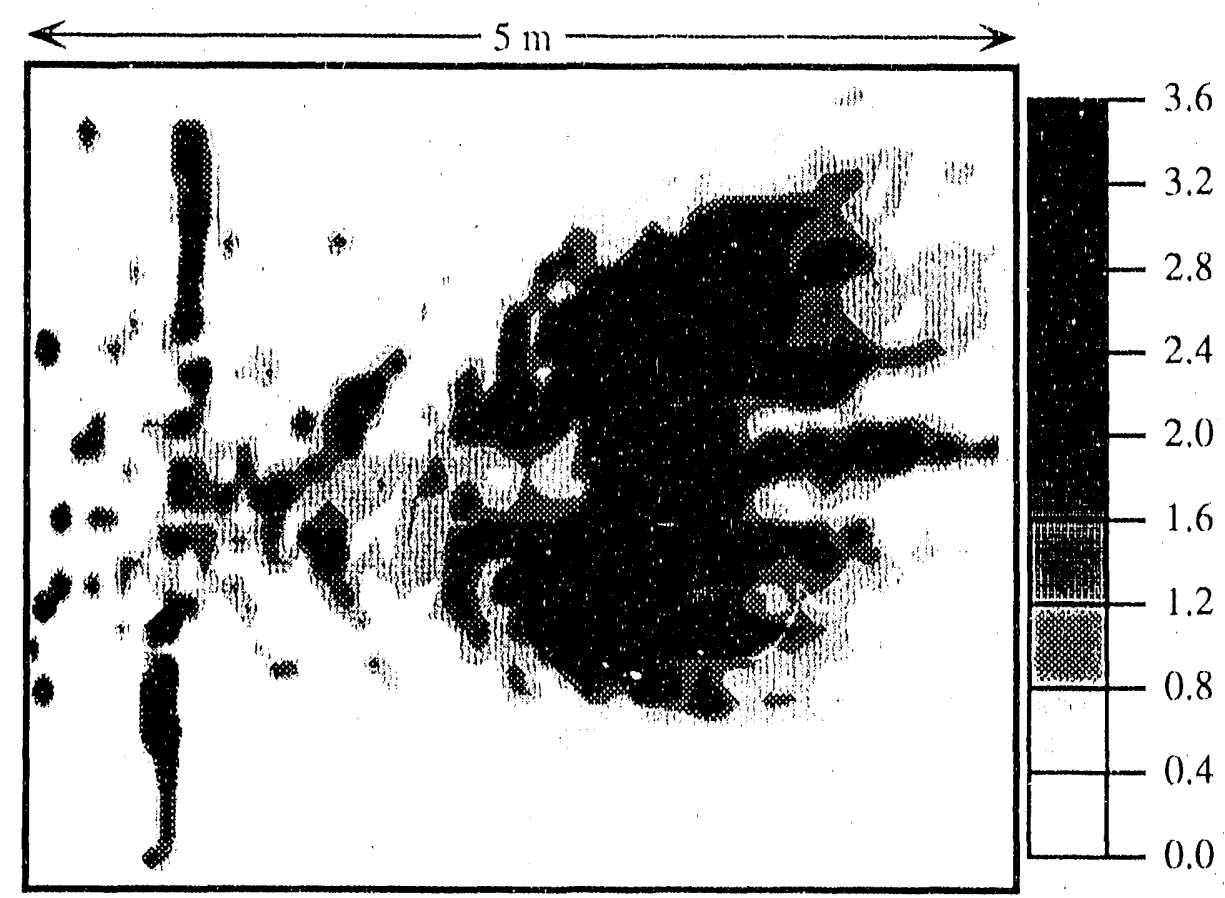

Figure 56: Equivalence ratio profile at $\mathrm{t}=60 \mathrm{~ms}$, Case 8 . 


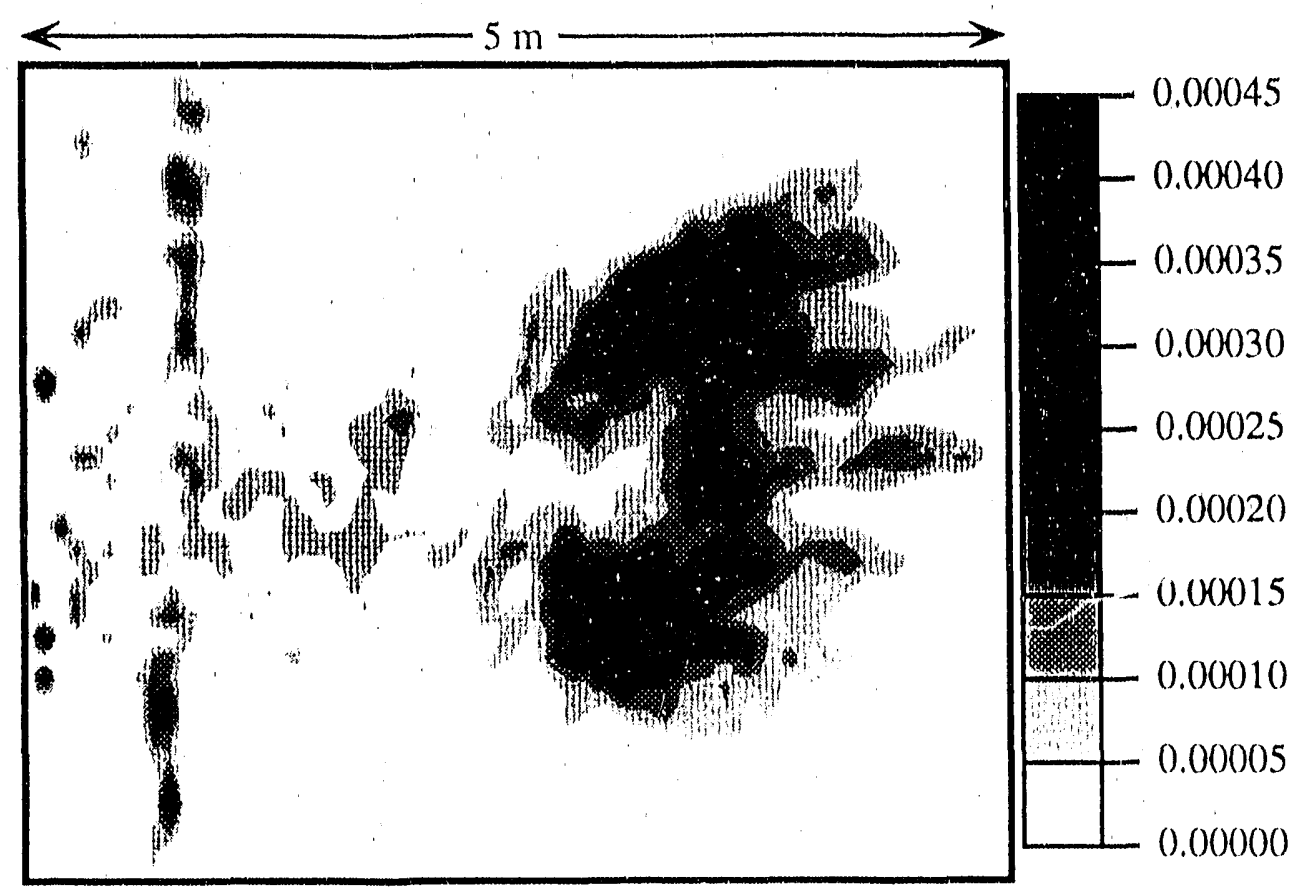

Figure 57: Fuel density profile at $\mathrm{t}=75 \mathrm{~ms}$, Case 8.

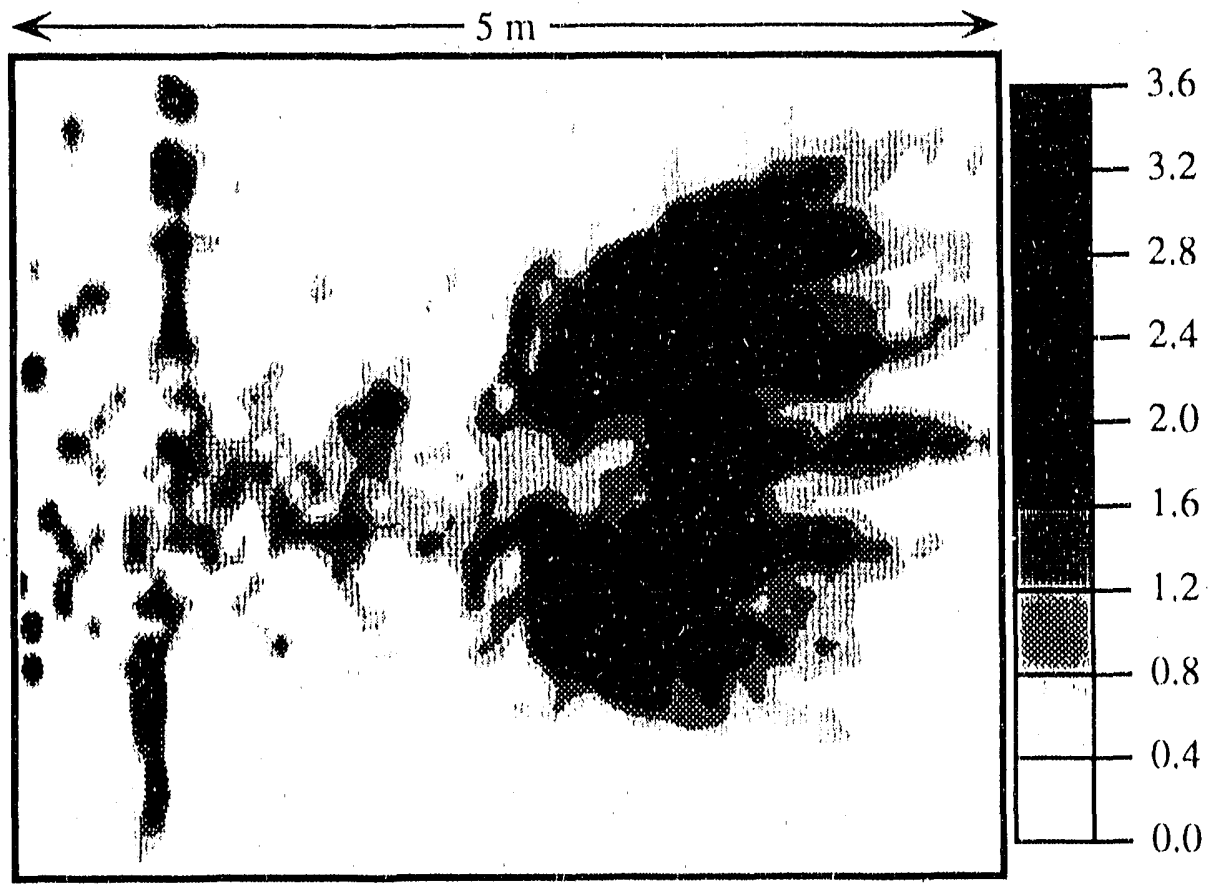

Figure 58: Equivalence ratio profile at $\mathrm{t}=7.5 \mathrm{~ms}$, Case 8 . 


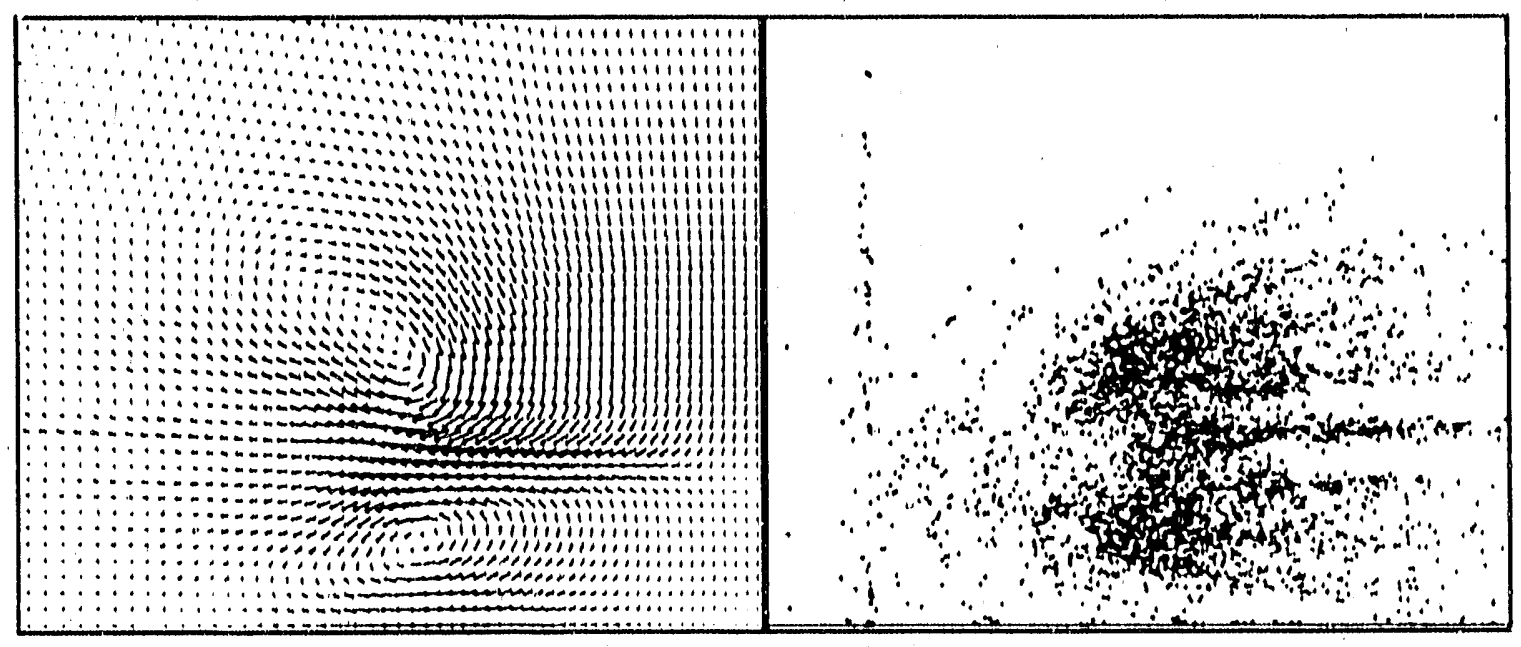

Figure 59: Velocity profile and fuel parcel positions at $t=60 \mathrm{~ms}$, Case 9. $\mathrm{v}_{\text {max }}=3230 \mathrm{~cm} / \mathrm{s}$

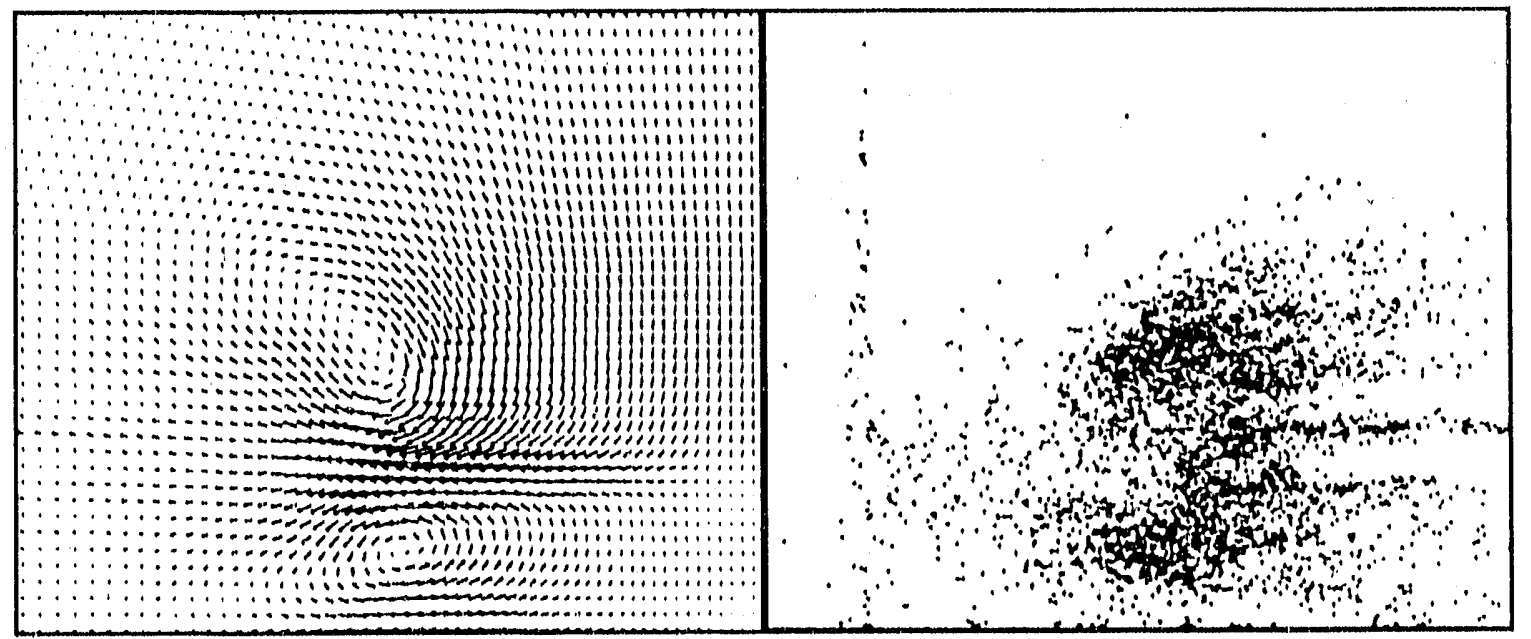

Figure 60: Velocity profile and fuel parcel positions at $t=75 \mathrm{~ms}$, Case 9 . $\mathrm{v}_{\max }=3120 \mathrm{~cm} / \mathrm{s}$ 


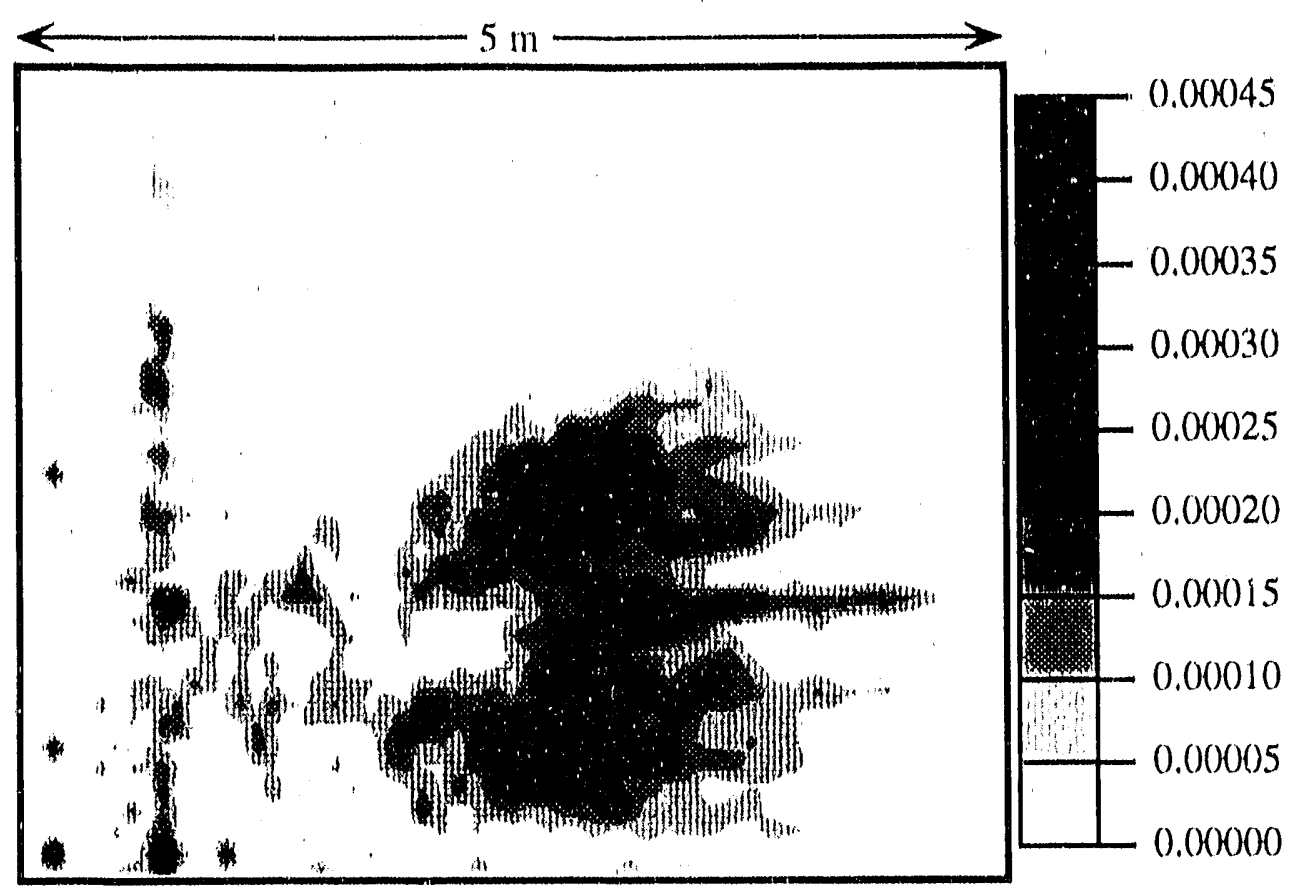

Figure 61: Fuel density profile at $\mathrm{t}=60 \mathrm{~ms}$, Case 9.

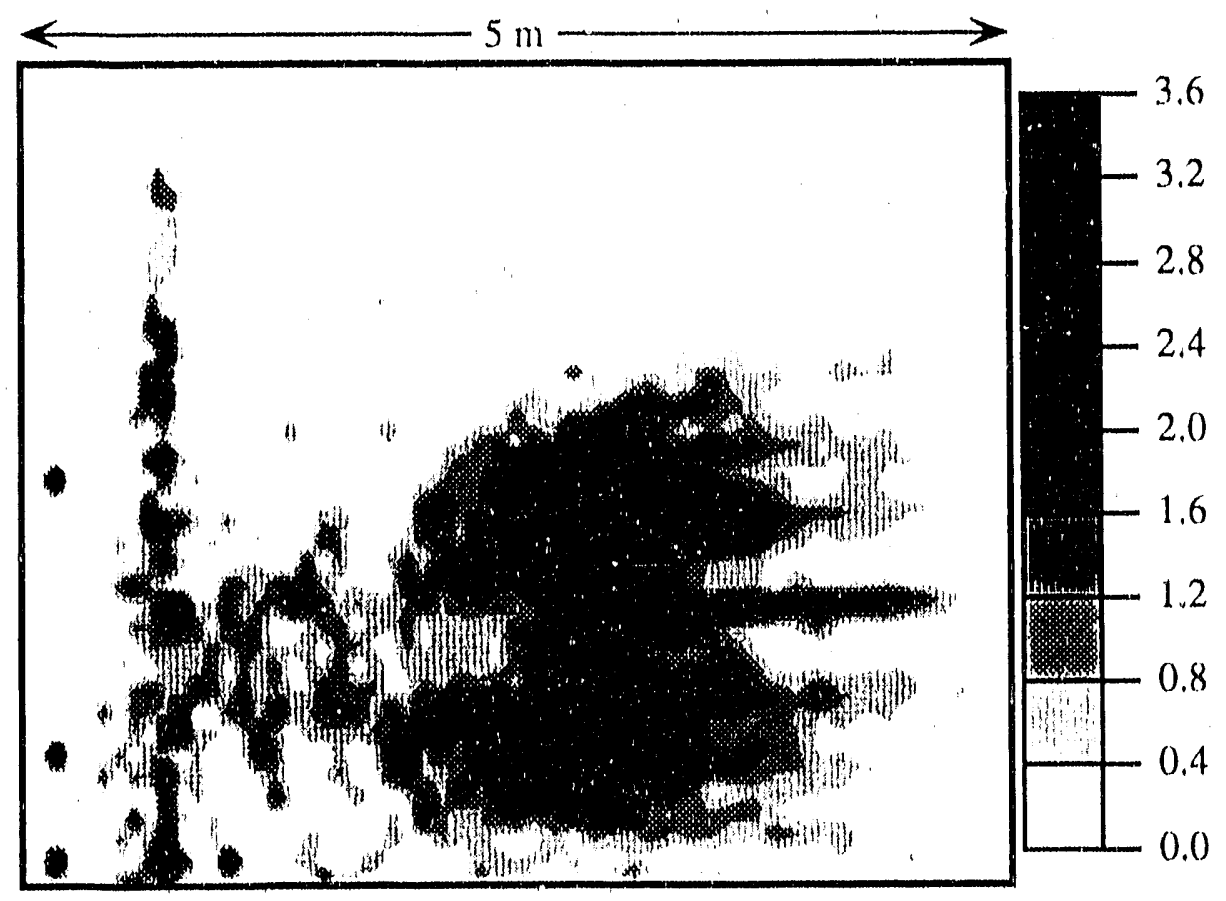

Figure 62: Equivalence ratio profile at $\mathrm{t}=6() \mathrm{ms}$, Case 9 . 


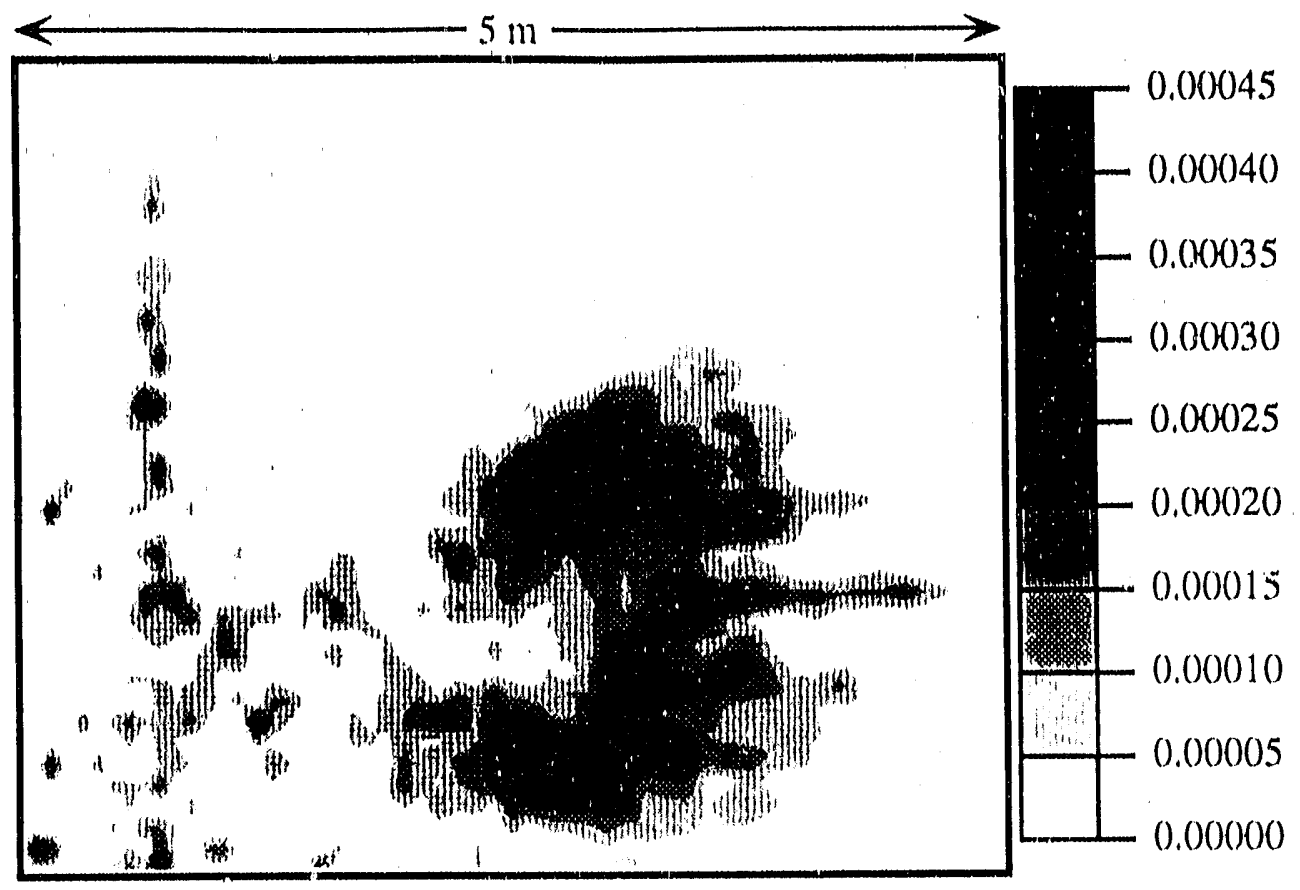

Figure 63: Fuel density profile at $t=75 \mathrm{~ms}$, Case 9.

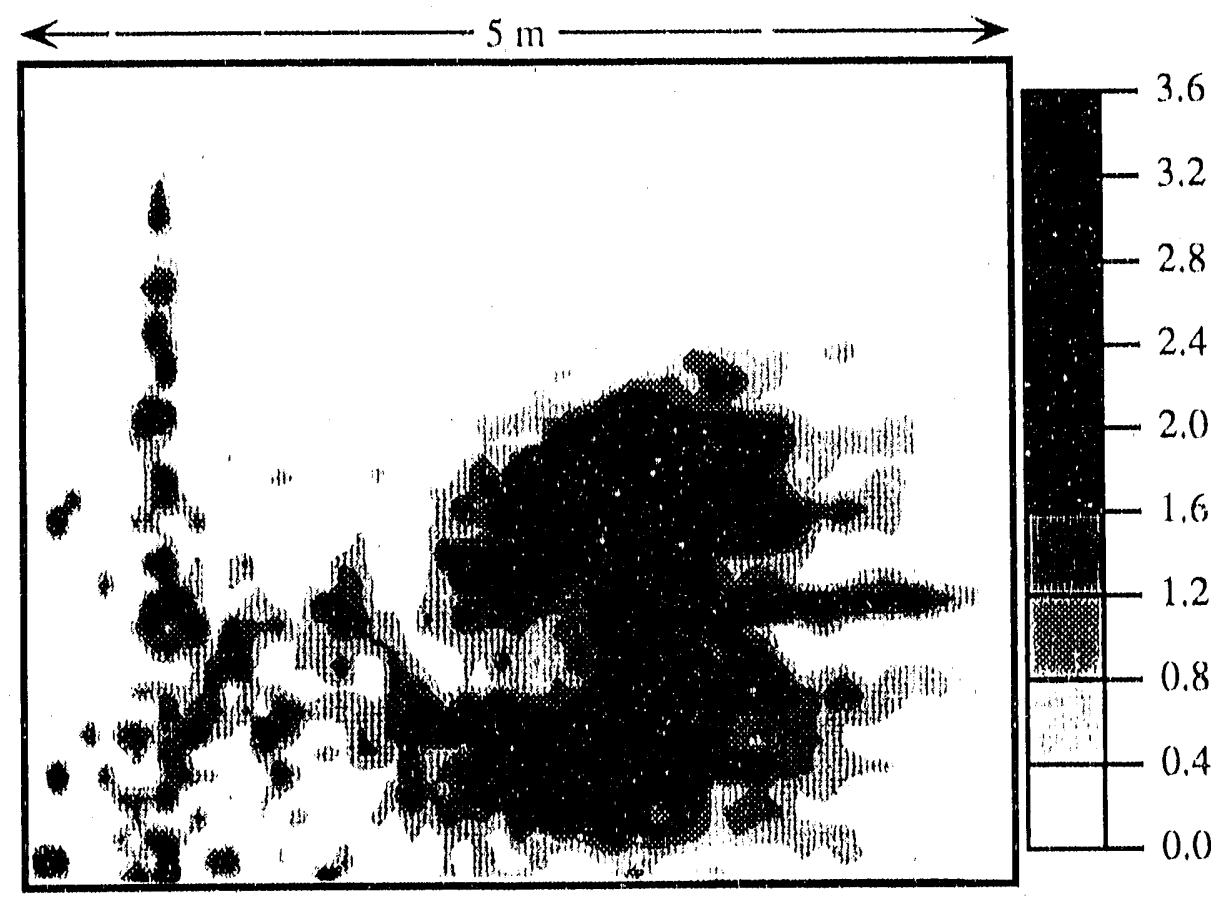

Figure 64: Equivalence ratio profile at $t=75 \mathrm{~ms}$, Case 9. 


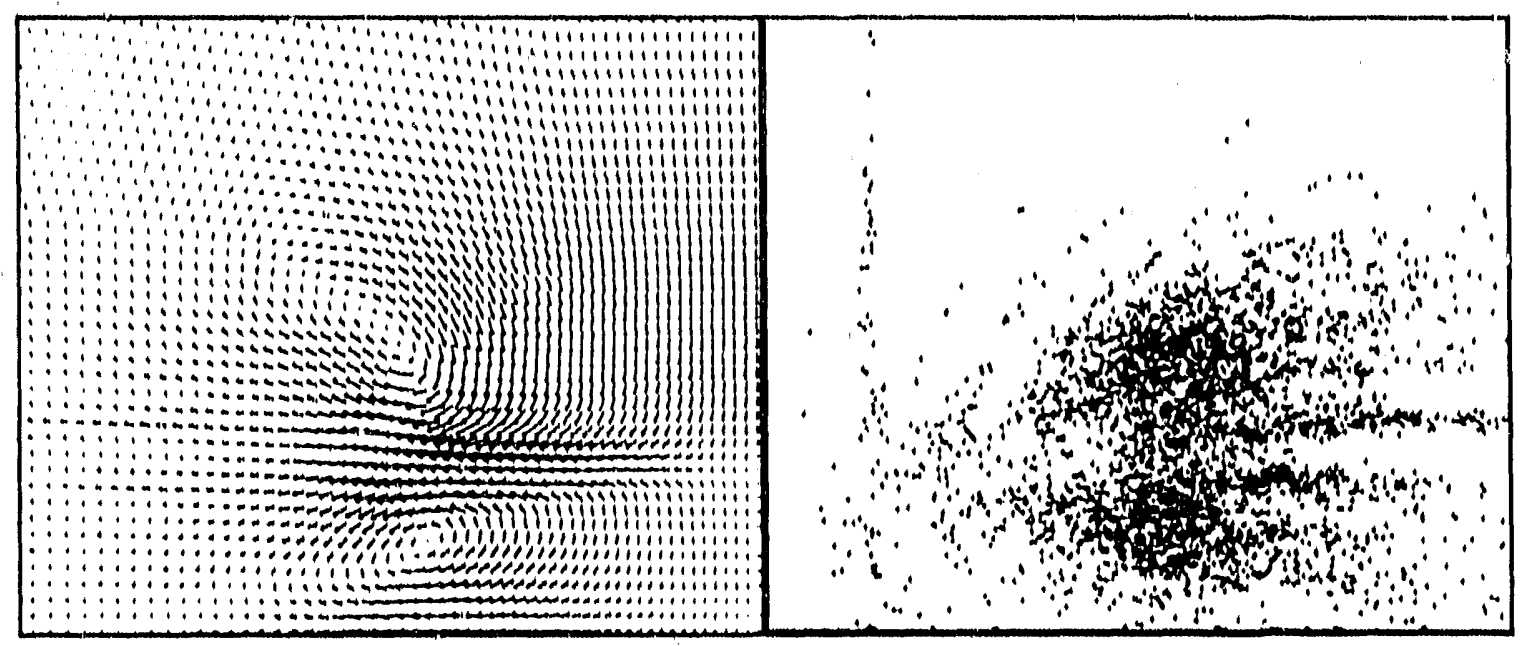

Figure 65: Velocity profile and fuel parcel positions at $t=60 \mathrm{~ms}$, Case 10 . $v_{\text {max }}=3210 \mathrm{~cm} / \mathrm{s}$
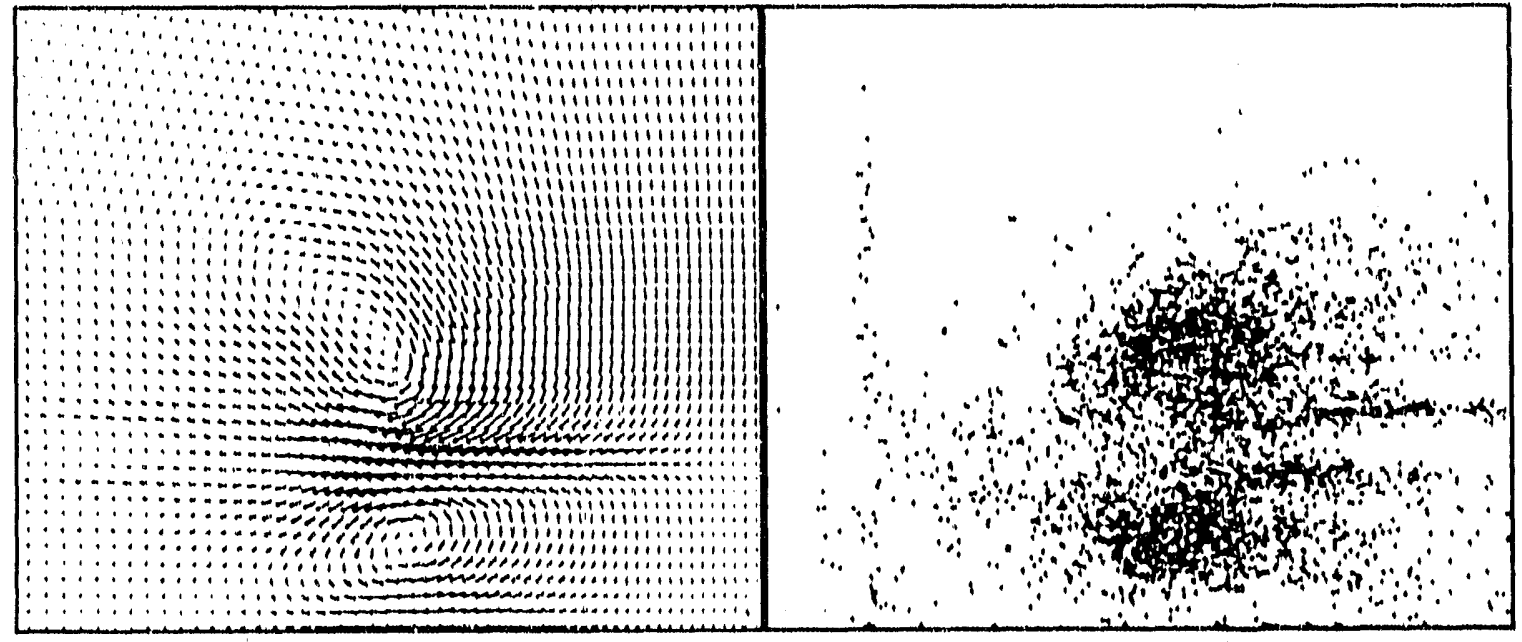

Figure 66: Velocity profile and fuel parcel positions at $\mathrm{t}=7.5 \mathrm{~ms}$, Case 10. $v_{\text {max }}=3150 \mathrm{~cm} / \mathrm{s}$ 


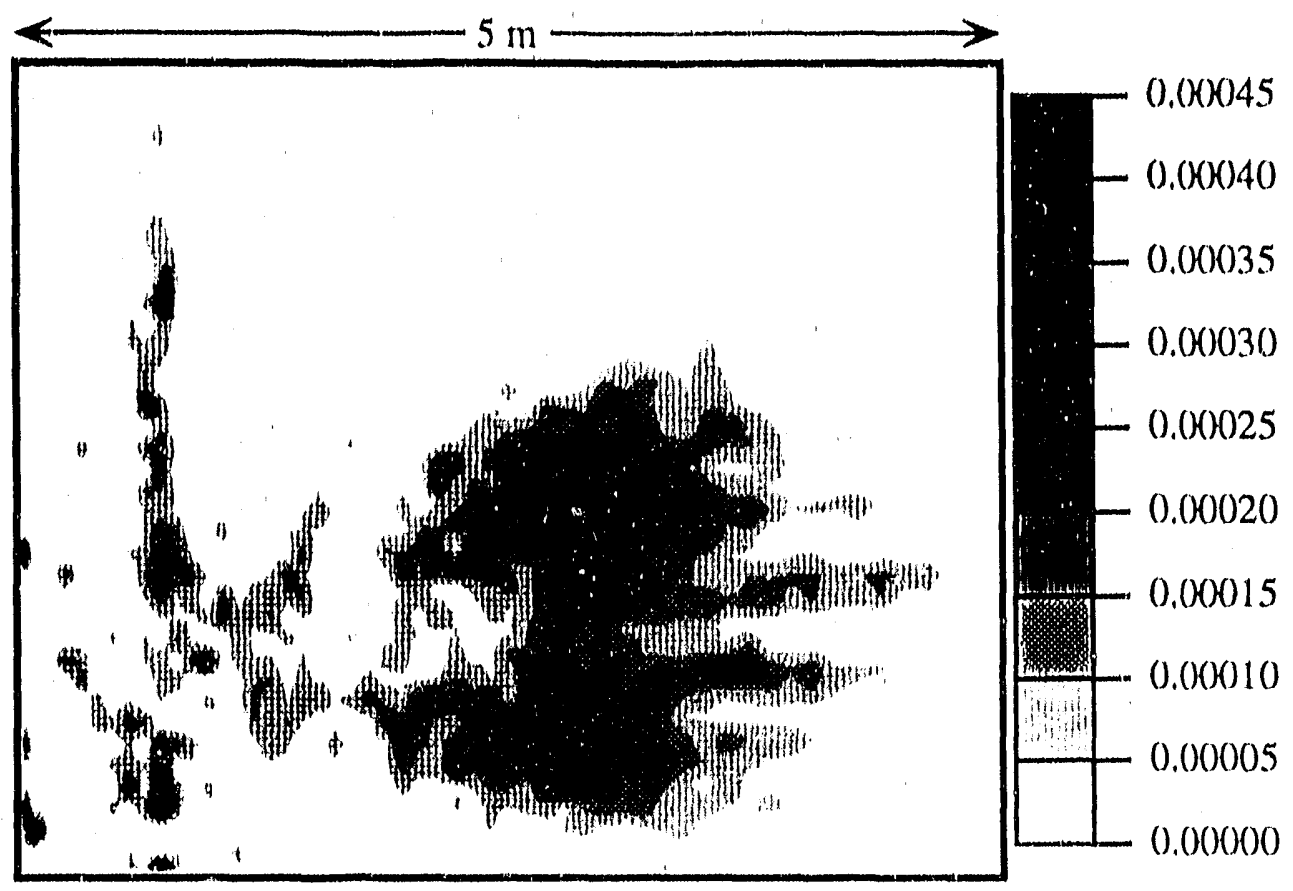

Figure 67: Fuel density profile $a t=60 \mathrm{~ms}$, Case 10 .

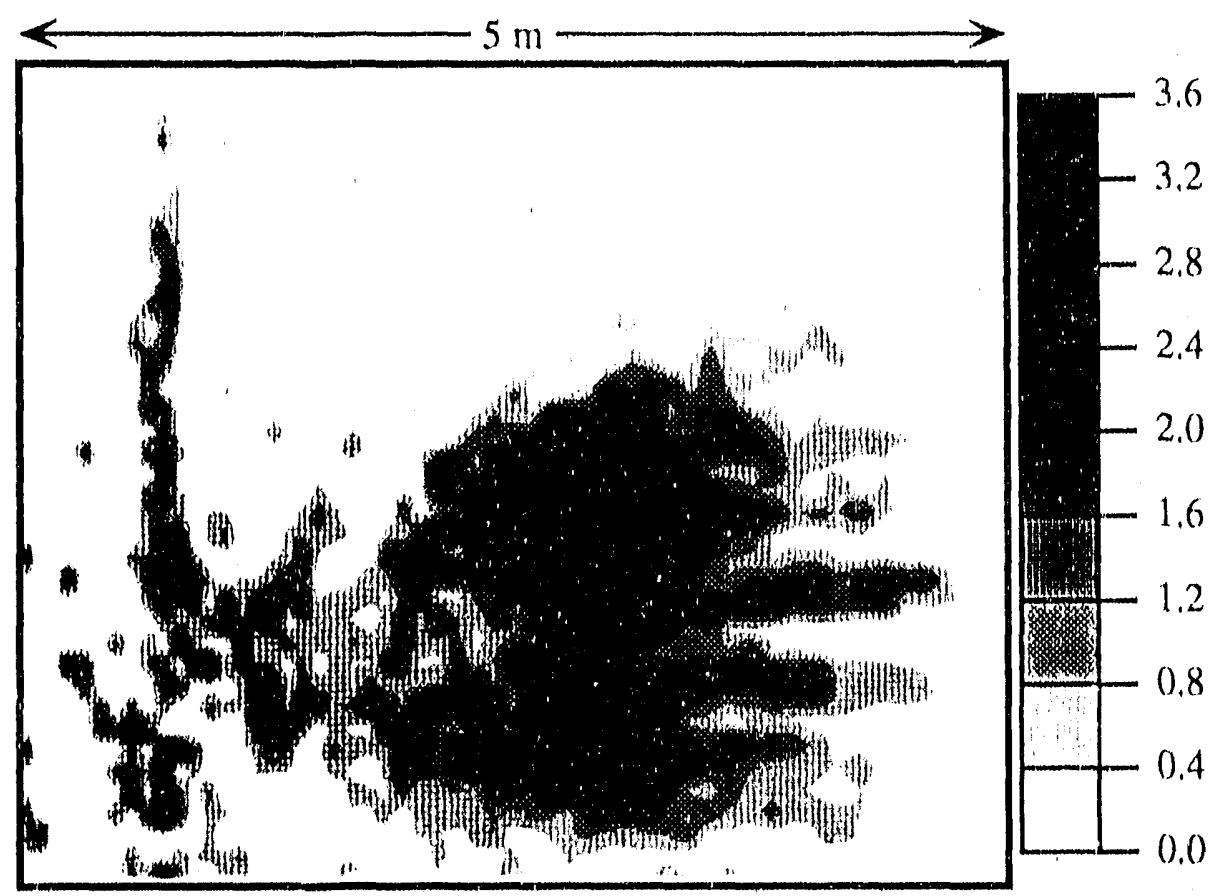

Figure 68: Equivalence ratio profile at $\mathrm{t}=60 \mathrm{~ms}$, Case $1($. 


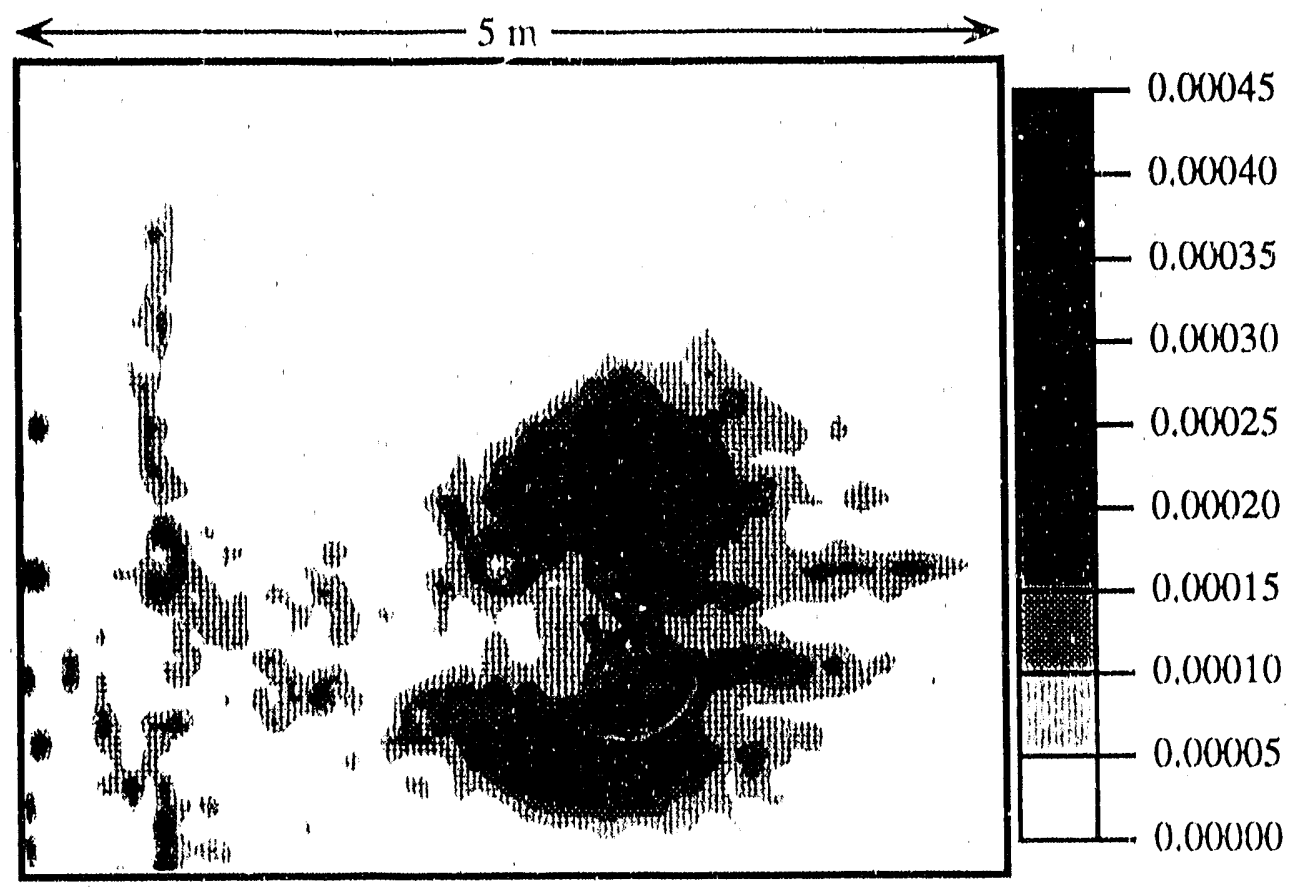

Figure 69: Fuel density profile at $\mathrm{t}=75 \mathrm{~ms}$, Case 10 .

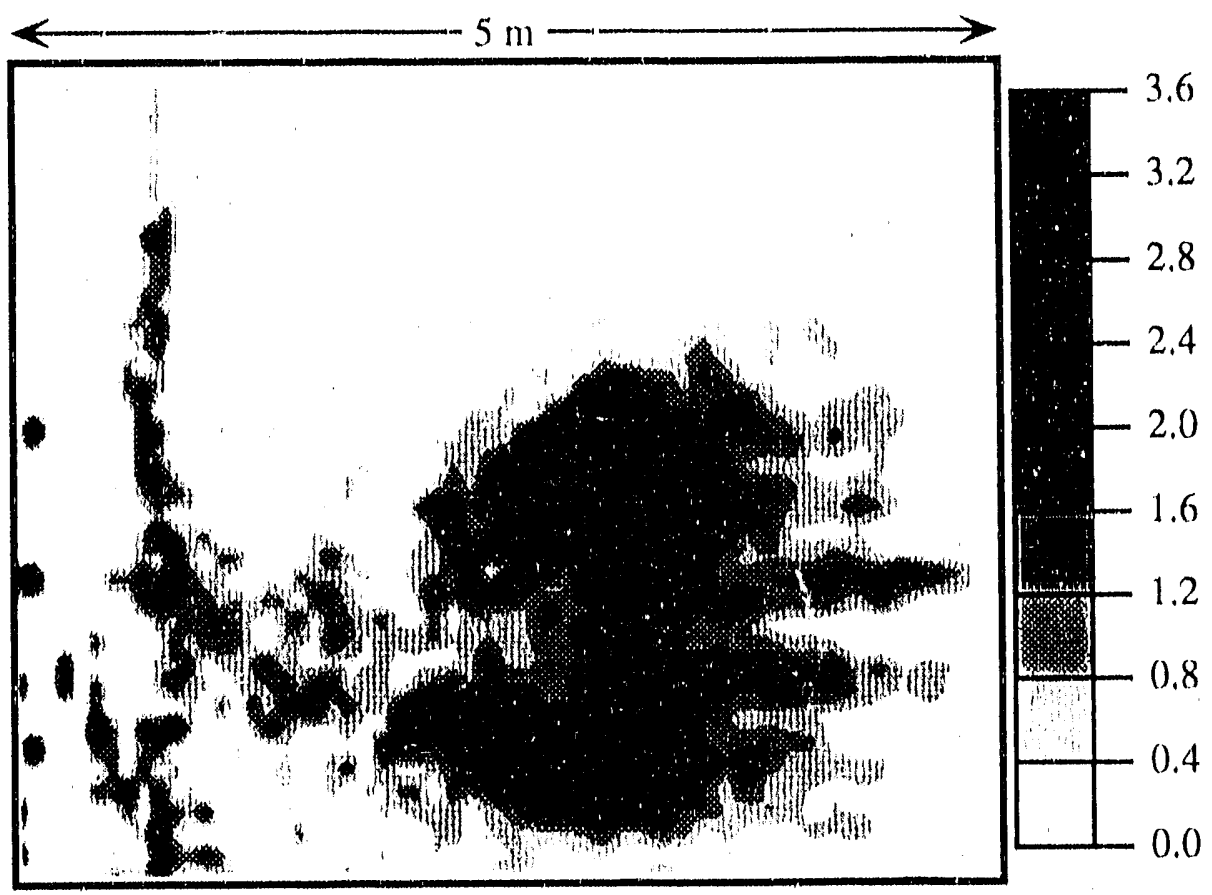

Figure 70: Equivalence ratio profile at $t=60 \mathrm{~ms}$, Case 10 . 


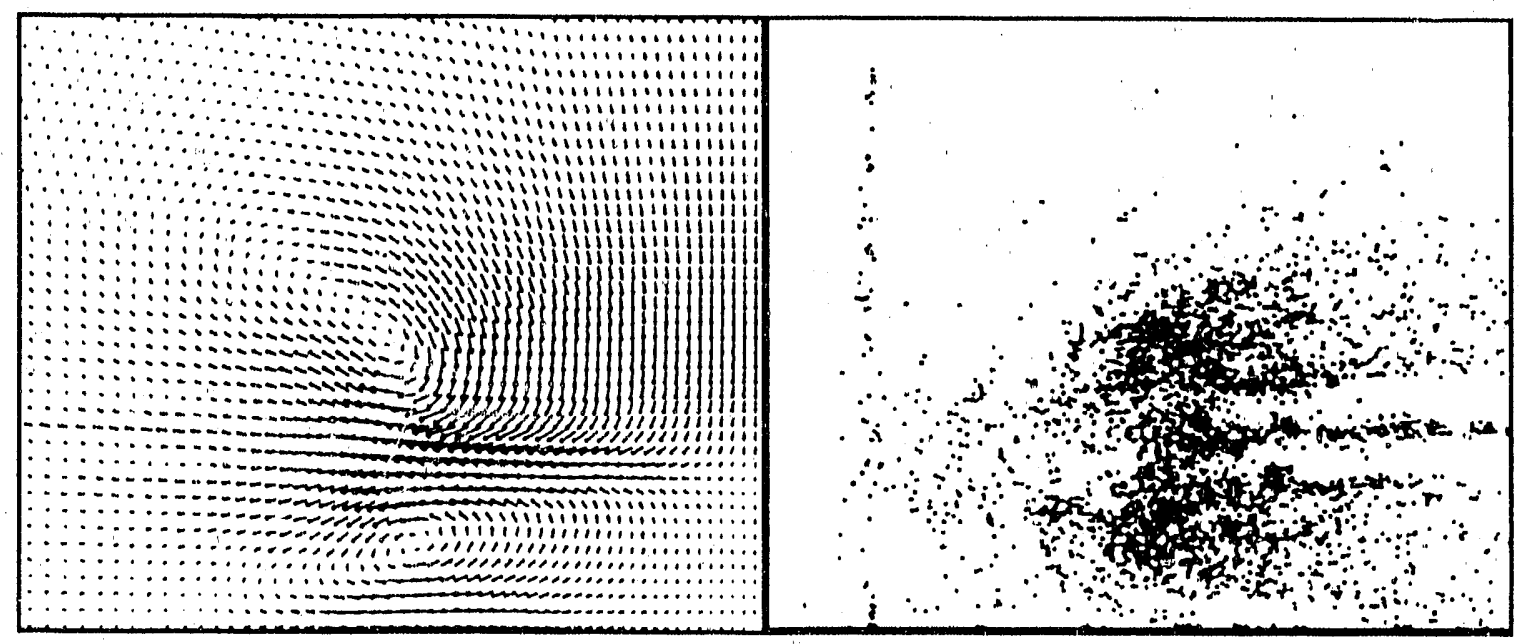

Figure 71: Velocity profile and fuel parcel positions at $\mathrm{t}=60 \mathrm{~ms}$, Case 11. $\mathrm{v}_{\text {max }}=3060 \mathrm{~cm} / \mathrm{s}$

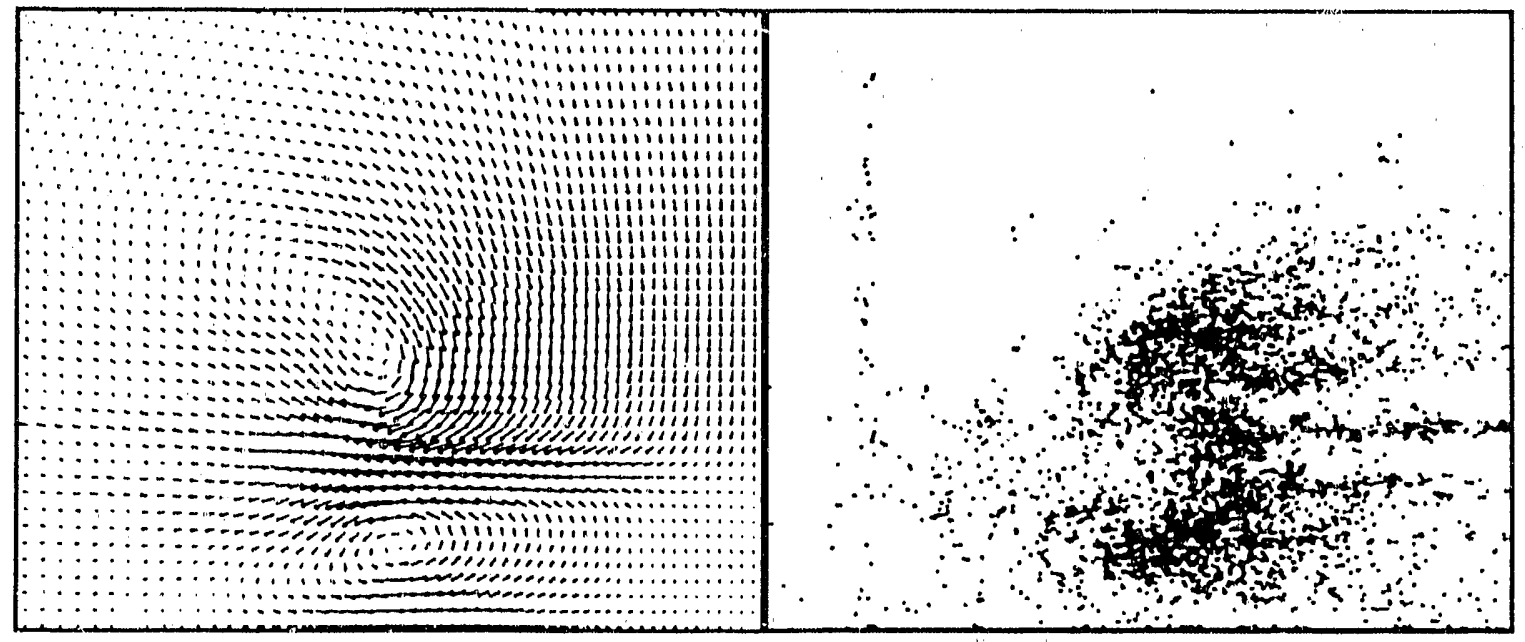

Figure 72: Velocity profile and fuel parcel positions at $\mathrm{t}=75 \mathrm{~ms}$, Case 11 . $v_{\text {max }}=2950 \mathrm{~cm} / \mathrm{s}$ 


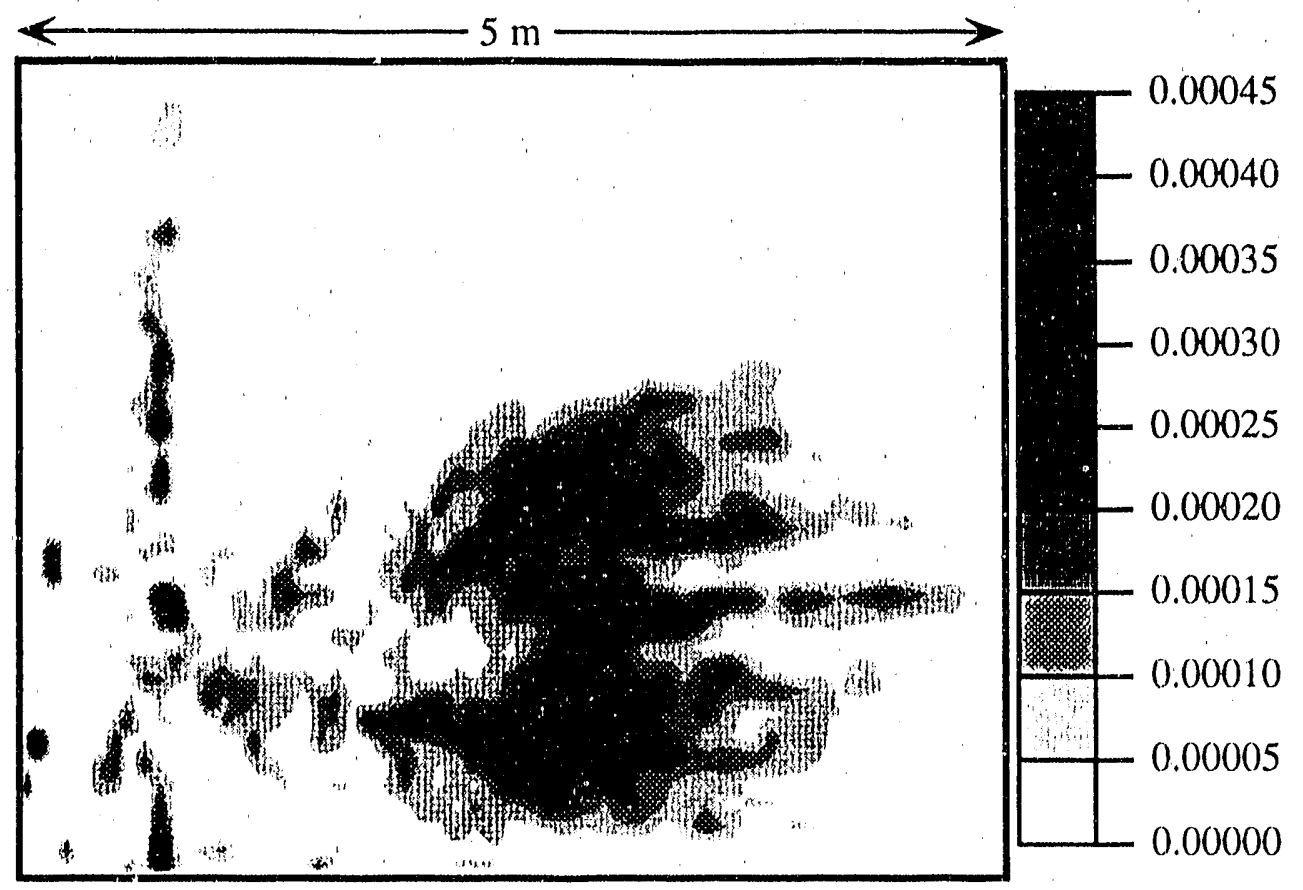

Figure 73: Fuel density profile at $\mathrm{t}=60 \mathrm{~ms}$, Case 11 .

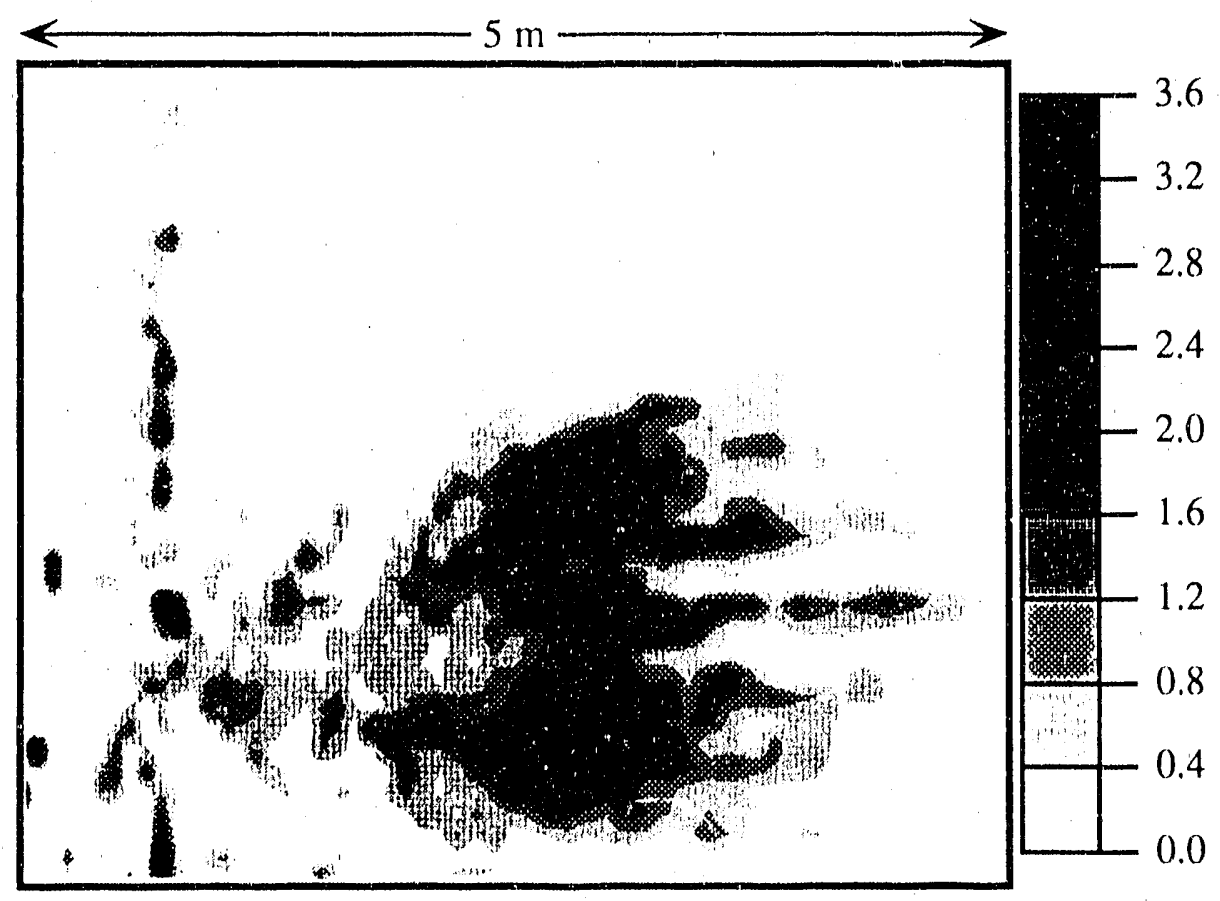

Figure 74: Equivalence ratio profile at $\mathrm{t}=60 \mathrm{~ms}$, Case 11 . 


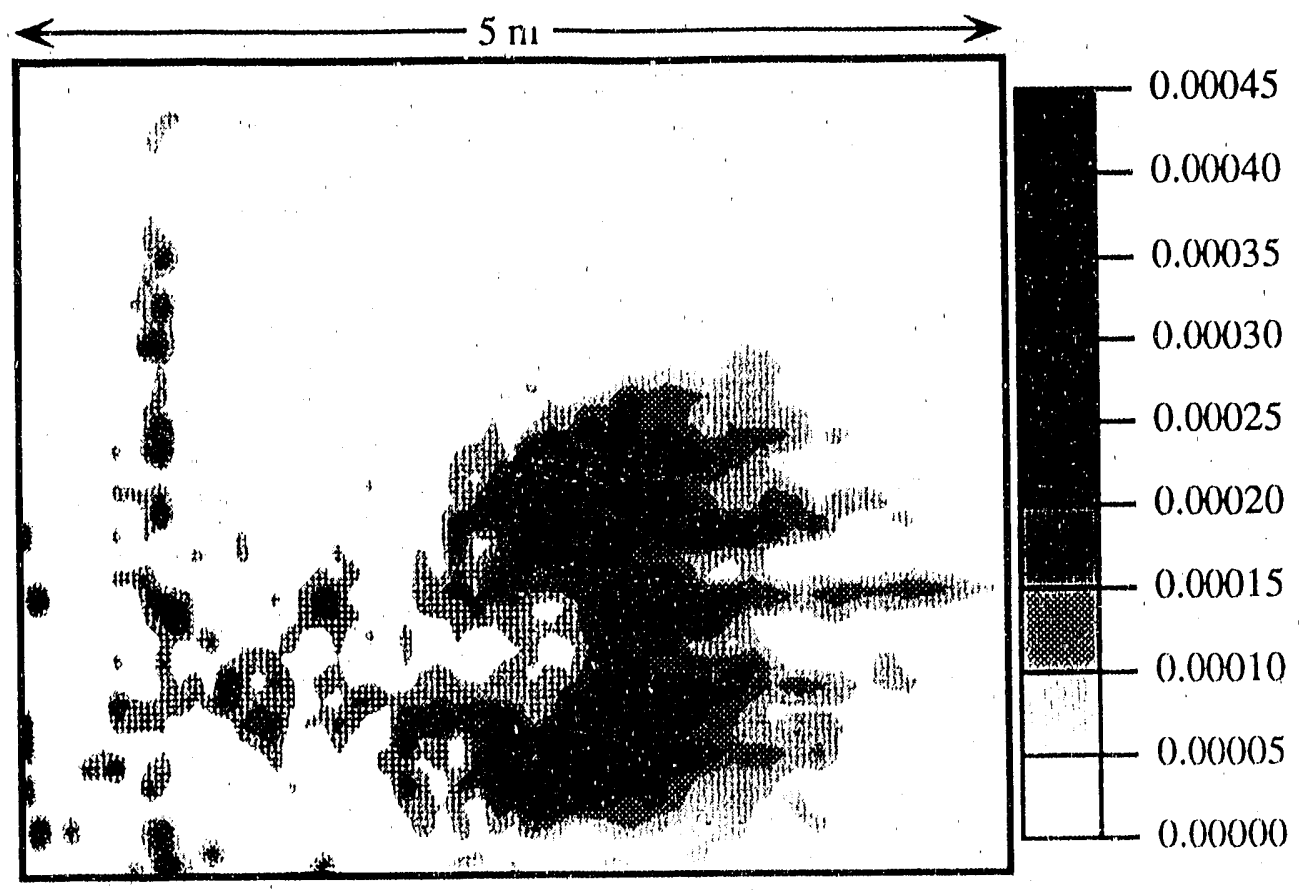

Figure 75: Fuel density profile at $\mathrm{t}=75 \mathrm{~ms}$, Case 11

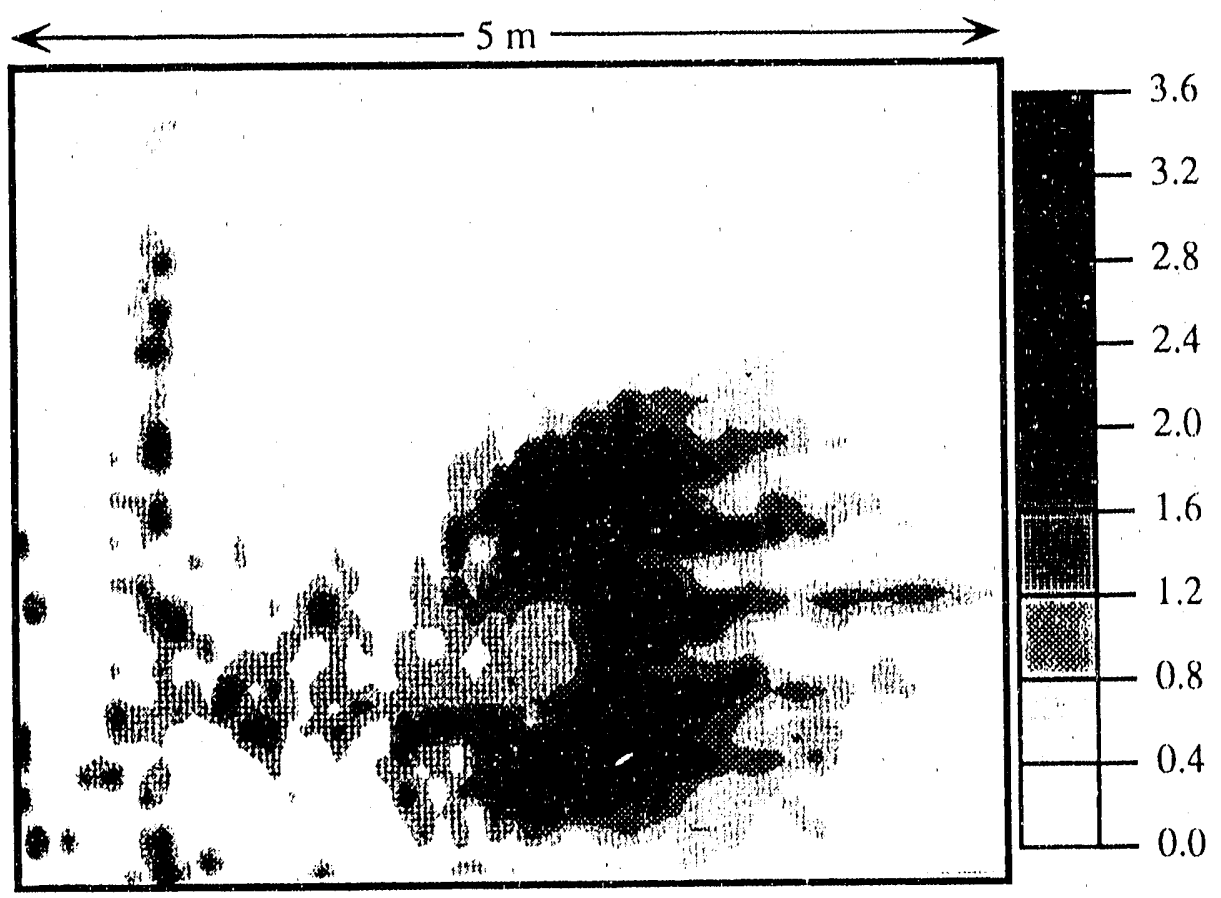

Figure 76: Equivalence ratio profile ai $t=75 \mathrm{~ms}$, Case 11 . 


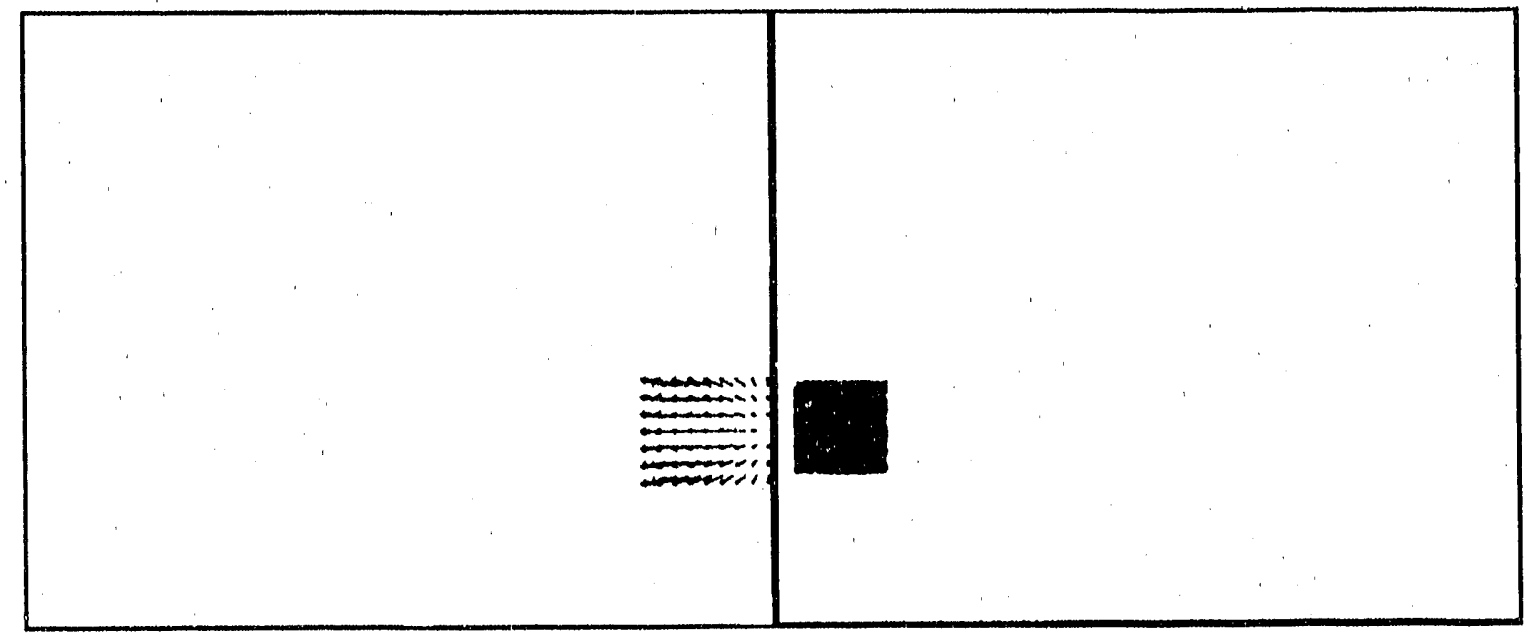

Figure 77: Velocity profile and fuel parcel positions at $\mathrm{t}=0 \mathrm{~ms}$, Case 12 . $v_{\max }=27300 \mathrm{~cm} / \mathrm{s}$

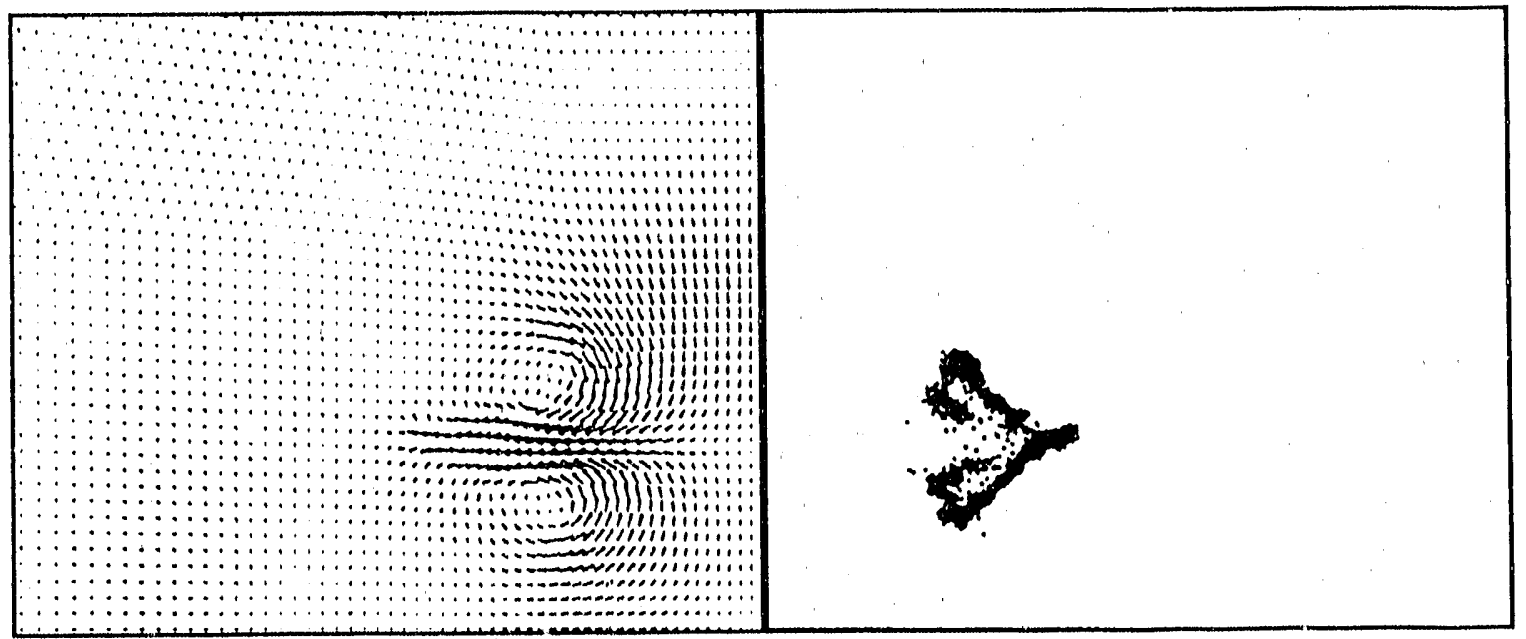

Figure 78: Velocity profilt and fuel parcel positions at $\mathrm{t}=15 \mathrm{~ms}$, Case 12 . $\mathrm{v}_{\max }=14200 \mathrm{~cm} / \mathrm{s}$ 


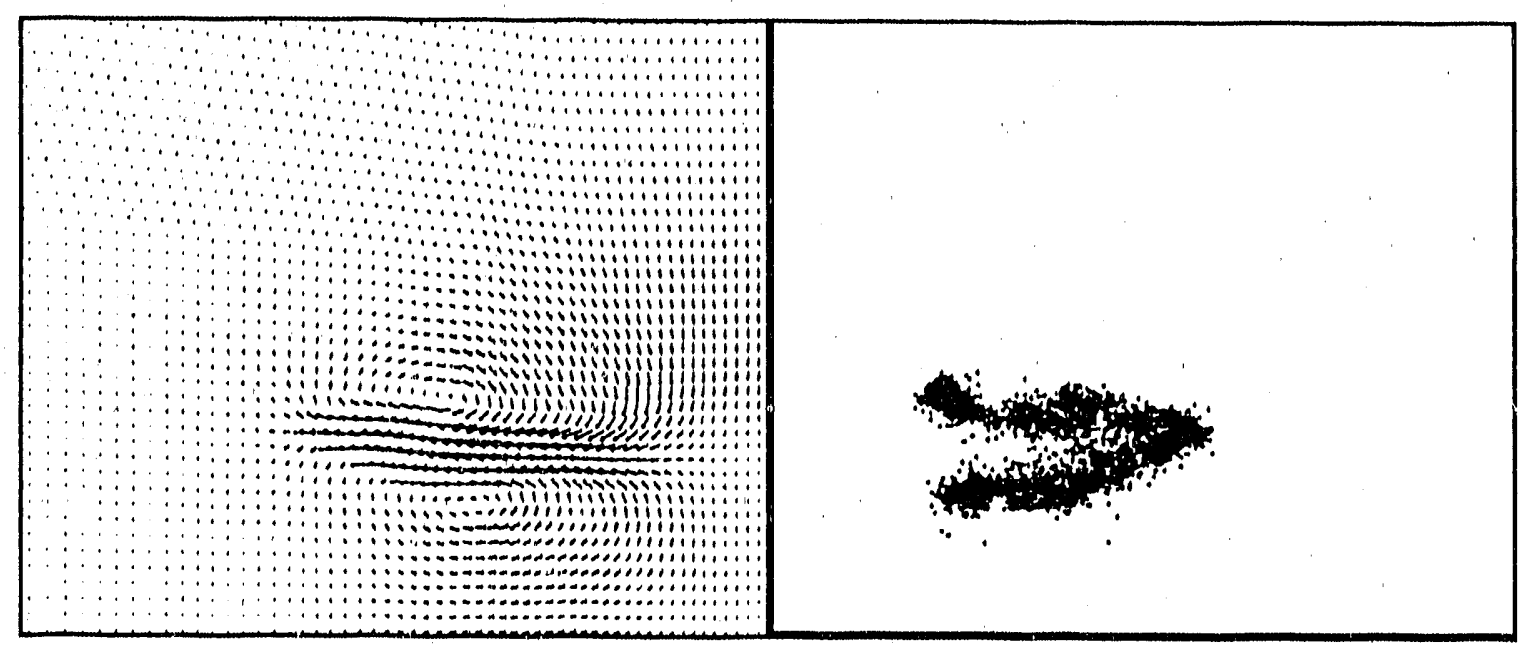

Figure 79: Velocity profile and fuel parcel positions at $\mathrm{t}=30 \mathrm{~ms}$, Case 12 . $v_{\max }=7350 \mathrm{~cm} / \mathrm{s}$

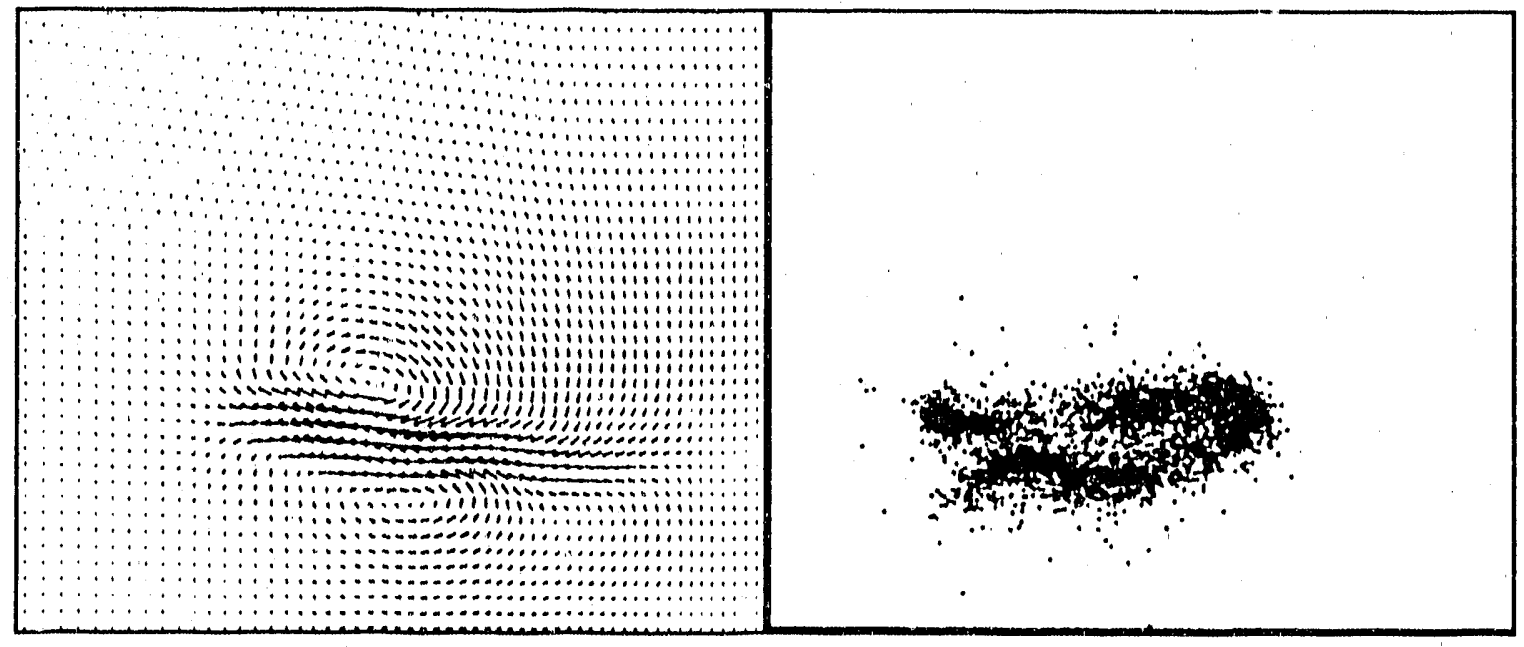

Figure 80: Velocity profile and fuel parcel positions at $t=45 \mathrm{~ms}$, Case 12 . $v_{\max }=5170 \mathrm{~cm} / \mathrm{s}$ 


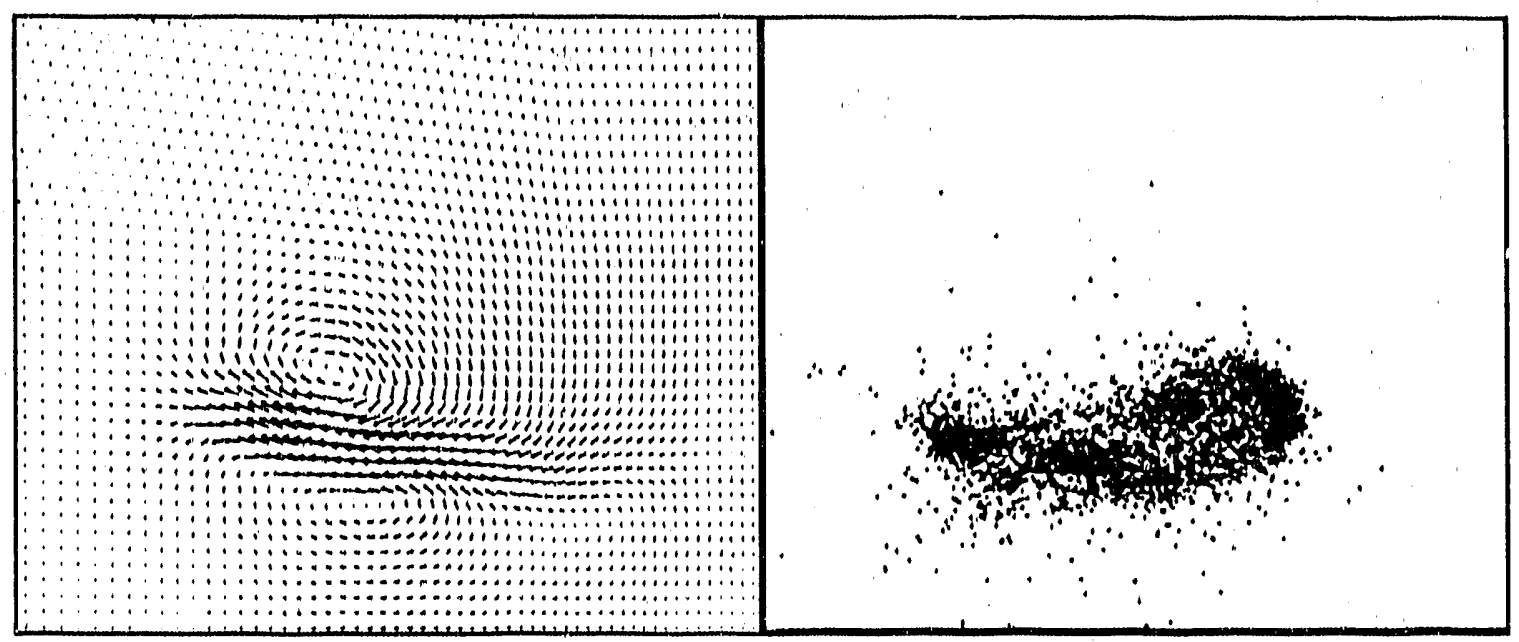

Figure 81: Velocity profile and fuel parcel positions at $t=60 \mathrm{~ms}$, Case 12 . $\mathrm{v}_{\max }=4280 \mathrm{~cm} / \mathrm{s}$

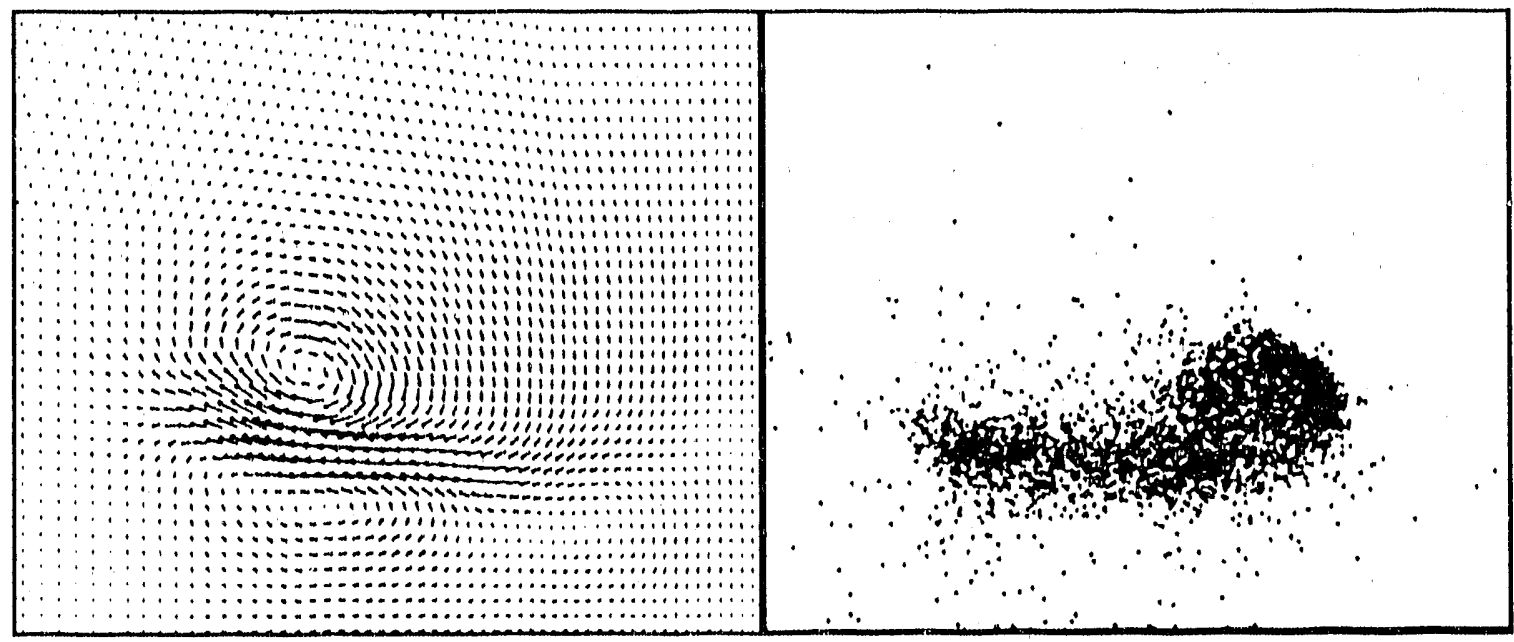

Figure 82: Velocity profile and fuel parcel positions at $t=75 \mathrm{~ms}$, Case 12 . $\mathrm{v}_{\text {max }}=3580 \mathrm{crn} / \mathrm{s}$ 


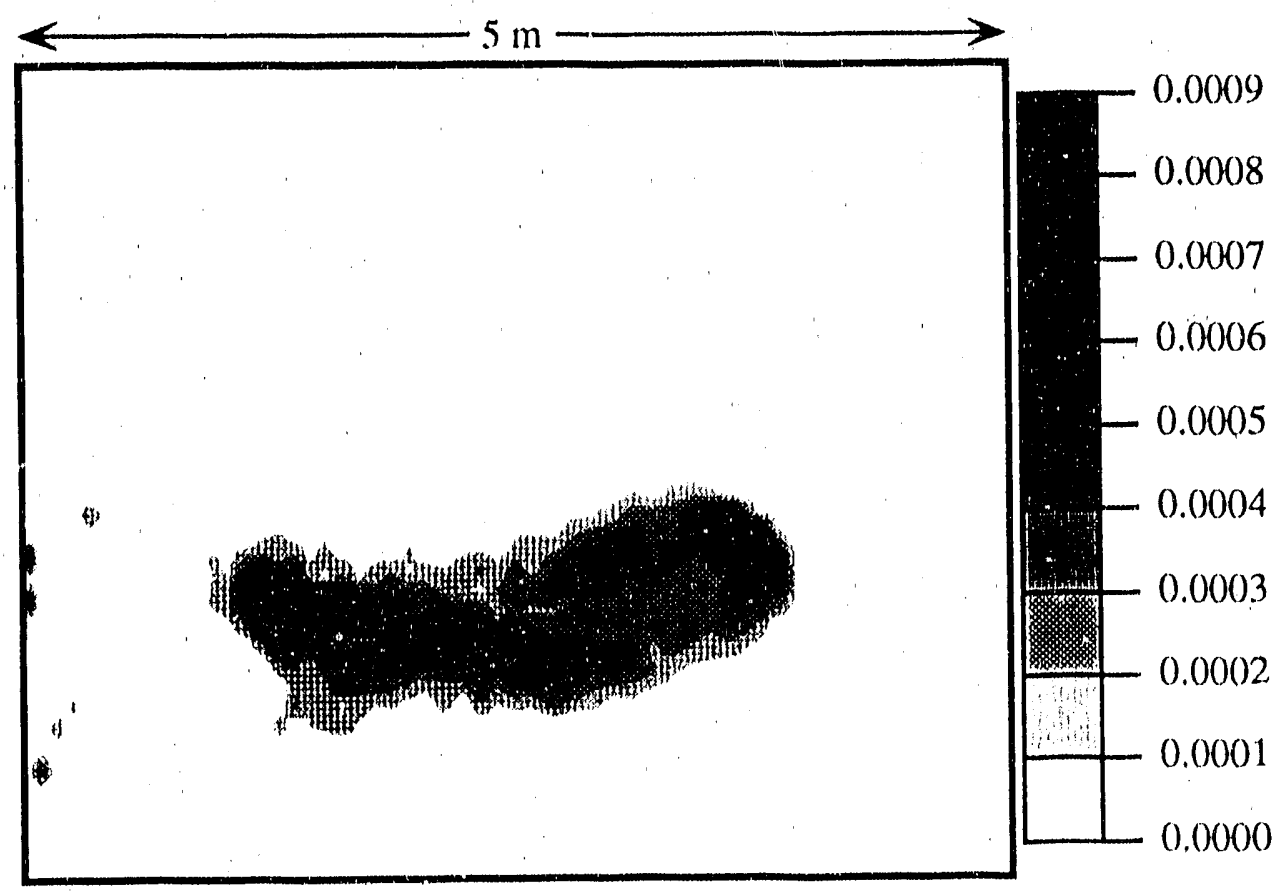

Figure 83: Fuel density profile at $\mathrm{t}=60 \mathrm{~ms}$, Case 12 .

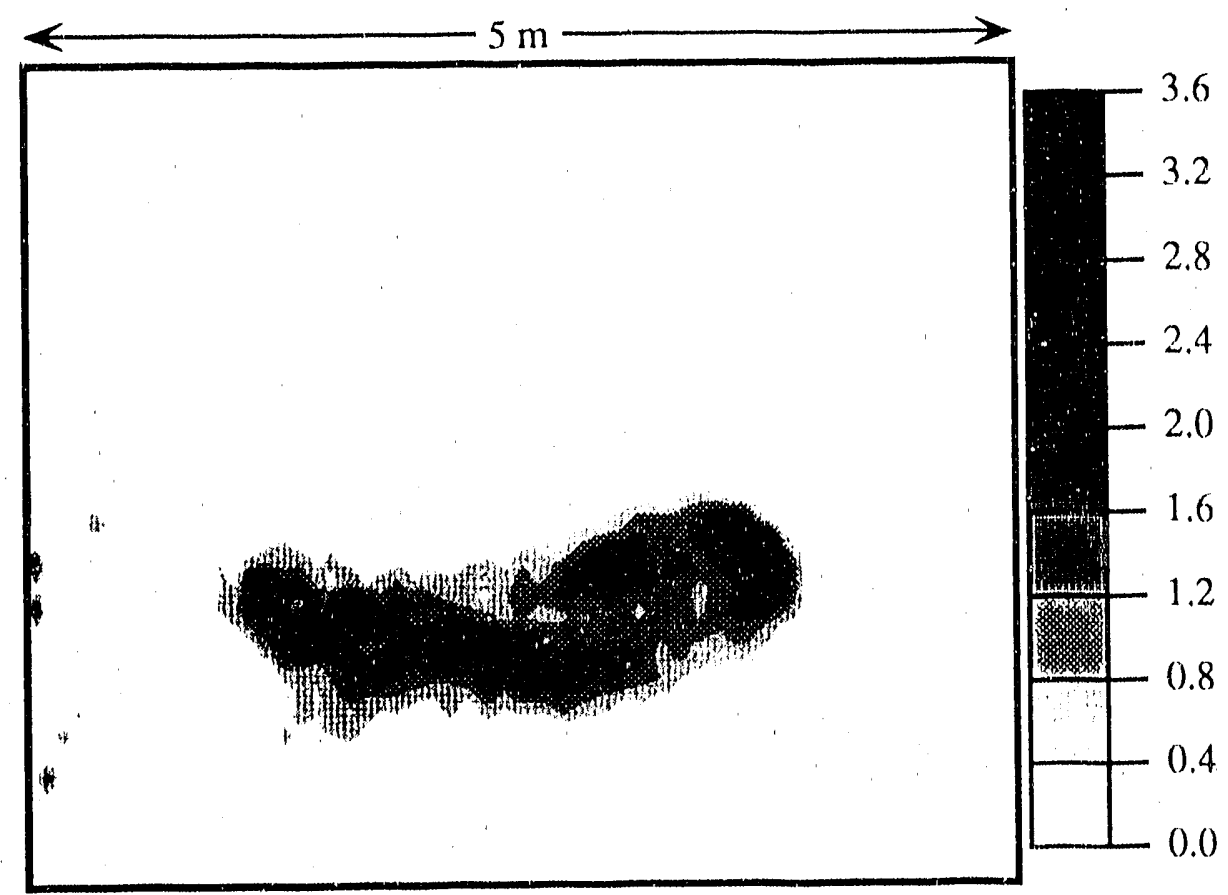

Figure 84: Equivalence ratio profile at $t=60 \mathrm{~ms}$, Case 12 . 


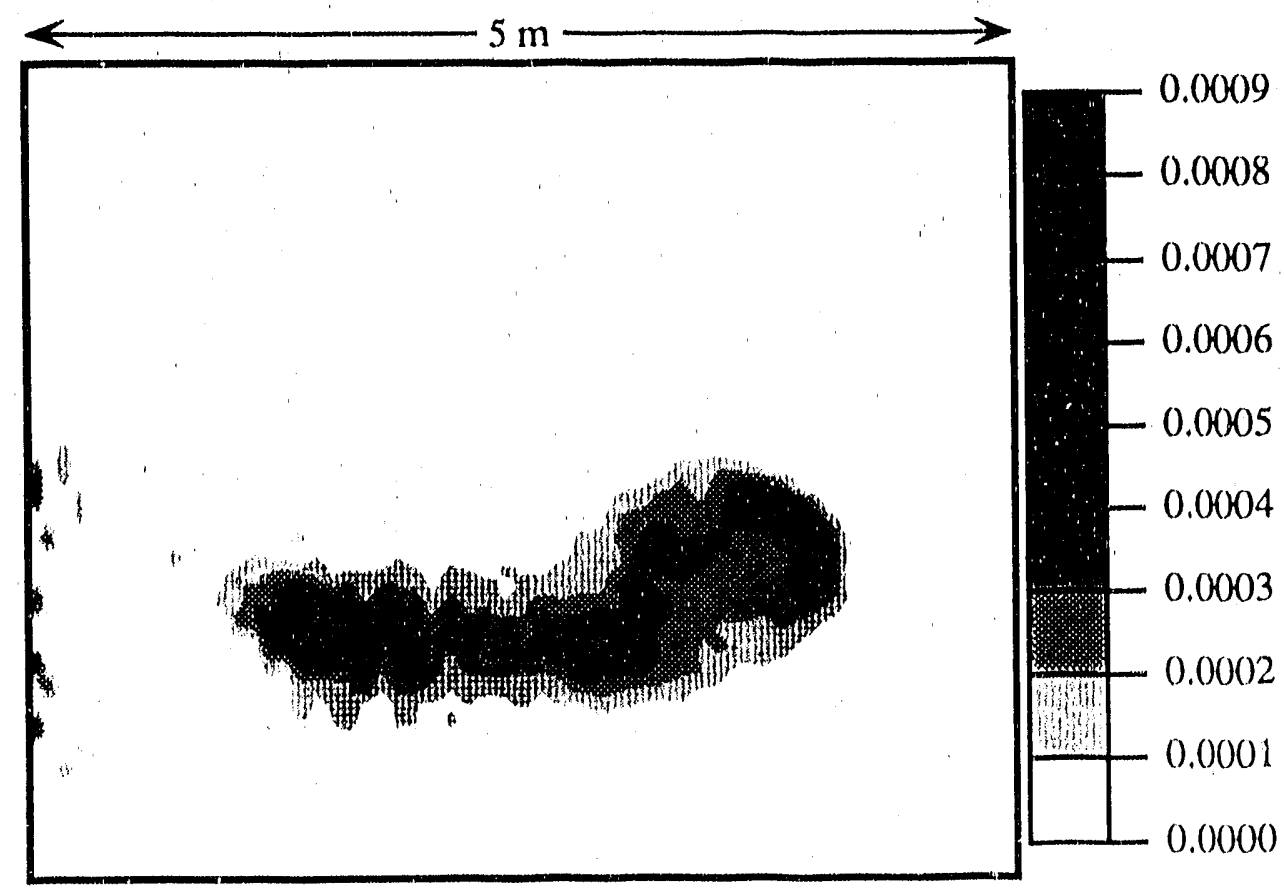

Figure 85: Fuel density profile at $\mathrm{t}=75 \mathrm{~ms}$, Case 12 .

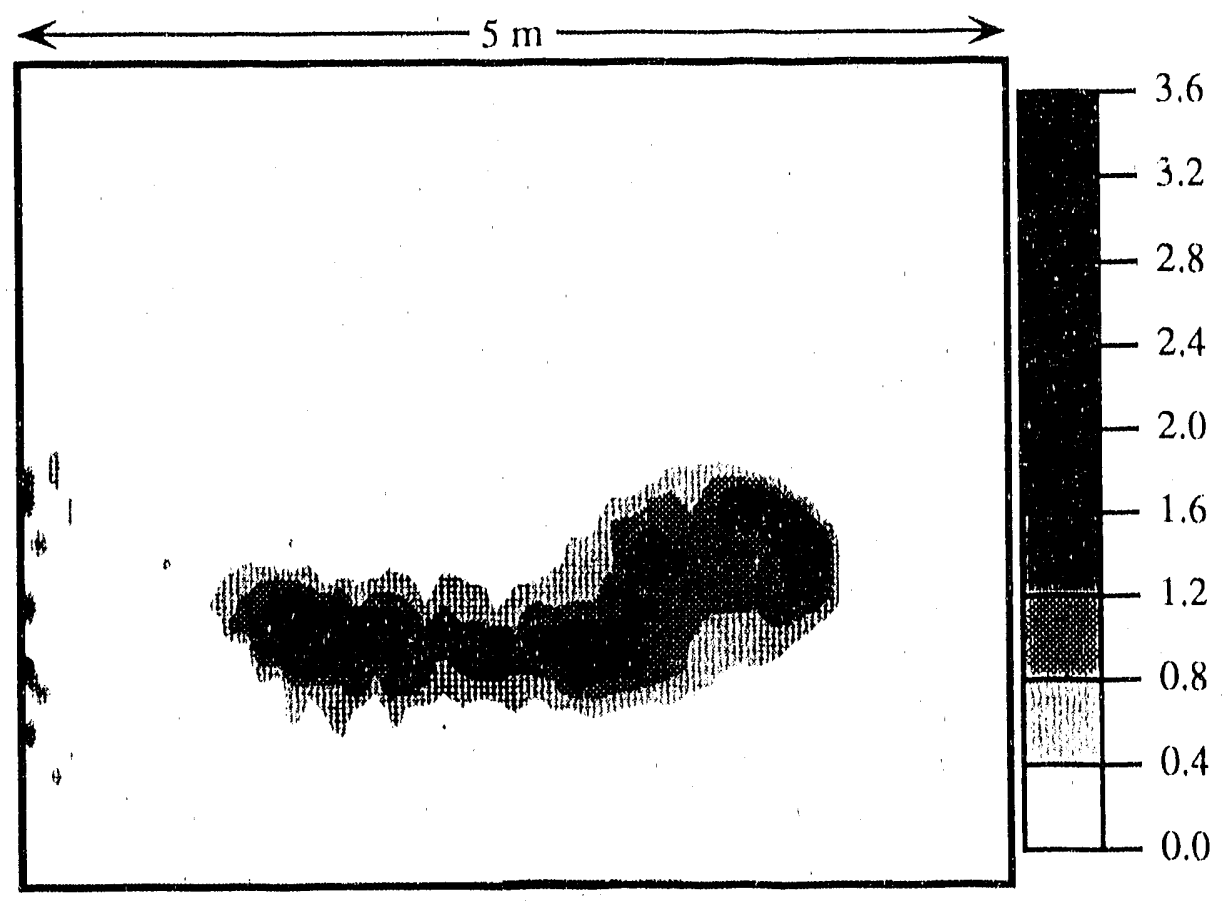

Figure 86: Equivalence ratio profile at $\mathrm{t}=75 \mathrm{~ms}$, Case 12 . 


\section{Conclusions}

The ability of KIVA-FAE to model the far-field dispersal regime for FAE devices has been demonstrated and applied to a variety of conditions and fuels. The results from KIVA-FAE qualitatively compare well with films taken of "jug" tests at the Naval Weapons Center. Detailed comparison to experimental results are impossible at this time because in-cloud measurements of such parameters as droplet size diatribution and fuel density are presently nonexistent. Once quantitative validation of KIVA-FAE can be achieved by comparison to wellcharacterized dispersal experiments, dispersal modeling can play an important role in further understanding the dispersal process and aid weapon designers in optimizing such parameters as height-of-burst, location of secondary cloud detonators, timing for the secondary cloud detonators and fuel-to-burster charge mass ratio.

A significant dependence of the fuel cloud characteristics upon the initial droplet size distribution was demonstratcd. Improvements to the initial conditions for both the droplet size distribution and the gas flow field should enhance the entire dispersal modeling effort. The next step in the dispersal modeling program will be to couple the results from a near-field model $\mid 181$. Additionally, the fuel-to-burster charge mass ratio was kept constant at 10():1. A coupled dispersal model will be able to determine its affect upon the dispersal process.

It should be noted that all the calculations showed very nonuniform fuel concentration profiles within the cloud. In the past, uniform cloud concentrations have always been assumed for such things as detonation modeling, timing for the secondary cloud initiators, etc. An accurate dispersal model could be used to quickly and cost effectively screen many design alternatives as to their affect upon the cloud's uniformity. 


\section{References}

1. R.W. Ostensen, Editor, "Compendium on Fuel-Air-Explosives (U)," Sandia National Laboratories report SAND86-2537 (May 1987).

2. G.R. Abrahamson, R.W. Gates, G.M. Muller, and K. Schreiner, "Explosive Dissemination," Stanford Research Institute technical report No. 18 (November 1967).

3. W.H. Anderson, N.A. Louie, and G. Ialongo, "Investigation of the Aerodynamic Breakup of Viscoelastic Liquids Phase I: Subsonic Dissemination," U.S. Army Armament Research and Development Command report ARCSL-CR-77037 (August 1977).

4. A.I. Ivandaev, A.G. Kutushev, and R.I, Nigmatulin, "Numerical Investigation of the Expansion of a Cloud of Dispersed Particles or Drops Under the Influence of an Explosion," Fluid Dynamics, 17: 68 (1982).

5. M. Rosenblatt, G.E. Eggum, and K.N. Kreyenhagen, "DICE-FAE Analysis of Fuel Dispersal and Detonation from a Fuel-Air-Explosive Device," Air Force Armament Laboratory report AFATL-TR-76-33 (March 1976).

6. R. Rhor, Defense Nuclear Agency, personal communication, (1988).

7. A.A. Amsden, J.D. Ramshaw, P.J. O'Rourke, and J.K. Dukowicz, "KIVA: A Computer Program for Two- and Three-Dimensional Fluid Flows with Chemical Reactions and Fuel Sprays," Los Alamos National Laboratory report LA-1()245-MS (February 1985).

8. A.A. Amsden, J.D. Ramshaw, L.D. Cloutman, and P.J. O'Rourke, "Improvements and Extensions to the KIVA Computer Program," Los Alamos National Laboratory report LA10534-MS (October 1985).

9. A.A. Amsden, T.D. Butler, P.J. O'Rourke, and J.D. Ramshaw, "KIVA: A Comprehensive Model for 2D and 3D Engine Simulations," SAE Technical Paper 850554 (1985).

10. A.A. Amsden, P.J. O'Rourke, and T.D. Butler, "KIVA-II: A Computer Program for" Chemically Reactive Flows with Sprays," Los Alamos National Laboratory report LA11560-MS (May 1989).

11. Y.S. Cheng, H.C. Yeh, and M.D. Allen, "Dynamic: Shape Factor of a Plate-Like Particle.," Aerosol Science and Technology, 8: 109 (1988).

12. D. Leith, "Drag on Nonspherical Objects," Aerosol Technology and Science, 6: 153 (1987).

13. R. Clift, J.R. Grace, and M.E. Weber, Bubbles, Drops, and Particles, Academic Press, New York, 1978. 
14. C. Arnold, Jr., "Selection of Liquid Fuels for Fuel-Air-Explosive Weapons," Sandia National Laboratorles report SAND88-3213 (March 1989).

15. B. Weinhardt, Naval Weapons Center, personal communication, (1988).

16. T.N. Hall and T.R. Holden, "Navy Explosives Handbook: Explosion Effects and Properties, Part III. Properties of Explosives and Explosive Compositions," Naval Surface Warfare Center report NWSC MP 88-116 (October 1988).

17. L. Perkins, Naval Weapons Center, China Lake, CA, personal communication, (1989).

18. D.R. Gurdner, "Near-Field Dispersal Modeling for Liquid Fuel-Air Explosives," Sandia National Laboratories report SAND90-0686 (March 1990). 

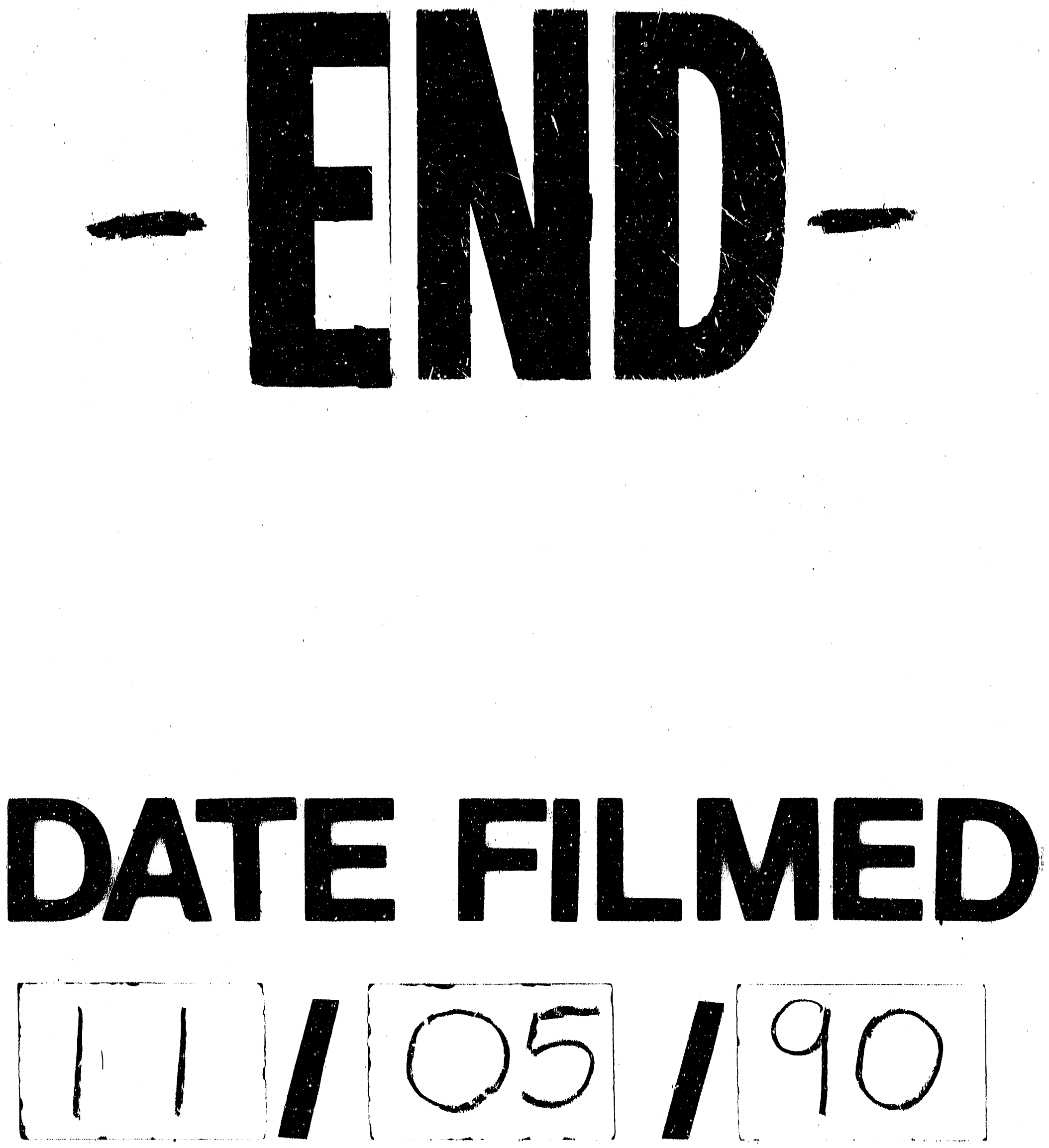
